University of Louisville

ThinkIR: The University of Louisville's Institutional Repository

$12-2011$

\title{
An investigation of a middle-high school system as a learning organization during the implementation of a grade eight to grade nine transition program.
}

Carol Jean Christian

University of Louisville

Follow this and additional works at: https://ir.library.louisville.edu/etd

\section{Recommended Citation}

Christian, Carol Jean, "An investigation of a middle-high school system as a learning organization during the implementation of a grade eight to grade nine transition program." (2011). Electronic Theses and Dissertations. Paper 250.

https://doi.org/10.18297/etd/250

This Doctoral Dissertation is brought to you for free and open access by ThinkIR: The University of Louisville's Institutional Repository. It has been accepted for inclusion in Electronic Theses and Dissertations by an authorized administrator of ThinkIR: The University of Louisville's Institutional Repository. This title appears here courtesy of the author, who has retained all other copyrights. For more information, please contact thinkir@louisville.edu. 


\title{
AN INVESTIGATION OF A MIDDLE-HIGH SCHOOL SYSTEM AS A LEARNING ORGANIZATION DURING THE IMPLEMENTATION OF A GRADE EIGHT TO GRADE NINE TRANSITION PROGRAM
}

\section{By}

Carol Jean Christian

B.S. Eastern Kentucky University, 1976

M.A. Eastern Kentucky University, 1979

\begin{abstract}
A Dissertation
Submitted to the Faculty of the

College of Education and Human Development of the University of Louisville in partial fulfillment of the requirements

for the Degree

Doctor of Education

Department of Leadership, Foundations, and Human Resource Education University of Louisville

Louisville, Kentucky
\end{abstract}

December 2011 


\title{
AN INVESTIGATION OF A MIDDLE-HIGH SCHOOL SYSTEM AS A LEARNING ORGANIZATION DURING THE IMPLEMENTATION OF A GRADE EIGHT TO GRADE NINE TRANSITION PROGRAM
}

\author{
By \\ Carol Christian \\ B.S., Eastern Kentucky University, 1976 \\ M.A., Eastern Kentucky University, 1979
}

A Dissertation Approved on

November 30, 2011

by the following Dissertation Committee:

Sam Stringfield, Dissertation Director

Tom Tretter

Bill Bush

Molly Sullivan 


\section{DEDICATION}

This work is dedicated to my parents, James J. and Mary E. Christian who instilled in me the desire to be a life-long learner. I also dedicate this work to my

brothers, Joe, Mike, and Dick and my sister Becky who set the bar by their example that made me reach. 


\section{ACKNOWLEDGEMENTS}

I would like to thank the members of my doctoral cohort for their support and encouragement. I forward a special thank you to Dr. Debbie Powers and Dr. John Casper for their patience and technology assistance. I thank the committee members and instructors for expanding my thinking on this journey; Dr. Molly Sullivan, Dr. Tom Tretter, Dr. Bill Bush, Dr. Bob Ronau and Dr. Sam Stringfield. Thank you to my committee chair, Dr. Sam Stringfield for your expertise and investment of time in providing feedback. I am thankful to my family, colleagues and friends who have provided unwavering support and encouragement throughout this process. 


\section{ABSTRACT \\ AN INVESTIGATION OF A MIDDLE-HIGH SCHOOL SYSTEM AS A LEARNING ORGANIZATION DURING THE IMPLEMENTATION OF A GRADE EIGHT TO GRADE NINE TRANSITION PROGRAM

\author{
Carol Christian
}

November 30, 2011

This study investigated the impact of articulation activities and the extent to which the Grant County Kentucky school district operated as a learning organization during the implementation of a research-based middle to high school student transition initiative. Grant County is predominantly rural, located between Louisville, Kentucky and Cincinnati, Ohio, and includes the town of Williamstown, Kentucky. This study analyzed the Grant County schools' to determine if they functioned as a learning organization to the characteristics common to organizational learning, high reliability organizations and effective schools that included the characteristics of systemic process, leadership/vision, collaboration, and the use of measures. This study's findings indicated that by using characteristics common to OL, HRO and ES in the development and implementation of this middle school to high school transition initiative, Grant County Schools' educators created a shared vision, developed systemic processes, created opportunities for teachers to collaborate within and between schools, and had a shared focus on the use of data to improve and to operate as a learning organization. 


\section{TABLE OF CONTENTS}

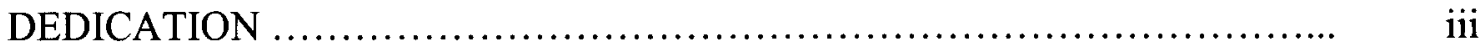

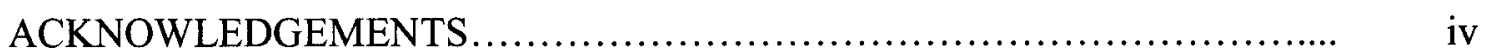

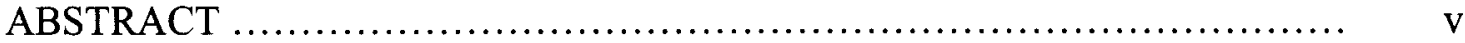

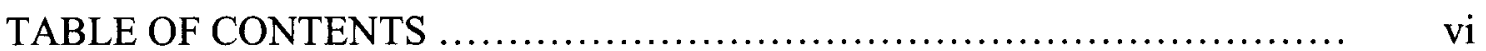

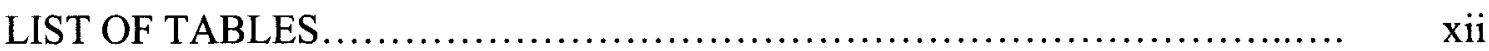

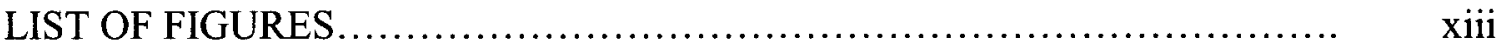

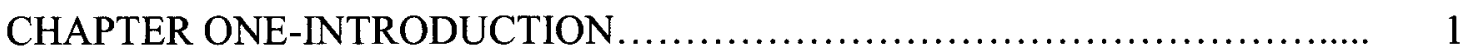

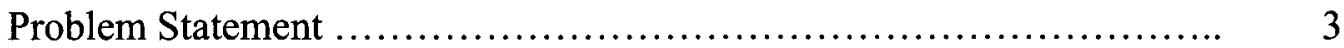

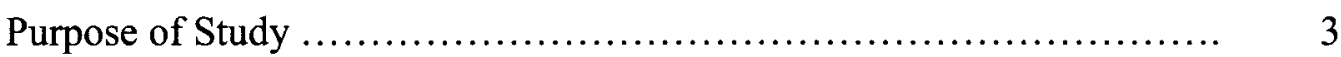

Significance of the Study .......................................... 3

Context-Inception of Grant County Transition Initiative ............... 4

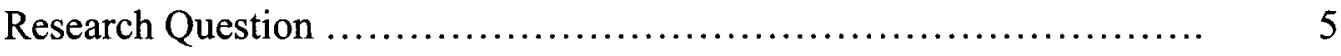

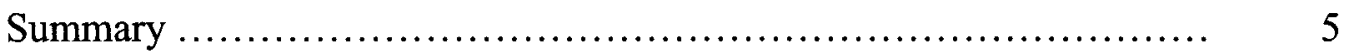

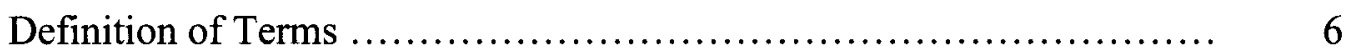

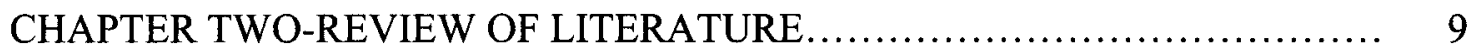

Conceptual Framework Foundation............................... 9

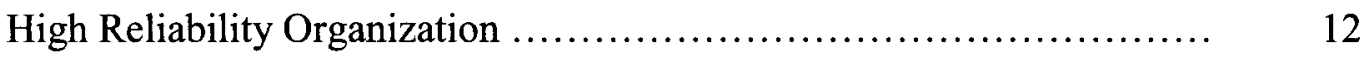

Effective Schools ................................................. 14

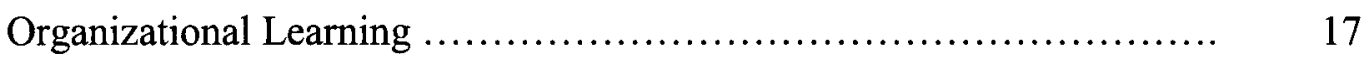


Effective Transition Programs ...................................... 21

Research on School Transitions ..................................... 22

Elementary School to Middle School Transition Research ........ 22

Middle School to High School Transition Research ............... 24

High School to College Transition Research .................... 29

Research on Implementation of Organizational Change ................. 31

Implementation Framework for the Grant County Transition Initiative.... 32

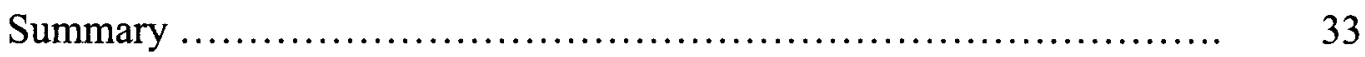

CHAPTER THREE-METHODOLOGY................................... 35

Research Question and Purpose .................................... $\quad 35$

Context / Sample: The Grant County Middle and High School ........... 36

Describing the Intervention: The Development of Grant County Transition

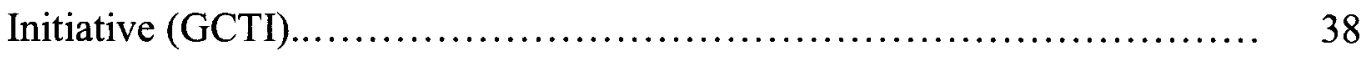

Articulation Activities ....................................... 39

Implementation Timeline of GCTI ........................... 43

Monitoring GCTI .......................................... 44

Independent Variables ........................................ 45

Dependent Variables ........................................ 45

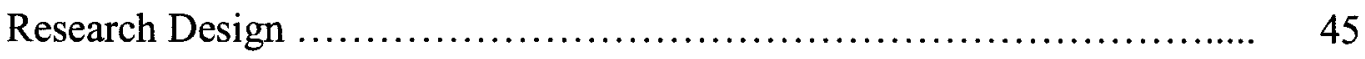

Instrumentation ....................................................... 46

Freshman Transition Survey .................................. 47

Transition Committee Interview................................... 48

Teacher Interviews .......................................... 49 
Archival Documents ........................................... 49

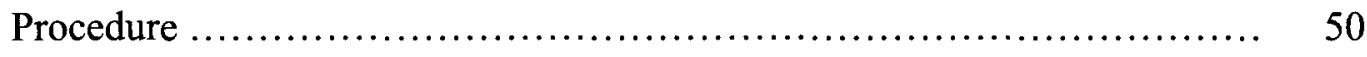

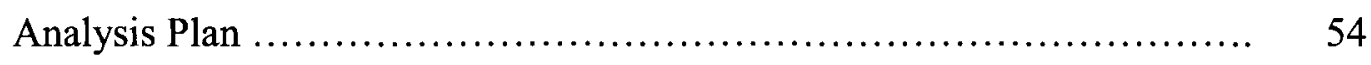

Freshman Transition Teacher Survey on Participation (Part I)........ 54

Freshman Transition Teacher Survey Regarding Valuing (Part III).. 54

Freshman Transition Teacher Survey Open Response (Part IV)..... 55

Transition Committee Interview. ............................ 56

Teacher Interview....................................... 57

Archival Document Analysis.................................. 57

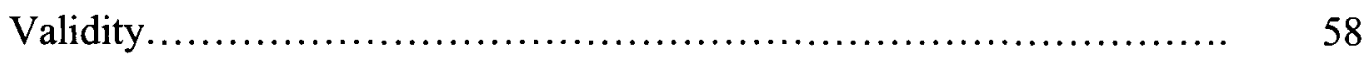

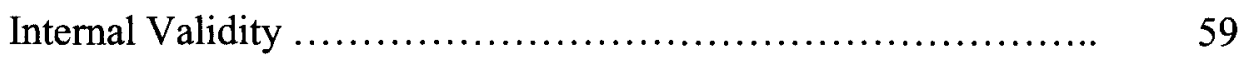

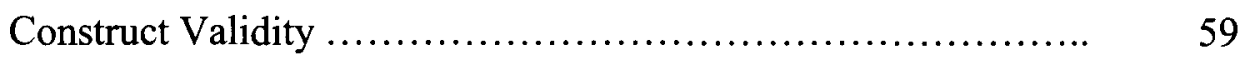

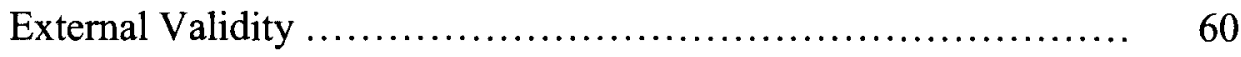

Limitations............................................................. 60

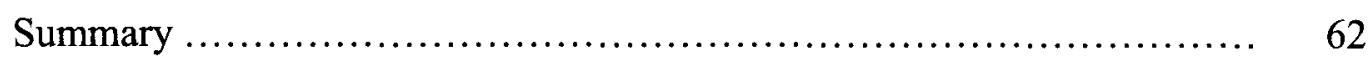

CHAPTER FOUR-RESULTS............................................. 63

Question Guiding this Dissertation ................................ 63

Teacher Participation and Valuing ............................ 64

Analysis of Written Open Response Comments.................... 71

Analysis of Results in the Four Categories........................ 72

Category 1. Systemic Processes ................................. 73

Archival Document Analysis Providing Evidence of Systemic

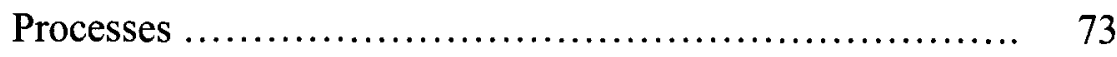

viii 
Transition Committee Interview Results Providing Evidence

of Systemic Processes

Teacher Interview Results Providing Evidence of Systemic

Processes

81

Open Response Comments Providing Evidence of Systemic

Processes................................................

82

Category 2. Leadership /Vision............................. 87

Archival Document Analysis Providing Evidence of

Leadership/Vision

Transition Committee Interview Results Providing Evidence

of Leadership/Vision.

Teacher Interview Results Providing Evidence of

Leadership/Vision.

90

Open Response Comments Providing Evidence of

Leadership/Vision.

Category 3. Collaboration

Archival Document Analysis Providing Evidence of

Collaboration

Transition Interview Results Providing Evidence of

Collaboration

Teacher Interview Results Providing Evidence of

Collaboration

Open Response Comments Providing Evidence of 
Archival Document Analysis Providing Evidence of Use of

Measures

Transition Committee Interview Results Providing Evidence of Use of Measures

Teacher Interview Results Providing Evidence of Use of

Measures

Open Response Comments Providing Evidence of Use of

Measures

Summary

CHAPTER FIVE-CONCLUSIONS, IMPLICATIONS \& RECOMMENDATIONS

Findings and Conclusions

116

Research Question

116

Learning Organization Category 1. Systemic Processes............ 116

Learning Organization Category 2. Leadership/Vision.............. 120

Learning Organization Category 3. Collaboration

Learning Organization Category 4. Use of Measures

127

Findings Summary

Implications for Practice

Implications for Future Research

Summary 
A. Articulation Activities Timeline ................................ $\quad 146$

B. Freshman Transition Teacher Survey ............................. 149

C. Transition Committee Interview .............................. 155

D. Teacher Interview ........................................ 157

E. Archival Documents Analyzed....................................... 159

F. Categorical Coding of Open Response Questions and Articulation Activities................................................... 161

G. Categorical Coding of Transition Committee Interview Questions..... 164

H. Categorical Coding of Teacher Interview Questions.......................... 166

I. Categorical Coding of Comments............................. 168

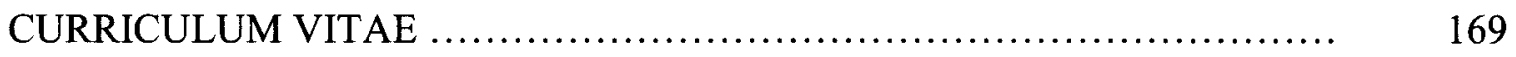




\section{LIST OF TABLES}

TABLE

PAGE

1 Student Demographics 2008............................................ 36

2 Teacher/Administrator Study Participants Demographics for $2010 \ldots \ldots \ldots \ldots \ldots . \ldots 37$

3 Articulation Activities Organized by Five Categorical Areas................. 40

4 Data Analysis Plan.................................................................................. 53

5 Teacher Value Data Providing Mean and Standard Deviation ................ 71

6 Summary of Evidence that GCTI Enhanced Grant County School's Ability to Operate as a Learning Organization.........................................

129 


\section{LIST OF FIGURES}

$\begin{array}{lll}\text { FIGURE } & \text { PAGE }\end{array}$

1 Grant County Transition Initiative Conceptual Framework............... 11

2 Individual Teacher Participation in Articulation Activities.............. 65

3 Middle School to High School Participation in Articulation Activities..... 67

4 Teacher Average Value Ratings of Articulation Activities............... 68

5 Middle School and High School Value Rating of Articulation Activities... 69

6 Combined Average Rating vs Combined Average Participation........... 70 


\section{CHAPTER ONE}

\section{INTRODUCTION}

Many students become lost in the transition from middle school to high school. During this transition period students many times move from smaller middle schools to larger, more impersonal high school environments with unfamiliar school cultures and more rigorous academic coursework (Kennelly \& Monrad, 2007). For many students their academic success begins to spiral downwards and absenteeism accelerates as they fall further behind on track to graduate with their grade level peers and ultimately fail to graduate (Wise, 2008). A logical place to begin intervening is during the transition from middle to high school. Few schools and districts have in place a systematic process to ensure the successful transition of students from grade eight to grade nine. Nor do they typically address the physical, social, emotional and developmental issues young adolescents face that further complicate and intensify the changes these students encounter in the transition from middle school to high school (Mizelle \& Irvin, 2000). The consequences of a school organization failing to implement strategies that provide an effective transition to high school often translate into low achievement, high dropout rates, and low graduation rates (Kennelly \& Monrad, 2007).

Over the past 30 years, the number of students enrolled in ninth grade relative to eighth and tenth grades increased. As a result of students being retained in grade nine, the freshman class in many high schools has the largest percentage of overall high school population. Kennelly and Monrad (2007) often referred to this as the ninth grade bulge. 
By the end of the 1970s, the ratio of students in grade nine vs. grade ten began to increase and accelerated in the 1980 s.By the year 2000 there were approximately $12 \%$ fewer students in grade ten than in grade nine of the previous year. Troublingly, the rate at which students disappear between grade nine and grade ten has tripled over the last three decades (Haney et al., 2004). Not only does grade nine post the largest failure rate in high schools nationally (George \& McErwin, 1999), but grade nine students who have been retained once during high school also face reduced likelihood of graduation by up to 50\% (Black, 2004; Carroll, S. J., \& Scherer, 2008). Furthermore, failure rates in grade nine are three to five times higher than that of any other grade (George \& McErwin, 1999).

Students who enter grade nine with poor grades, high absenteeism, and inappropriate behavior incidence records have failed to successfully navigate the system at the middle school level (Kennelly \& Monrad, 2007). Frequently these grade nine students are unprepared to handle the increased behavioral and academic expectations of high school. As success breeds success, the reverse is true for students who experience failure in grade eight. They are likely to repeat grade nine and become at risk for dropping out of high school. This situation is critical for local and national communities since students who have been retained twice have a less than $25 \%$ chance of attaining a high school diploma (Hertzog \& Morgan, 1999). In the $21^{\text {st }}$ century, schools and entire schools systems are being held accountable for improving student outcomes or facing consequences when goals are not met (Innes, 2009). The federal No Child Left Behind (NCLB) legislation (2001) requires schools and districts to report results on academic performance as well as non-cognitive indicators that include dropout and retention data. 
As a result, schools and districts must find ways to improve their organizational effectiveness, their processes and practices and develop strategies to improve these undesirable outcomes.

This study is guided by the idea that change can be managed within an organization to produce growth in both student and organizational outcomes. This study focused on systems and processes, a shared vision of the need for change, the collaborative efforts of school and district stakeholders and the use of data measures in producing a learning organization.

\section{Problem Statement}

Little evidence exists that typical middle schools and high schools create collaborative partnerships in developing and implementing activities that lead to the successful transition of students from middle school to high school (Hertzog \& Morgan, 1999). Mizelle and Irvin (2000) reported that on average, middle and high schools implement fewer than three articulation activities that provide support to students in the transition from grade eight to grade nine.

\section{Purpose of this Study}

This study investigated the eighth and ninth grade Grant County Transition Initiative (GCTI), developed and implemented by the Grant County (KY) School District. The purpose of this study was to investigate the impact of the GCTI on the learning organization during the implementation of a middle to high school transition initiative.

\section{Significance of the Study}

There is limited empirical research available that examines student transition from middle school to high school. Available studies on transition have focused on the 
transitions in elementary school from one grade level to another. Minimal research exists which provides specific recommendations on what strategies, activities and programs schools can implement to ensure successful transition from grade eight to grade nine (Akos \& Galassi, 2004; Mizelle, 1995). Therefore, this study examined articulation activities embedded in a middle to high school transition initiative and its impact on the organization to function as a learning organization.

\section{Context: Inception of the Grant County Transition Initiative}

The Grant County Transition Initiative (GCTI) was implemented at the beginning of the 2008-2009 school year. Grant County High School administrators recognized an effective strategy was needed to address freshman failure rates and the number of dropouts. The lack of success for many of these students too often translated into students dropping out of school. In 2007-2008 school-year, Grant County reported a drop-out rate of $5.72 \%$ compared to the state of Kentucky drop-out average of $3.17 \%$. The freshman failure rate at Grant County was 37\%. School and district leaders acknowledged that the high school and middle school could no longer work in isolation to combat these statistics.

In response to these substantial problems, the Grant County school system created a middle to high school transition initiative to improve grade nine failure rates and ultimately graduation rates. In 2008 a transition committee was formed to review transition literature and develop an initiative that would impact grade eight to grade nine outcomes of student academic performance, student behaviors, student attitudes and learning organizational outcomes. 
Three interrelated research studies have focused on this initiative: a study of the impact of articulation activities on student performance and behaviors (Allen, 2011); a study on the impact of articulation activities on student attitudes (Hibbett, in process); and this study examining the impact of articulation activities on the learning organization.

\section{Research Question}

This study addressed the following research question:

Has the creation and work of the Grant County Transition Initiative and the subsequent implementation of articulation activities enabled the middle-high school system to function as a more productive learning organization?

\section{Summary}

In this era of high stakes accountability, school and district personnel must work together to seek solutions to problematic school issues such as those faced during transition from middle to high school. According to Louis (2006), reform programs can temporarily fix schools, but for long-term results to occur, schools and systems must become learning organizations that focus on continuous, long-term improvement. Creating more effective schools will require school personnel to understand and document both what happens in the classroom and at the school level. Organizational learning requires a shared, social construction common to all members of the school organization (Louis, 1994). This study examines the extent to which the GCTI facilitated Grant County schools' ability to function as a learning organization.

In Chapter 2, a theoretical framework will be presented on Organizational Learning (OL) that connects the components of High Reliability Organizations (HRO) and Effective Schools (ES) into one cohesive framework that guides the implementation 
of a grade eight to grade nine transition initiative. OL will lay the groundwork for the implementation of articulation activities to improve student academic performance, student behaviors, student attitudes and the organization as students transition from middle school to high school. This background information will inform the data gathering and analyses that frame the remainder of this dissertation.

\section{Definitions of Terms}

Articulation activities - Articulation activities are activities designed to create a smooth transition from grade eight to grade nine, thereby increasing the likelihood of student success in high school. In this study, 13 activities define the articulation activities in the GCTI. These activities will be described in Chapter Two.

Dropout - A dropout is defined as a student who leaves school prior to completing the school year or fails to return to school each year until he or she has completed high school graduation requirements

At-Risk Students - At risk students are those students not identified through special education criteria but identified through other data as being at greater risk of failure. Other indicators include a combination of poor grades, high absenteeism, high levels of inappropriate behavior incidences or a general lack of involvement in school activities.

EXPLORE Data - EXPLORE is a component of the American College Testing (ACT) assessment program (a commercially marketed curriculum-based assessment program) designed to help eighth grade students gain an understanding of their academic development in terms of preparation for college. EXPLORE assesses academic progress and student interest for future educational opportunities. 
Feeder Schools- elementary and middle schools that contribute to a high school is typically referred to as a feeder pattern. Feeder school patterns are normally based on a student's residential address.

Freshman Academies- ninth grade smaller learning communities (SLCs). In this setting students are assigned to a particular group and remain with that group of peers and teachers through the school year.

GCTI - Grant County Transition Initiative. Grant County is the district that implemented the grade eight to grade nine articulation activities studied in this dissertation. Collectively, the acts of forming committees, reviewing previous literature on transitions, and creating and implementing a transition plan became known as the Grant County Transition Initiative (GCTI).

Organizational Learning- defined as the social processing of knowledge that constructs a clear, commonly held set of ideas that involves turning data into knowledge that can be shared and acted upon to improve the organization (Louis, 1994).

Outcomes- academic performances that include final grades in reading and math/grade point averages (GPA), student behavior (reported discipline incidences) and attendance (reported absences).

PLVS- practical Living/Vocational Studies classes (Physical Education, Art, Music, Band, Drama and Vocational classes).

Teacher Swap- teachers from different schools change places for a period of time, usually a day. In this study, grade eight teachers went to the high school and taught grade nine students and grade nine teachers went to the middle school to 
better prepare students for the transition to high school and to build student relationships.

Tier Consequences - five levels of labels and implications created by federal legislation for individual schools or districts not meeting specific federally mandated assessment goals: Tier 1, not meeting AYP two years; Tier 2, not meeting AYP for three years; Tier 3, not meeting AYP for four years; Tier 4, not meeting AYP for five years; and Tier 5, not meeting AYP for six years. The consequences of these Tiers are dependent upon the number of years not meeting goals, and range from providing parents and students school choice, revising the school plan, offering supplemental services, instituting a corrective action plan and submitting a plan for alternative school governance.

Transition Committee - These committees includes teachers, counselors and administrators, from the middle school and high school, whose task is to develop a transition program that consists of a set of structured articulation activities for students moving from grade eight to grade nine.

Vertical Alignment Meetings - Meetings held among same content area teachers (ex., all math teachers) across multiple grades or schools. In the GCTI study, the alignment meetings were to examine transition issues and student academic and behavior issues. 


\section{CHAPTER TWO}

\section{REVIEW OF LITERATURE}

This chapter contains the description of and literature support for the conceptual framework of this study developed from three bodies of research: Organizational Learning (OL), High Reliability Organizations (HRO) and Effective Schools (ES). This chapter reviews research on three additional topics: effective transition programs, research on the three school transitions students typically navigate and research on the implementation of organizational change. In a final section the implementation framework of this study is presented.

\section{Conceptual Framework Foundation}

A core assumption of this project is that research on OL can effectively link the constructs of HROs with ES to create a structure for the development of a successful transition program.

The ideas of ES and HRO formed the foundation for a middle school to high school transition program that are effectively linked by OL. OL combined with an understanding of transitions generally and research-based articulation activities specifically were hypothesized to have an impact on the schools' ability to engage in organizational change, function as a productive learning organization and as noted in two supporting studies of the Grant County Transition Initiative (GCTI), improve student academic performance, behaviors and student attitudes (Allen, 2011; Hibbett, in process). 
Rumberger and Palardy (2005) explored the relationship between school characteristics and student outcomes. Their study found that school inputs plus prior knowledge plus school experiences equal outputs. The conceptual framework for this transition study reflected the findings of Rumberger and Palardy with regard to the characteristics that produced organizational outcomes that ultimately lead to improved student academic performance and behavioral outcomes and student attitudes. Organizations become learning organizations when they employ the three ideas of this study: organizational learning, high reliability and effective schools and specifically the four characteristics common to the three ideas: systemic processes, leadership/vision, collaboration and the use of measures. How organizations learn, how high reliability organizations work and how effective schools operate using the characteristics common to all three determined if the Grant County schools grew from a school system to a system that functioned as a productive learning organization during this transition initiative.

This set of relationships is graphically represented in Figure 1. Each of the building blocks of this figure is described in detail in the following pages. The dash lined boxes represent the outcomes of the two supporting studies. 
Figure 1. Grant County Transition Initiative Conceptual Framework

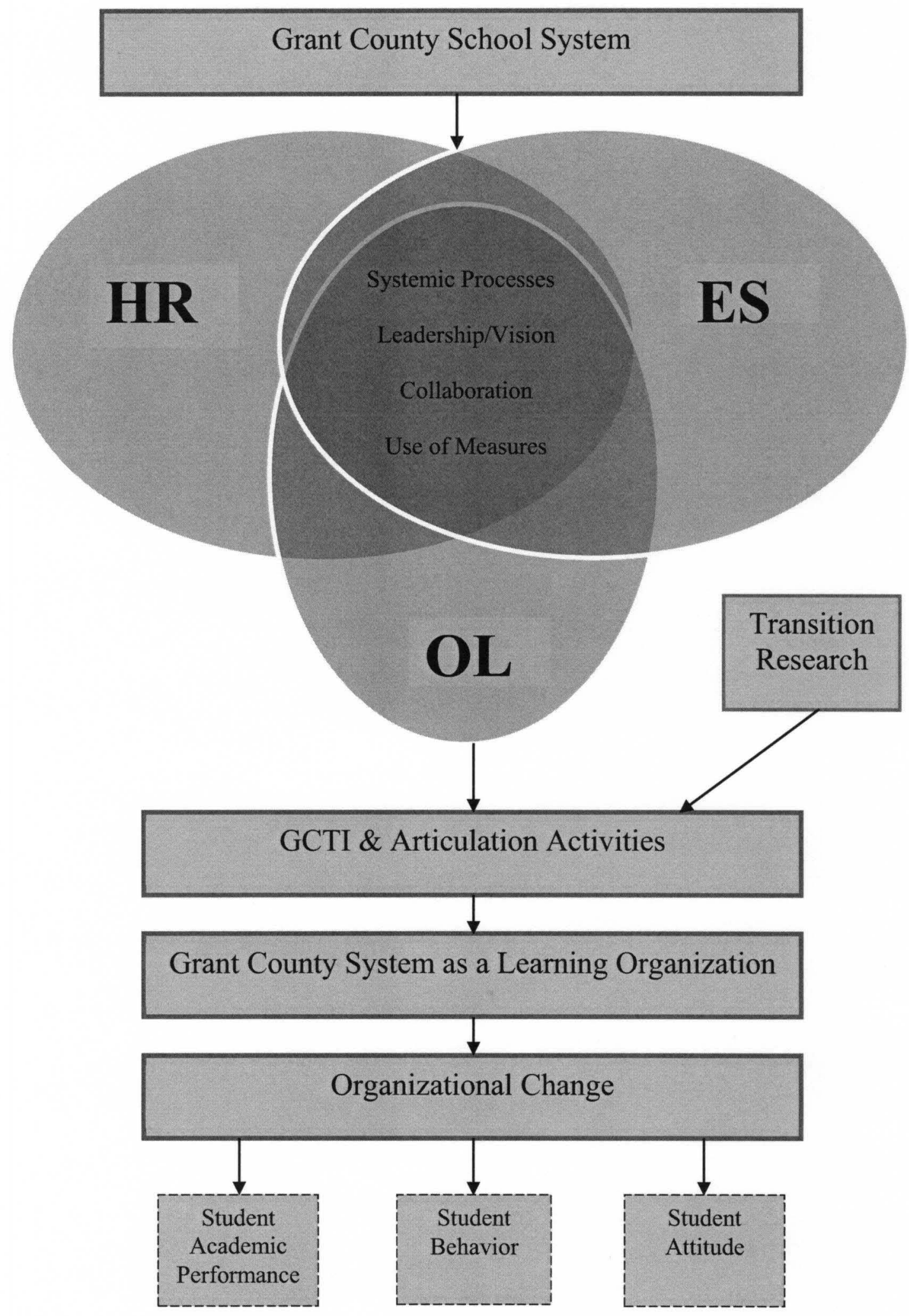




\section{High Reliability Organizations}

High reliability organizations use sophisticated forms of organizational learning (Marais, Dulac \& Levison, 2004). Datnow and Stringfield (2000) described the characteristics of organizational learning that included a set of clear goals, a shared belief across all levels, and maintenance of databases, standard operating procedures, extensive recruiting, targeted training, two-way monitoring, collegial decision making and strong communication. HROs engage in a similar set of processes in which the work is planned and intentional, where change is planned, strategic and systematic to ensure predictable outcomes (LaPorte \& Consoline, 1991; Weick, Sutciffe \& Obstfeld, 2000).

Datnow and Stringfield (2000) noted that HROs require coordination among key groups within a school, district, and state. Changing the atmosphere and giving a school new direction requires the organizational process of change to occur from top to bottom and the reverse during the implementation stages. Stakeholders involved in the implementation process must be involved in the developmental process throughout each step of the journey. Datnow, Hubbard \&Mehan (1998) proposed that social structures such as schools and school systems follow a pattern of emphasis on structure, culture, and agency. In more direct terms these structures are seen as "real people confronting real problems in classrooms, school board meetings, and reform design labs" (Datnow \& Stringfield, 2000, p.8). In applying Datnow and Stringfield's HRO research to effective transition programs, all stakeholders must be involved in the development and implementation of the program to produce effective change. People within the organization at every level must be involved in creating the structure and processes for organizational change to occur to produce a high reliability organization. 
According to (Stringfield et al., 2008), in almost every school where success was documented, teachers worked collaboratively under a guiding coalition of leaders or design team members in a systematic manner of co-construction of the strategies. In the schools that demonstrated success, leadership developed a clear vision of the goals, expectations on the use of data and a shared understanding of the basis for the reform. In these schools, teachers and leaders were contributing partners in the implementation and development of the strategies.

Schools need district support to be effective. Stringfield and Yonezawa (2000) noted the impact of district support for schools implementing HRO characteristics and the need for reform strategies to include support from district level administrative teams. District support is a critical characteristic of the high reliability organization that requires a connection at all levels of the organizational structure.

Stringfield and Teddlie (1991) pointed out that district leadership, school level administration, and building level instructors need to be prepared to spend the time required to develop an effective program. Stringfield and Datnow (1998) studied numerous school districts, examining why they experienced success or failure with reform movements. Schools that experienced success in organizational change received early district support and used the HRO tenants to establish sustainability for reform. Schools that experienced instability of district leadership derailed the sustainability of the reform attempt.

HRO and OL have in common the characteristics of a shared set of goals and beliefs created by strong leadership, systems thinking, team based learning, and strong communication with all stakeholders. These characteristics are indispensable 
components of the foundation that when added to the organizational learning structure, form the foundation for this study's middle school to high school transition program. When middle and high schools share a collective vision of the need for a transition program that includes a focus on data measures of student success and a systematic process for implementing transition activities, the organization begins to emulate the characteristics of an HRO.

The research shared above clearly directs schools and school districts toward embracing HRO characteristics. The set of structured articulation activities used in this study's transition program were collaboratively developed, systemically planned and regularly monitored using measures of student academic performance and behavior data with the shared goal of impacting student outcomes and growth within the organization.

\section{Effective Schools}

Organizational Learning effectively links HRO and ES by improving actions within the organization through a commonly held set of ideas that better informs the organization for reform to occur (Fiol \& Lyles, 1985). Effective School research recognized the school as having the power to make a difference in student achievement regardless of a student's socio-economic status (Brookover et al., 1982; Edmonds, 1982). These studies found that virtually all students can achieve at high levels in a variety of school settings from rural to urban, elementary to high school, and among varying income levels and that student outcomes are not solely based on the environmental backgrounds of the student. More important is what schools do within these settings that make a difference. Edmonds's question summarized the authority of schools in developing organizational structures that make a difference in student outcomes: 
What is the interaction between pupil performance and family background? If there is an interaction, is it a correlation or is it a casual interaction? I take this to be a fairly serious question because if you conclude, as does a good deal of the literature, that family and social class causes pupil performance, then the only way to do something about that is to intervene in the nature of the American family, at least those families whose characteristics we have reservations about. If you conclude, on the other hand, that it is merely a correlation, and that social class and family background are not, in fact, causes of performance, then you don't have to intervene in the life of the family. You intervene instead in the nature of the way schools respond to the differences in families that they are supposed to serve (1980, p. 5).

With the research of Edmonds, schools began to analyze how they responded to the differences among children in schools. Edmonds (1982) published the first of several updates to what became known as the Correlates of Effective Schools that identified what effective schools had in common: (1) strong leadership of the principal, (2) a focus on instruction, (3) a safe and orderly climate, (4) high expectations for all students, and (5) the use of data measures of student achievement. Case studies noted in Effective Schools Review (Purkey \& Smith, 1983) included the research of numerous studies that all shared many of the same characteristics of Effective Schools. The high expectations of both schools and teachers make the difference in improving student learning outcomes (Weber \& Omotani, 1994). Effective schools exist when the teachers and leaders within these 
organizations believe they can respond to the students and positively impact student outcomes.

Nine characteristics of effective schools emerged from the extensive review of research conducted by Teddlie and Reynolds (2000). The nine included: effective leadership, systemic processes, a focus on instruction and best practices, maintaining a clear and focused purpose, creating a positive school culture, high expectations for all students, an understanding of rights and responsibilities, monitoring student progress and collaborative decision.

The original correlates (Edmonds, 1982) have been expanded by several researchers in the past thirty years. Lezotte's update to the correlates included: (1) "instructional leadership, (2) clear and focused mission, (3) safe and orderly environment, (4) climate of high expectations, (5) frequent monitoring of student progress, (6) positive home-school relations and (7) opportunity to learn and time of task," (Lezotte, 2007, p.5). International studies on effective schools concluded effective schools shared a finite set of goals, the use of data, standard operating procedures, a focus on instruction, collaboration on best practice, skillful leadership and teacher motivation (Stringfield, Reynolds \& Schaffer 2008). Although diverse reviewers of the field have concluded that effective schools have somewhat differing sets of characteristics, many of the overlapping characteristics of effective schools surface.

Overlapping characteristics emerged from the literature on ES, HRO and OL. These characteristics, when embedded in a middle school to high school transition program, produce change within the organizational structure that ensures the likelihood of successful student transition from one school level to the next. These common 
characteristics include: (1) a clear and finite set of goals, (2) systemic processes for working on the work, (3) strong leadership to guide the organization's goals and vision, (4) a collaborative school culture with a focus on instruction, and (5) an expectation of analyzing data measures of student and organizational outcomes.

Research by Deal et al., 1977 parallels the characteristics of high reliability organizations and effective schools, suggesting the inclusion of teachers and district leadership in the development of activities that impact change. This same study suggested that change would more likely be engrained within the culture of the school if teachers were empowered and involved in the process.

Collectively, the characteristics of ES and HRO, when utilized in developing a reform initiative help create an organization that learns and grows. Initiatives that share a common vision, that develop systemic processes of operating procedures, that nurture a collaborative culture with a focus on monitoring progress ultimately impacts organizational learning and how the organization operates and improves.

\section{Organizational Learning}

Organizational learning plays a major role in determining and understanding systems and organizational effectiveness. For organizations to be effective leaders must first understand those systems (Schlechty, 2001). How organizations learn, grow and improve as an organization is critical to the success of organizational outcomes.

Organizational growth does not occur without intentional planning and implementation of systemic processes.

High performing organizations function as learning centers when they develop the ability to manage change in dynamic environments (Fullan, 1993; Giles \& Hargreaves, 
2003; Louis, 2006; Silins, Mulford \& Zarins, 2002). To manage change, organizations must create mechanisms and systems for such learning to take place. During the last decade, organizational learning has provided a research-based framework for examining school improvement (Cousins, 1998). Organizational learning is defined as the social processing of knowledge that constructs a clear, commonly held set of ideas that involves turning data into knowledge that can be shared and acted upon to improve the organization (Louis, 1994). Murphy's (1992) study of organizational learning identified four critical components to create positive school change: the belief in the educability of learners, a focus on outcomes, attention to consistency, and coordination throughout the school community. These four components are critical to organizational learning to create organizational change.

Each organization develops unique characteristics that influence the individual members of the organization and are transmitted to communities of individuals through their history and norms (Fiol \& Lyles, 1985). Senge (1990) identified the characteristics of a learning organizations to include: systems thinking, shared mental models, teambased learning, and shared vision building, "where people continually expand their capacity to create the results they truly desire, where new and expansive patterns of thinking are nurtured, where collective aspiration is set free, and where people are continually learning to see the whole together" (1990, p.3). Several studies (Fiol \& Lyles, 1985; Levitt \& March, 1988) described organizational learning as routine-based, history-dependent, and target-oriented, where learning occurs within the organization when better knowledge and understanding are shared and acted upon. 
This same concept applies to schools as organizations. Schools that establish systematic processes in which educators work collaboratively to find solutions to school issues become effective schools that work as high reliable organizations that learn and grow. Systemic processes must be designed in schools that create opportunities for educators to collectively gather and share information on a continuous basis, establishing systemic structures, and practices that facilitate learning for all its members (Silinis \& Mulford, 2002). School organizations need to develop systems that create a collaborative culture and provide common planning time for teachers that allow teachers to collectively use data when making decisions that impact the organization (DuFour et al., 2004). Knowledge of the organization and how it works can benefit schools and districts in developing a systemic process for implementing activities that assist students in the transition to high school.

During the years that NCLB has been in effect, emphasis has been placed on student achievement and school performance, both measured through standardized achievement tests. Attendance and retention rates are non-cognitive components figured into school performance indices. NCLB requires high schools to attain a graduation rate of $90 \%$ or better to meet adequate yearly progress (AYP) and avoid state and Federal sanctions and subsequent consequences (Innes, 2009). As the pressures of accountability occur concomitantly with federal sanctions and consequences for those schools not meeting AYP, schools are faced with the need to implement strategies and activities that ensure successful transition from grade eight to grade nine as part of the overall drive to improve student academic performance and non-cognitive student data. Schools must 
explore a variety of avenues to enhance their students' prospects for a seamless and effective transition from middle to high school.

Effective school transition programs that incorporate the characteristics of organizational learning have teachers and leaders working collaboratively within the school and between feeder schools to create clear goals and a commonly held set of ideas and beliefs that guide the work. This shared knowledge can change the way teachers work within the organization and how the school intentionally develops programs for dealing with the needs of students during the transition, therefore improving the organization, (Lezotte, 2007). Staff behaviors must change as well as organizational structures and the change must be systemically planned to turn advocacy into action and improve the organization.

School faculties that work collaboratively as opposed to working in isolation gain a better understanding of the needs of the organization and are reflective of a learning organization in the application of: shared knowledge, strong leadership, clarity of purpose, developing a collaborative culture and a focus on measures of results (DuFour et al., 2004).Organizational learning represents a core competency of both effective schools and high reliability organizations that is paramount to creating an effective school.

To investigate if the schools in this study operated as one learning organization during a transition initiative while implementing articulation activities, this study elected to analyze the characteristics common to OL, HRO and ES and included systemic processes, leadership/vision, collaboration and the use of measures. To answer this study's research question, the literature revealed how organizational learning effectively linked HRO and ES. This study focused on the characteristics common to OL, HRO and 
ES that included clear goals, systemic processes, leadership/vision, collaboration and use of measures. Schools that create systemic processes or procedures for working on the work, that share a common vision for the reform initiative, that work collaboratively to improve outcomes with a focus on data measures confirm a learning organization exists. The literature revealed these characteristics are critical to creating organizational change that ultimately leads to organizational learning.

\section{Effective Transition Programs}

Mizelle and Irvin (2000) noted schools that apply the characteristics of effective schools when developing transition initiatives have the opportunity to create effective middle school to high school transition programs. Transition programs that utilize ES characteristics are led by strong visionary school leaders who create a shared understanding of why the need exists for transition programs. These leaders provide time for teachers to collaborate and utilize data to identify student needs. Visionary school leaders foster collaborative partnerships between schools to develop a shared vision of student transition success. The implementation of effective school characteristics impacts the organization in changing the way people within the schools do business.

Transition programs that use the characteristics of organizational learning and high reliability organizations that are common to effective school characteristics should be able to help create a systemic structure where people work within, among and between people within the organization to improve the organization and outcomes. Transition programs enable schools to intervene and respond to the needs of students from various demographic backgrounds (Edmonds, 1982). Transition programs that include 
articulation activities help connect students and parents with available resources and provide intervention opportunities that help increase student opportunities for success.

It is hypothesized that transition programs that systemically implement articulation activities improve the effectiveness of the organization by improving how teachers respond to students during the transition, ultimately improving the school organization (Darling-Hammond \& Friedlaender, 2008).

\section{Research on School Transitions}

This section describes research on three school transition levels most students negotiate through their years of schooling, (1) the transition from elementary school to middle school, (2) the subsequent transition from middle school to high school, and (3) for many students, the transition from high school to college. With each transition, the students' transition experiences either add to their educational foundation, or create a barrier that diminishes their chances of successful completion at each level.

\section{Elementary School to Middle School Transition Research.}

After five to six years in elementary school, students negotiate the first transition from the elementary school environment to the middle school environment. Elementary students typically leave behind classrooms where everybody knows their names, and where they are largely taught by a single teacher who serves in loco parentis. Students then enter middle schools with departmentalized, multi-teacher schedules. Within a short period of three years, the next transition occurs as these same students who have become accustomed to the culture of the middle school move to larger more impersonal high schools that are grade oriented rather than student oriented (Eccles, Midgley \& Adler, 1984). During the transition from elementary to middle school, students face a variety of 
issues such as changes in school configuration, classroom organization, varied teaching styles, larger class sizes, higher academic standards and higher teacher expectations (Blyth, Simmons, \& Bush, 1978). The transition from elementary school to middle school can be characterized by a focus more on academics and less on the affective development of students (Schumacher, 1998).

Waggoner (1994) conducted a study of 171 sixth-graders at the elementary level. This study indicated that elementary students who rotated between classes were more self-confident and had fewer concerns when transitioning into middle schools. The rotation mirrored middle school class changes and allowed students to interact socially and academically with various student groups. This opportunity to rotate prepared these students to adjust to the multi-teacher, multi-room middle school schedules.

As students move from elementary to middle school student-teacher relationships change. Middle school teachers may have five classes of twenty-six students each, which greatly reduce time spent with each student, thus making it harder to forge important teacher-student bonds.

For a student to make a smooth transition, Schumacher (1998) recommended elementary students receive assistance before, during, and after the move to avoid damage to their social, psychological, and academic well-being. Schumacher also reported that highly organized elementary schools would benefit from using transition research when developing transition programs that include articulation activities to better prepare students for the move to the middle school. 


\section{Middle School to High School Transition Research}

In the transition from middle to high school, students experience many of the same intellectual, social, emotional and physical changes common to other school transitions. Grade nine transition success is the shared responsibility of both the middle school and the high school. To ensure adolescents make a successful transition into high school, middle and high school educators must work together to align the curriculum, communicate behavior expectations and develop activities that help create a "seamless transition between schools" (Williamson \& Johnston, 1999, p. 16).

Finding solutions to address the transition to grade nine should start in the middle school with personnel at both levels preparing students to enter high school. The transition into high school involves coordinating efforts between the middle and the high school program on academic and behavior expectations, as well as specific articulation practices at the time of the transitions (Gruhn \& Douglass, 1947; McEwin, 1998; Vars, 1998; Williamson \& Johnston, 1999). High schools and middle schools whose faculties work collaboratively to develop transition activities that address adolescent needs create opportunities for a successful transition to high school.

Hertzog and Morgan (1998) found that transition programs must go beyond a few superficial activities such as building tours and developing student schedules to activities that foster teacher/student relationships, connect students to intervention supports, inform students of available resources and extra-curricular opportunities and better prepare and engage students in the transition. Epstein (1995) reported that middle to high school transition programs that included activities that increased parental involvement along 
with activities that prepared students for the higher academic rigor expected in the transition better ensured the likelihood of transition success.

The transition from middle to high school is a complex one. Without the proper school structural supports, incoming ninth graders can become disconnected from school that can later manifest into detrimental outcomes (Oakes,2009). For example, detrimental outcomes such as poor attendance can negatively impact transition success. The Center for Comprehensive School reform and Improvement Fund (Oakes, 2009) found that $90 \%$ of freshmen who missed less than a week of school per semester are more likely to graduate than students who missed more than a week. Freshmen who arrived with high achievement test scores who missed more than two weeks of school were more likely to fail a course than freshmen with low test scores who missed only one week of school (Consortium on Chicago School Research, 2007). Of students who missed five to nine days of school their ninth grade year, only $63 \%$ graduated compared with $87 \%$ who missed fewer than five school days. "Attendance not only predicted graduation, but it also predicted course failure. Grade nine attendance rate was eight times more predictive of course failure than grade eight test scores" (Allensworth \& Easton, 2005, p. 16). The importance of success in grade nine is critical to the long-term success in high school. This same study found that $95 \%$ of Chicago students with a B average or better in grade nine graduated from high school. A student being on-track in grade nine is a strong predictor of graduation from high school. Students are considered on-track if they have completed five out of seven high school credits and have failed no more than one course in grade nine. Researchers found that on track students were three-and-a-half times more 
likely to successfully complete high school in four years than students who were not on track.

Studies conducted by (Barone, Aquirre-Deandries, \& Trickett, 1991; George, 1999; and Hertzog, Morgan, Diamond, and Walker, 1996) all noted the challenges eighth graders experience in the transition from the middle to the high school. As a result of these and similar studies, more schools in the middle are developing transition programs aimed at meeting the specific needs of the adolescent as they enter high school (Cognato, 1999). According to (Gruhn \& Douglas, 1947; McErwin, 1998;Vars, 1998; and Williamson \& Johnston, 1999) educators need to implement transition activities at both the sending and receiving institutions to ensure successful entry into high school and throughout grade nine.

Findings from a longitudinal study conducted by Isakson and Jaris (1999) and qualitative studies by Kinney (1993) found that many transition programs function at the surface level by implementing a small number of activities designed to ease the transition from middle school to high school. These surface level activities usually include discussion about course offerings and building tours. According to Kinney, even though familiarity of courses and the facilities are important in initiating a smooth transition, they do not address issues that students themselves see as critical during this time of transition such as increased academic rigor, behavioral expectations and social acceptance.

A 2006 research summary from the National Middle School Association (NMSA) reported that students are very concerned with affective issues during the transition such as the need to belong, peer acceptance and fitting in (Oakes, 2009). Academic concerns, 
though understood by students as important, are less important to most transitioning students than social development. Freshmen are excited about the possibilities of becoming more involved in extra-curricular activities, meeting new friends and the freedom associated with this transition such as having some power over course selection and electives (Cognato, 1999; Maute, 1991; Mizelle, 1995; Phelan, Yu \& Davidson; 1994; Wells, 1996). These same studies found students also admit to the anxieties of not fitting in, being harassed by other students, bullying, getting lost and making poor grades.

"Transition is a process, not an event" (Hertzog as quoted by Oakes, 2009, p. 1). Schools and districts need to systematically design a process of transitions that begin early in grade eight and continue through grade nine. Some research models even support effective transition processes lasting five to six years (NASBE, 2008). This longterm model is supported by involving parents and school guidance counselors working collaboratively to helping students realize the connection between course offerings at the middle school and high school levels and their relevance to career goals.

NMSA (2006) found four actions critical to effective transition programs. These actions include:

"(1) ensuring collaboration between the eighth-grade and ninth-grade building, (2) providing targets and early interventions to support academic recovery for failing students, (3) making available to students and families pertinent and consistent information about academic, social, and organizational similarities and differences between the middle school and high school, (4) offering information on the curriculum, facilities, safety and discipline of the high school" (p. 2). 
Hertzog and Morgan (1999) conducted a study of fifty six high schools in Georgia and Florida. The results indicated that high schools that offered extensive transition programs had significant reductions in failure and dropout rates. The researchers concluded schools that included activities such as counseling, schools visits and special summer programs improved student outcomes.

Many studies have been conducted on the effect of the number of transitions on student success comparing double transitions versus the single transition. Double transitions are defined as a move from elementary to middle and then another move from middle school to high school. Single transitions are experienced by students who make only one transition from K-8 to high school. Alspaugh (1998) found that when students participated in the double transition, greater achievement loss and higher dropout rates occurred than if they had only taken part in one transition. In response, schools incorporated transition programs that provided extra academic interventions and support services to students who experienced multiple transitions. This support came in the form of tutoring and counseling and included an effort to increase parental participation. Manning \& Baruth (1995) provided evidence that such programs produce positive results in student performance and attitudes. Chapman (2001) supported the need for schools to provide collaborative efforts among middle school and high school faculty to address the needs of at-risk students.

Sunrise Middle School in inner city Philadelphia created a comprehensive program for middle school students as they transitioned into high school. The Community for Learning Program (CLP) provided the following key components to middle school students at Sunrise Middle: (1) support and professional development 
training for the teachers, (2) learning systems to assist students in taking responsibility for their own learning and behavior, and (3) the importance of community and family involvement. The results from this program indicated that students who participated were more successful as they transitioned into high school than students who did not have the opportunity to participate in the program (Oates, 1998).

To keep incoming ninth grade students from getting lost in the high school setting, Needham B. Broughton High School in Raleigh, North Carolina created a comprehensive transition program called Project First Step. The program included strategies to help students stay on track. This included, among other programs a lunchtime program which allowed students to spend their lunchtime completing missing assignments for credit. It was determined successful as it provided an avenue for students who had been sheltered in middle school to find success in the high school setting (Hertzog, 1999).

The research clearly provides support for the need for middle schools to collaboratively and intentionally with high schools to develop strategies that better prepare students for the transition.

\section{High School to College Transition Research}

The third transition to take place during many students' educational careers happens from high school to college. For others, the transition is leaving high school to enter the world of work. Like the transition from middle school to high school, the students' transition from high school to college is filled with challenges. With each transition, students increase their chances of becoming lost in the transition unless 
schools implement research based practices that help create a sense of community (Lee \& Smith, 1995; Lee, Bryk \& Smith, 1993; Johnston, 1992; and Bryk \& Driscoll, 1988).

The UCLA Center for Mental Health found that the successful transition of high school students to college needed a solid system of transitional activities to help students experience success during their first year of college (Entin, 2009, p. 18). The center researchers suggested the following: (1) develop an individual transition plan, (2) ease anxieties and strengthen specific coping and self-advocacy attitudes and skills, (3) ensure availability and access to relevant support mechanisms, (4) ease college demands, (5) minimize financial concerns, (6) monitor, problem solving, and celebrating success and (7) revamp plans and supports (Journal of College Admissions, 2009, p. 18). The potential use of these transitions strategies is centered on developing support systems at the level that a transitioning high school student will find helpful and productive. The Center's research indicated the importance of preparing the ground for new students to find support systems that invest in their well-being.

Bragg \& Rudd (2007) reported that one articulation activity that eases the transition from high school to college is the opportunity to take dual credit courses. According to these researchers, students who took dual credit courses experienced success rates that were significantly higher than their fellow students who did not have the same experiences. These courses helped prepare students for the academic rigor associated with college attendance.

Tech Prep, along with dual credit, provided strong transition programs that can help students move into college with success. This was pointed out by the Abell Foundation (2007) and their Jump Start program implemented in Baltimore City, 
Maryland. In addition, the Abell Foundation found students who took AP course work, regardless of their score on the AP exam, were more likely to experience college success.

As the above synthesis shows, students transitioning from high school to college benefit from a systematic process of implementing articulation activities to address their transition needs. Student success in grade nine is a predictor of success throughout the student's high school career and plays a vital role in increasing chances the student graduates from high school. Each of these successes helps to ensure student success in the transition from high school to college. Students exiting high school face many of the same challenges in the transition to college that they encountered when moving from elementary to middle school and from middle to high school. This study supports the need for schools and districts to develop a systemic process of articulation activities to help students with this transition from high school to college.

\section{Research on Implementation of Organizational Change}

The change process is difficult to develop, complicated to implement, and even more challenging to sustain. For schools to effectively implement and sustain initiatives such as a grade eight to grade nine transition programs, all stakeholders must be involved in the development and implementation process in order to impact long term effects. Stakeholders must understand the need for the change and be committed to reaching the desired outcomes. Greenwood, Mann and McLaughlin (1975) found in their in-depth examination of the process of change in education that "projects generated essentially by opportunism were characterized by a lack of interest and commitment on the part of the local participants, from district administrators to classroom teachers" (p.20). This type of 
culture created an atmosphere of indifference toward the change and the results of the change had little or no impact on the desired outcomes from the process.

Teacher buy-in is critical to reform change. This aspect of buy-in is an important component of the change process that Datnow and Stringfield (2000) noted is needed for any change to occur with reliable results. For teacher buy-in to occur, teachers need to be included in the process of developing the initiatives they will be expected to implement rather than have programs handed down to them from administrative hierarchy with little to no input.

Teachers must also be informed of the results measures of the change initiative and provided the proper professional development needed to implement the change. MacIver, Kemper and Stringfield (2003) found, "In schools where teachers have become heavily invested in the program with scores rising, we believe it is particularly important to continue implementing the reform, as change would be potentially disruptive" (p.7). Miles (1998) examined the aspect of teacher training in the change process in education. He described specific strategies needed to impact school change: train individuals in group skills and train change agents to be the guiding coalition. These variables of the change process described to teacher educators the skills necessary to make a dramatic attempt to organizational performance.

\section{Implementation Framework for the Grant County Transition Initiative}

The conceptual framework that serves as the theoretical reasoning for implementing a transition initiative that included articulation activities is built on the foundation that a learning organization exemplifies the four characteristics common to OL, HRO and ES: systemic processes, leadership/vision, collaboration and the use of measures. The three ideas that undergird this study were organizational learning, high 
reliability organizations and effective schools combined with an understanding of transition research. Through the study of transition research and the use of articulation activities during the transition from grade eight to grade nine, the GCTI was developed and implemented to improve student's graduation rates. The three inter-related studies of the GCTI, described in Chapter 1, were conducted to determine various effects of the initiative. This specific study was designed to determine the impact of the initiative on Grant County Schools' ability to function as a learning organization.

This study hypothesized that a transition initiative built on this framework and the common characteristics of all three robust ideas, when applied to the implementation of thirteen articulation activities during a grade eight to grade nine transition initiative would impact the learning organizational environment of a school and determine the organization functions as a learning organization.

\section{Summary}

The supporting literature for this study provided guidance for developing a grade eight to grade nine transition program. To be successful, initiatives should incorporate the characteristics common to organizational learning, high reliability organizations and effective schools with an understanding of the transition issues students face with each transition. Schools that emulated the characteristics common to OL, HRO and ES that embedded these same characteristics in the development of a transition program better ensured the successful transition of students to grade nine and increased the likelihood that the organization operated as a learning organization. In order for change to be effective, it cannot occur merely at the school level. For sustainable, long term, systemic 
change to take place, numerous stakeholders must be involved in the development and implementation of any initiative to include teachers, administrators and district personnel.

When organizations create a unified process for reform (systemic processes), when teachers and leaders create shared goals (leadership/vision) for working collaboratively within and between schools (collaboration) to improve student and organizational outcomes (use of measures) they are increasingly likely to become effective school learning organizations, and move toward creating more nearly HROs. These combined efforts at every level help transform the system into a more sophisticated, more effective learning organization in which people collaborate, share a common vision of what the school is and what it can become, in which decisions are data driven, where systemic processes and procedures are developed and implemented that affirm a learning organization is in place. This chapter provided a foundational structure for developing and implementing a grade eight to grade nine transition program that incorporated key characteristics common to organizational learning, high reliability organizations, and effective schools, that this study identified from the research as systematic processes, leadership/vision, collaboration, and the use of measures. These four characteristics are critical components of an effective learning organization.

Chapter three describes the methods used for gathering data that are intended to determine the extent to which Grant Count Schools operated as a learning organization during this transition initiative. The data build from the conceptual framework and the four characteristics common to the conceptual framework of HRO, ES and OL: systemic processes, leadership/vision, collaboration and use of measures. 


\section{CHAPTER THREE}

\section{METHODOLOGY}

This chapter describes the research question, context/sample, development of GCTI, research design, instruments, procedures, analysis plan, validity and limitations inherent in this study.

\section{Research Question and Purpose}

The purpose of the present study was to investigate the use of Effective Schools and High Reliability Organization logic in creating a productive Organizational Learning environment for the implementation of a research-based middle-to-high-school transition program ${ }^{1}$. This study hypothesized that a school feeder pattern in which faculty members share a vision of reform and collaboration, that create systemic processes of implementation while monitoring data measures will help develop the organization as a learning organization.

This study addressed the following research question: Has the creation and work of the Grant County Transition Initiative and the subsequent implementation of articulation activities enabled the middle-high school system to function as a productive learning organization?

${ }^{1}$ As has been noted previously, the larger study in which this study is situated included a study of student achievement outcomes (Allen, 2011) and student attitude outcomes (Hibbett, in process) from the same transition initiative in Grant County, Kentucky. 


\section{Context/Sample: The Grant County Middle School and High School}

Two schools in one Kentucky district were chosen for the conduct of this study. The two participating schools, Grant Middle School and Grant County High School were within the Grant County School System.

Grant County (KY) School District is located in a rural setting along the Ohio River between Cincinnati, Ohio and Louisville, Kentucky. The county's population is overwhelmingly of European-American descent. At the time of this study, Grant County School System included seven schools- one high school, one middle school and five elementary schools. At the inception of this study, the high school had freshman academies in place and the middle school had teaming in place. Both schools had professional learning communities (PLCs) and scheduled time and opportunity for small groups of teachers to meet during the school day in each school to discuss student academic achievement, behavioral and curricular issues. Neither school had a systemic process for facilitating students' transitions from middle to high school prior to this initiative.

Table 1 describes the student demographics of Grant County Middle School and Grant County High School at the start of the initiative in 2008.

Table 1

Student Demographics for 2008

\begin{tabular}{lll}
\hline Demographics & GCMS & GCHS \\
\hline Total \# of Students & 852 & 1090 \\
Caucasian & 818 & 1058 \\
African American & 6 & 8 \\
Hispanic & 15 & 12 \\
American Indian & 0 & 3 \\
Asian & 2 & 2 \\
\hline
\end{tabular}




\begin{tabular}{lll}
\hline Other & 0 & 7 \\
Limited English & 11 & 0 \\
Free \& Reduced Lunch & 481 & 547 \\
Students with disabilities & 102 & 107
\end{tabular}

Note. Information provided in this table was retrieved from the Grant County Student Information Reporting Data System (STI) August, 2008. GCMS = Grant County Middle School. GCHS = Grant County High School.

Grant County Middle School was structured in grades 6-8. Grant County High School served students in grades 9-12. Table 2 displays school-level teacher and administrator demographic information for the schools. Data reflected high school freshman and grade eight teacher/administrator data. Minimal diversity existed within the student population.

Table 2

Teacher/Administrator Study Participants' Demographics for 2010

\begin{tabular}{lll}
\hline Demographics & GCMS & GCHS \\
\hline Total \# of Teacher/Administrator/Counselor Participants & 12 & 15 \\
Grade Level & 8 & 9 \\
Science Content Teachers & 2 & 2 \\
Math Content Teachers & 2 & 3 \\
Social Studies Content Teachers & 2 & 2 \\
Language Arts Content Teachers & 2 & 3 \\
Special Education Teachers & 1 & 1 \\
Practical Living/Vocational Studies Teachers & 1 & 2 \\
Administrator/Counselor & 2 & 2 \\
Average years' experience & 14.3 & 10.5 \\
Average years in present school & 8.6 & 5.2 \\
\hline Ne.
\end{tabular}

Note. Information provided in this table was retrieved from the Freshman Transition Teacher Survey administered May, 2010. GCMS = Grant County Middle School. GCHS $=$ Grant County High School.

A total of twenty seven teachers and administrators participated in the GCTI that included twelve middle school grade eight teachers and fifteen grade nine high school and teachers. 
Grant County Middle School with grades 6-8 was the only middle school.

Teachers shared a weekly common planning period arranged in content department PLC meetings. The school was arranged in teams with a set number of students assigned to each team. Each grade level consisted of three teams. A typical team included one teacher in each of the content areas of English, math, science and social studies and served ninety-five students per team.

Grant County High School had one feeder school, Grant County Middle School. The high school served grades 7-12. Grade nine was configured as a Freshman Academy where grade nine teachers shared a weekly common planning period arranged in content department PLC meetings. Most grade nine classrooms were housed in a designated wing of the high school. The majority of freshman teachers were assigned to teach grade nine students only.

\section{Describing the Intervention:}

\section{The Development of Grant County Transition Initiative (GCTI)}

The GCTI evolved as an intervention to address the system's high freshman failure and school drop-out rates. The high school freshman principal initiated the discussion and began investigating strategies for improvement. In response, the Grant County superintendent created a transition committee that included middle and high school teachers, administrators, counselors and the district superintendent. The superintendent charged this group with creating and leading the Grant County Transition Initiative (GCTI). The GCTI began during the summer of 2008 .

The GCTI transition committee members used the literature on OL, HRO and ES to create a vision for change by working collaboratively with middle and high school 
leaders, teachers and district stakeholders to development and implement a systemic process for developing and implementing the articulation activities. GCTI committee members created a systemic process or structure that changed the way people worked. Transition committee members communicated the vision for the transition initiative and collaboratively developed a systemic process for implementation and monitoring the initiative.

Building from the research of Hertzog and Morgan (1999), the team recognized the importance of implementing five or more articulation activities for increasing the likelihood of transition success. Transition committee members reviewed the literature on articulation activities and collaboratively selected the thirteen articulation activities used in this study.

\section{Articulation Activities}

The transition committee members selected the thirteen articulation activities based on the collective research of Hertzog and Morgan (1999). Each activity aligned to one or more of Hertzog and Morgan's five categorical areas. The five categorical areas are; (1) curriculum; (2) facilities; (3) safety and discipline; (4) teachers, counselors and administrators; (5) general. Intentionally planned activities in these areas informed students of high school curriculum expectations, familiarized students with the new facility, informed students of safety and behavior expectations, and helped students build relationships with teachers, counselors and administrators prior to entering the high school.

The articulation activities that comprised the GCTI are listed by category in Table 3 and described in further detail in the following text and in Appendix A. 
Table 3

Articulation Activities Organized by Five Categorical Areas

\begin{tabular}{ll}
\hline Area & \multicolumn{1}{c}{ Activity Description } \\
\hline Curriculum & $\begin{array}{c}\text { Grade eight parent orientation meeting to determine HS } \\
\text { class schedule }\end{array}$ \\
HS special education teachers attending grade eight team \\
meetings \\
HS Counselor Meeting with grade 8 students to discuss \\
study skills and coping skills for the transition to the \\
HS \\
MS/HS Vertical Alignment Meetings collaboratively \\
involved MS and HS content teaches \\
Team Building Sessions with grade eight and grade nine \\
teachers to discuss College Readiness \\
Grade eight At-risk student meetings grade eight teachers \\
and the high school counselor
\end{tabular}


General Counselor/Parent meetings to discuss transition to HS that included academic and behavioral expectations

Summer Freshman Transition Program lead by HS student leaders

Grade eight parent orientation meeting. Two meetings were designed for parents: the grade eight parent orientation meeting and the grade eight parent scheduling meeting. The parent orientation meeting informed parents on what to expect as their child transitioned from the middle school to high school and included topics such as available resources, opportunities for extra-curricular involvement, and parental involvement opportunities.

Grade eight parent orientation meeting for scheduling. This parent meeting was designed to inform parents of high school course offerings and student schedule development for their child.

Teacher swap. In this activity middle school and high school teachers traded places for a day. The purpose was to build teacher/student relationships in advance of grade eight students entering the high school.

Progress meetings. Progress meetings took place during regularly scheduled PLC meetings. The PLC meetings were scheduled by departments at the high school and by teams at the middle school. Teachers at each school separately discussed and analyzed middle and high student data at the end of each grading period. Students identified as at risk of failure in reading and math along with students who exhibited poor behavior and attendance histories were identified to be provided additional intervention strategies to address individual student needs. An additional type of progress meeting included the school principals meeting with the superintendent in four and a half week 
progress meetings also referred to as Status of School Report meetings to discuss student transition data that included academic performance and behavior data.

High school special education teacher meetings. High school special education teachers attended grade eight team meetings to discuss the transition needs of students with individual education plans (IEPs).

High school tour. A tour of the high school took place with grade eight students. During the tour, middle school students were assigned to a station rotation where high school students and high school teachers informed middle school students about such topics of after school tutoring, response to intervention offerings, extra-curricular involvement opportunities, school safety measures, the high school code of conduct, the high school dress code and high school academic expectations.

Counselor/parent meeting. These meetings informed parents of resources available in the form of counseling, remediation or tutoring, scheduling and the academic rigor required at the high school.

Counselor/student meeting. The high school counselor met with grade eight students to discuss coping skills, study skills, family youth resource services, self-help opportunities, career planning and scheduling.

Vertical alignment meetings. Vertical alignment meetings were collaboratively designed meetings that included middle school and high school teachers and administrators. These meetings were data driven and included student academic and behavioral data as well as curriculum alignment data for preparing students for the transition from the middle school to the high school. 
Attendance at student events. Middle school and high teachers attended student events to build positive teacher/student relationships and a positive school culture. The high school teachers were required to attend the middle school dance and grade eight graduation.

Team building sessions. Team building session were scheduled that included middle school teachers and Freshman Academy teachers to analyze middle school student EXPLORE data and develop intervention strategies in reading and math for identified students.

Summer transition program. The Summer Transition Program was scheduled and lead by high school ROTC students. The purpose was to equip grade eight students entering the high school in the fall with organizational, team-building and leadership skills.

At-risk teacher meetings. At-risk meetings included middle school and high school teachers. These meetings were data driven with a focus on students who demonstrated low academic performance but who did not qualify for special education services. These meetings identified student areas of weakness academically and behaviorally with the intent to provide intervention strategies. These activities are further detailed in (See Appendix A).

\section{Implementation Timeline of GCTI}

In the summer of 2008 , the transition committee was formed. The team included administrators, counselors and teachers from the middle and high school and central office leadership. Transition committee members reviewed the literature provided by the superintendent on OL, HRO and ES, articulation activities and transition research. Using 
knowledge gained from the research, the committee members collaboratively designed the systemic processes for implementation of GCTI that included thirteen articulation activities. During the 2008-2009 school year, principals at the middle and high school introduced their respective faculties to the selected articulation activities during regularly scheduled faculty meetings.

Some activities were one-time events while others were on-going. One-time events included a grade eight parent orientation, grade eight parent scheduling meeting, teacher swap, grade eight tour of the high school, counselor/parent meeting, HS counselor meeting with grade eight students, team building session and the Summer Transition Program. Activities that occurred on a regular, on-going basis during the school year included vertical alignment meetings, progress meetings, at-risk student meetings, high school teachers attending grade eight special education meetings and middle and high school teacher attendance at middle school events.

\section{Monitoring GCTI}

Monitoring the impact of GCTI occurred in transition committee meetings led by the superintendent at various other meetings led by the principals, department chairs, academy and team leaders and counselors. The transition committee oversaw the overall implementation of GCTI. The transition committee met monthly, beginning July 2008 to discuss GCTI timelines and the systemic processes for implementing the articulation activities using the characteristics common to OL, HRO and ES in developing GCTI. Monitoring GCTI also occurred in weekly PLC meetings, monthly academy and team meeting meetings, four and a half week Status of School Report meetings with principals and the superintendent, school level progress meetings after each grading period and 
monthly middle and high vertical alignment meetings. Discussion focused on the processes for implementing the articulation activities, the vision of the initiative, expectations of the initiative and student academic and performance data. Data examined included student data measures on GPA, failures, reading and math grades, behavior reports and data on attendance.

\section{Independent Variable}

The independent variable of this study was the introduction of the Grant County Transition Initiative (GCTI). The GCTI included the implementation and monitoring of thirteen articulation activities at Grant County Middle School and Grant Count High School.

\section{Dependent Variable}

The dependent variable of this study was the ability of Grant County Middle and High School to function as an effective learning organization. This study examined the impact of thirteen articulation activities in determining if Grant County functioned as a learning organization.

\section{Research Design}

This study used a mixed method, phenomenological research design. Qualitative and quantitative data were used to provide in-depth analyses to determine if Grant County functioned as a learning organization during the GCTI that included articulation activities. The phenomenological research design allowed the researcher to examine teacher and administrator reactions to - or perceptions of - the specific phenomena under investigation. Information from surveys, transition committee interviews, teacher 
interviews and documents were collected and organized into categories aligned to the characteristics common to OL, HRO and ES that define a learning organization.

A critical attribute of phenomenology is its intentionality in determining content or meaning from information gathered (Denzin \& Lincoln, 2005). This study intentionally examined OL, HRO and ES principles and the characteristics common to all three: systemic processes, leadership/vision, collaboration and use of measures during the implementation of GCTI to determine if Grant County Middle and High School functioned as a productive learning organization. These four characteristics formed the categories of data collection for this study.

Qualitative data gathering allowed a detailed story to emerge from the information from surveys, interviews and other data (Adler \& Adler, 1987). Qualitative methods relied extensively on a rich, in-depth description of the phenomenon through content document reviews and interviews that used direct quotes from participants who described the phenomenon (Patton, 2002). Quantitative data were used to determine the amount of teacher participation and teacher value using a 1-4 Likert scale.

\section{Instrumentation}

The four sources used to gather and triangulate data for this study included the Freshman Transition Teacher Survey, transition committee interview, teacher interview and diverse archival documents gathered from school and district meetings that involved transition initiative information. The Freshman Transition Teacher data were collected in May, 2010. The transition committee interview and teacher interview were administered in December, 2010, seven months after completion of the Freshman Transition Survey. All five members of the transition committee members were interviewed. The five 
member committee consisted of the superintendent, a principal from the middle school and high school and a counselor from each school. Four middle school teachers and four high school teachers were interviewed. Meeting minutes and articulation activity documents were collect through December 31, 2010. Each of these is described below. Freshman Transition Teacher Survey

The Freshman Transition Teacher Survey was collaboratively developed with the help of a University of Louisville professor familiar with this study. Questions were designed to collect information that would help determine participation and value of the activities and if the middle school and high school functioned as a learning organization to the four common characteristics. The survey consisted of four parts: Part I gathered information in a yes/no format regarding teacher participation in the structured articulation activities. Part II gathered frequency of participation information using a 1-4 Likert scale. Part III collected data on teacher value given to each articulation activity using a 1-4 Likert scale. Part IV elicited written comments from open response questions that gathered teacher input on the articulation activities to the four characteristics of a learning organization. The survey is described in greater detail (See Appendix B). The Freshman Transition Teacher Survey was developed and administered in spring 2010 after two complete years of GCTI. Transition committee interviews, teacher interviews and archival documents were administered and collected in December 2010. Interview and document data were analyzed seven months following administration of the Freshman Transition Teacher Survey.

Since many of the articulation activities took place one time during the year, many teachers did not respond to Part II, the frequency portion of the survey. Only five 
teachers responded to Part II and these teachers did not respond to frequency of participation for all thirteen articulation activities. The frequency data therefore was not used in the final analysis of this study's results. Part IV of the instrument included fourteen open response questions and two follow-up questions. These open-response questions provided teachers and administrators the opportunity to respond with written comments that provided qualitative information about the articulation activities. The qualitative information gathered from the open-response portion of this instrument collected data on whether teachers were informed about the structure of the activities, understood the vision for the activities, worked within and between schools and if data were shared in these activities.

\section{Transition Committee Interview}

The transition committee interview included seven questions with various possible follow-up questions. The list of transition committee interview questions is provided (See Appendix C). These questions were collaboratively developed by the author of this study and a University of Louisville professor familiar with the study. The questions were intentionally developed to examine the phenomenon under investigation, the four characteristics common to OL, HRO and ES. The seven questions and various follow-up questions examined the committee's understanding of the processes used to implement the Grant County Transition Initiative, how the initiative was shared with others, how the activities were selected and monitored, what activities are still in place, suggested changes to GCTI and how the middle school and high school faculties worked collaboratively. Transition committee members were interviewed in a group setting and comments were recorded and transcribed. The questions investigated if the organization 
operated as a learning organization using the characteristics common to the conceptual framework of the study that became the organizing categories of the study: systemic processes, leadership/vision, collaboration and use of measures.

\section{Teacher Interview}

Six interview questions with various follow-up questions were administered during the teacher interviews. To view the interview protocol See Appendix D. These questions were collaboratively developed by the author and a University of Louisville professor familiar with this study. Teacher interview questions described the processes teachers followed to collaborate and help students during the transition, what teachers did when students were failing, acting out, or demonstrating high absenteeism along with inquiries into teacher knowledge of processes used for tracking student extra-curricular involvement. Data collected helped determine if the organization functioned as a learning organization through the implementation of systemic processes, a shared vision, the collaboration of teachers and the use of student measures of academic performance and behavior data.

Teachers were interviewed in a group setting and comments were recorded and transcribed. Information collected was organized to determine the impact of GCTI on the learning organization to the characteristics common to OL, HRO and ES: systematic processes, leadership/vision, collaboration, and use of measures.

\section{Archival Documents}

Archival documents provided information on whether a systemic structure was in place for the implementation and monitoring of the initiative's articulation activities, whether articulation activities took place on a regular basis, what meetings were 
collaborative within and between the middle school and high school and if meetings included student academic performance and student behavior data. Documents were available from various meetings that included transition discussion and articulation activity data. School and district archival documents were provided in the form of meeting minutes and agendas that included Freshman Academy and team meetings, department/PLC meetings, vertical alignment meetings, progress meetings, faculty meetings and Status of School Reports. Some GCTI activities had additional documents such as the lesson plan template used in the teacher swap activity and the teacher assignment schedule of roles and responsibilities for the station rotation activity used in the middle school student tour of the high school. The Grant County School System's central office staff provided documents on the Status of School Report. All documents were secured electronically or in hard copy. For a detailed list of archival documents See Appendix E.

\section{Procedure}

The Freshman Transition Teacher Survey was administered during a faculty meeting at the middle school and the high school May 2010 after two years implementation of GCTI. Grade eight and grade nine teachers and administrators completed the survey. The transition committee interview and teacher interview were conducted December 2010, two-and-half years after the implementation of GCTI. Survey and interview data were gathered to assess if Grant County functioned as a learning organization during the GCTI to the four categories of systemic processes, leadership/vision, collaboration and use of measures. 
The transition committee included five members: the district superintendent, the high school freshman principal, the middle school principal and one counselor from each school. Teacher committee members interviewed were selected by the district superintendent and included four teachers at the middle school and four teachers at the high school. The superintendent selected teachers from both schools one teacher from the content areas of math, science, social studies and language arts.

Transition committee members and teachers interviewed were assigned pseudonyms and comments were transcribed. Interviews were conducted in an unstructured, open-ended group format with the researcher taking notes. Data was gathered was using a "priori thematic categorization" technique for organizing information by themes to the common characteristics. A directed approach was used to code responses. A directed approach uses research to guide the development of codes. The research of OL, HRO and ES guided this study. Categorical codes were assigned to open response comments, transition committee interview and teacher interview comments as they aligned to systemic processes, leadership/vision, collaboration and use of measures. Codes organized information to determine if systemic processes were in place, a vision was developed, collaboration occurred and data measures were used in the initiative's articulation activities. Words that relate to systems, vision, collaboration and measures and words synonymous to these four were used to organize comment information (See Appendix I). An educator familiar with the GCTI initiative served as second reviewer in coding these four sets of comments to the categorical areas.

The four sets of qualitative data included the survey's open response comments, transition committee and teacher interview comments and archival documents. The 
second reviewer was provided brief training on the key words then worked independently with the researcher coding comments and documents (See Appendix I). Written and transcribed comments from surveys, interviews and documents provided information on the impact of GCTI to determine if Grant County schools functioned as a learning organization in the four areas.

Archival documents were collected through December 31, 2010. The results from documents provided additional information to determine if the Grant County system functioned as a learning organization as identified by the characteristics of systemic processes, leadership/vision, collaboration and use of measures. A content analysis of these documents provided additional evidence to determine the impact of GCTI and the articulation activities on the Grant County learning organization. Documents were coded using a directed approach that guided the development of the codes to the research of OL, HRO and ES. Categorical codes were assigned to documents as they aligned to systemic processes, leadership/vision, collaboration and use of measures. Codes organized information to determine if systemic processes were in place, a vision was developed, collaboration occurred and data measures were used in the initiative's articulation activities.

Data were analyzed to determine whether school leadership had created a unified vision for the middle-high school transition program as evidenced throughout meeting and activity documentation. Documents were analyzed to determine if the vision was created for GCTI, if a systemic process was in place to implement the articulation activities, if the use of measures were employed in addressing transition data and if 
collaboration within and between both schools occurred as a result of this transition initiative.

Surveys, interviews and documents provided a multi-way triangulation of evidence to ascertain if the articulation activities and the GCTI impacted Grant County in functioning as a learning organization to the four characteristics common to OL, HRO and ES. To analyze the impact of the thirteen articulation activities, six analyses were conducted. Analyses are summarized in Table 4. Analyses conducted included the Freshman Transition Teacher Survey Part I, Part III, Part IV, transition committee interview questions, teacher interview questions and archival documents. Column one presents the research question, column two the instrument and column three the analysis technique.

Table 4

Data Analysis Plan

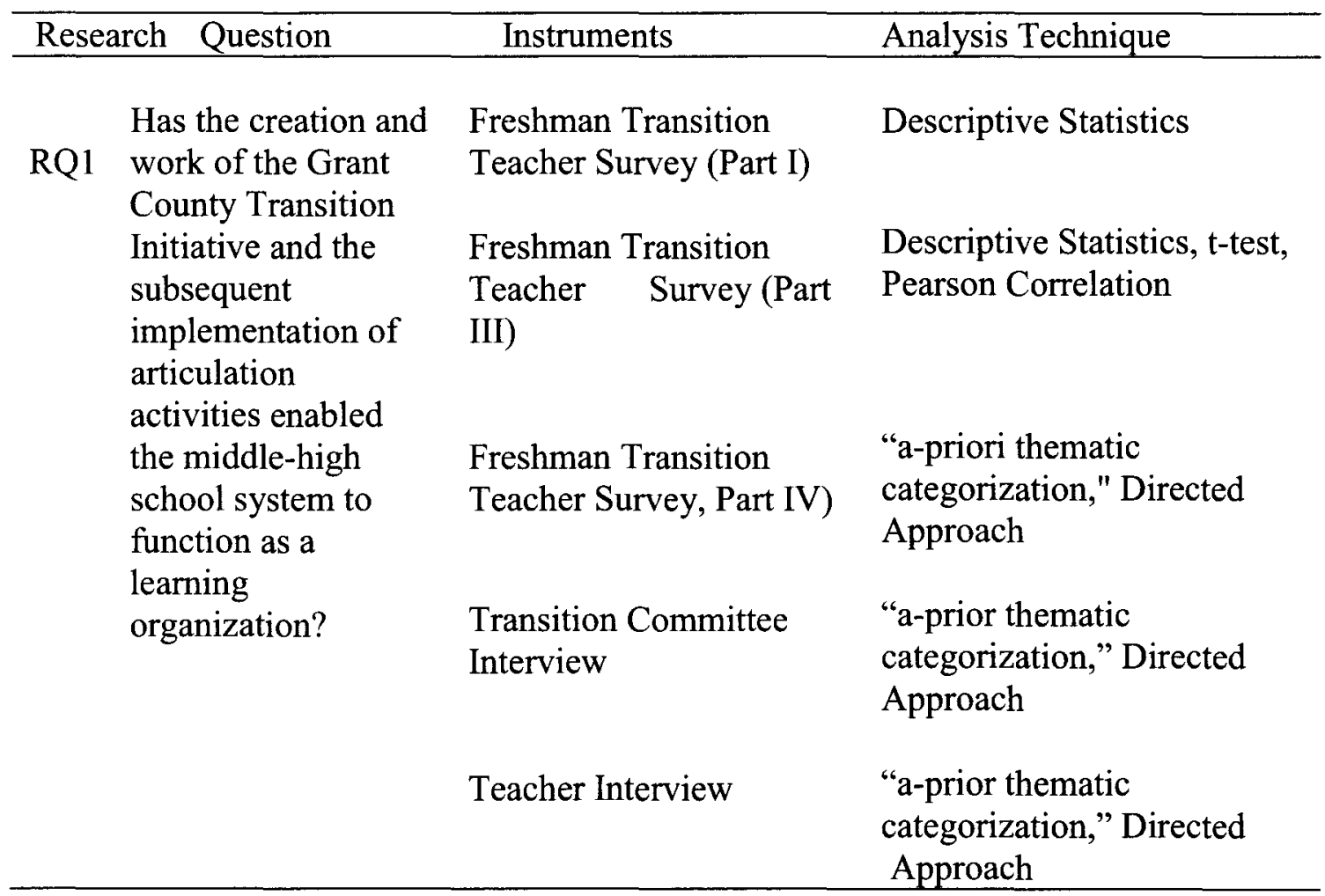




"a-priori thematic
categorization," Directed
Approach

\section{Analysis Plan}

\section{Freshman Transition Teacher Survey on Participation (Part I)}

Part I of the Freshman Transition Teacher Survey collected dichotomously coded data on participation in the thirteen articulation activities that included individual teacher participation totals in the thirteen activities and school-wide percent participation.

To arrive at teacher participation data, teachers responded to each of the thirteen articulation activities with yes/no responses. A yes response was assigned (1) and a no response (0). Teacher participation was calculated by totaling the number of (yes) responses on all thirteen activities for each teacher. Descriptive statistics using mean and standard deviation were used to determine similarities and differences between the two schools. Teachers' (yes) responses were analyzed by individual school and combined schools. Middle school percent data were calculated to include the twelve middle school teachers. High school percent data included the fifteen high school teachers.

\section{Freshman Transition Teacher Survey Regarding Valuing by Teachers (Part III)}

Quantitative data were collected from the Freshman Transition Teacher Survey

Part III that determined the average teacher value rating of all thirteen articulation activities and multiple teacher ratings combined to compute aggregate school and combined school ratings. This data helped determine the impact of the articulation activities and the perceived value teachers assigned to the articulation activities. 
Descriptive statistics, $t$-tests and a Pearson correlation were used to report similarities and differences among teachers and between schools.

\section{Freshman Transition Teacher Survey Open Responses (Part IV)}

Open response questions in Part IV provided qualitative data on teacher perceptions of various aspects of the GCTI. Written responses to these fourteen questions were analyzed and comments were coded to determine content meaning aligned to the four categorical areas of systemic processes, leadership/vision, collaboration and use of measures. This study's evidence from a synthesis of the literature of OL, HRO and ES and the four common characteristics provided the guidance for the codes.

Using the same process for open response question comments, transition committee interview and teacher interview comments, codes were developed that aligned to the common characteristics found in the research or words that were synonymous to these key words (See Appendix I). Comments were coded independently to these four categories by the researcher and a colleague familiar with this study to determine content meaning.

Out of a total possible 144 comments recorded for the open response, transition committee and teacher interview comments, the researcher and the reviewer were in agreement on 130 out of 144 . This provided an interrater reliability of $90 \%$. In the questions where disagreement occurred, the question had multiple codings possible as several key words applied to more than one category. The researcher and reviewer collaborated on comments in question to arrive at a consensus for coding. There were a total of 54 comments that provided evidence of systemic processes, 15 providing 
evidence for leadership/vision, 57 for collaboration and 18 providing evidence of use of measures.

Data collected from written teacher comments on the survey described the impact of GCTI and the articulation activities that helped determine if the middle school and high school functioned as a learning organization during this initiative. Data were collected to determine whether systemic structures were in place as a result of GCTI, if a shared vision and understanding of the initiative was present, if teachers collaborated and communicated with each other within and between schools on articulation activities and if the use of measures or data were an expectation in the articulation activities.

\section{Transition Committee Interview}

The transition committee interview provided additional qualitative data. A phenomenological research design was used to collect data from transcribed transition committee member interview comments to determine content meaning to the four categorical areas aligned to the characteristics common to OL, HRO and ES. Content meaning was determined using a directed approach analysis for coding data. This study's evidence from a synthesis of the literature of OL, HRO and ES and the four common characteristics provided the guidance for developing the codes used in gathering data.

Codes were developed that aligned to the common characteristics found in the research or words synonymous to the key words that describe the characteristics. The researcher and a second reviewer coded the comments that provided a level of interrater reliability. The seven transition committee interview questions and various follow-up questions were specifically designed to collect data to determine if this middle to high school transition 
initiative and articulation activities helped the organization function as a learning organization.

\section{Teacher Interview}

Teacher interview comments provided further qualitative data. Using a qualitative method and phenomenological research design, transcribed teacher interview comments were analyzed in an effort to determine content meaning. Content meaning was determined using a directed approach analysis of coding data. This study's evidence from a synthesis of the literature of OL, HRO and ES and the four common characteristics provided the guidance for the codes used in gathering data. Codes were developed that aligned to the common characteristics found in the research or words synonymous to the key words that describe the characteristics. The researcher and a second reviewer independently coded the comments providing a level of interrater reliability. Words were aligned to the key words of the common characteristics or words synonymous to the characteristics of systemic processes, leadership/vision and use of measures. Six teacher interview questions and various follow-up questions were specifically designed to collect data to determine if this middle to high school transition initiative that included articulation activities helped the organization function as a learning organization.

\section{Archival Document Analyses}

Documents were collected from various transition initiative meetings and articulation activities. Using a phenomenological research design, data in the form of documents were gathered to determine content meaning aligned to the four categorical areas common to a learning organization that included systemic processes, 
leadership/vision, collaboration and use of measures. Content meaning was determined using a directed approach analysis in coding data. Codes were developed that aligned to the common characteristics found in the research or words synonymous to the key words that describe the characteristics. The researcher and a second reviewer independently coded the comments providing a level of interrater reliability. The data collection determined the impact of GCTI on the organization and whether this initiative helped the Grant County system to function as a learning organization to the common characteristics of systemic processes, leadership/vision, collaboration and use of measures.

Documents were collected through December 31, 2010 from the middle school and high school. Archival documents were requested on each of the articulation activities and meetings where the transition initiative was a topic of focus. A list of archival documents used in these analyses is provided in See Appendix E. A content analysis of these documents provided additional evidence in determining the impact of articulation activities on the Grant County learning organization. Data were analyzed to determine whether school leadership had created a unified vision for this middle to high school transition initiative, if a systemic processes were in place to implement the thirteen articulation activities, if the use of measures were employed in addressing transition data and if collaboration within and between both schools occurred as a result of this transition initiative.

\section{Validity}

Cook and Campbell (1979) defined validity as the "best available approximation to the truth or falsity of a given inference, proposition or conclusion" (p. 37). In this 
study the following types of validity are identified based on the validity types from Shadish, Cook, and Campbell (2002).

\section{Internal Validity}

Internal validity determines if a condition or treatment supported by evidence makes a difference on the outcomes (Shadish, Cook and Campbell, 2002). In this study, evidence was collected to determine if the GCTI that included articulation activities made the difference in the two schools involved in the initiative to function as learning organizations. Internal validity is a measure of the extent one can trust the causal connection between the treatment provided and the results seen. Did the thirteen structured articulation activities impact growth in the learning organization or could it have been the result of pre-existing school structures such as: Professional Learning Communities, the Freshman Academy structure or middle school teaming? The internal validity refers to the degree to which one is justified in concluding that the outcomes observed were caused by the treatment. Attrition of some of the original participants during this study could impact internal validity. A triangulation of evidence from surveys, interviews and documents instruments was conducted to minimize threats and strengthen internal validity.

\section{Construct Validity}

Construct validity determines how well ideas or theories are articulated or translated into measures (Cook \& Campbell, 1979). Did the measures reflect what the study wanted them to? Did the data gathered collect evidence that determined the intended outcomes? Did the data provide direct evidence that explained the phenomenon under investigation? Did GCTI that included articulation activities help the Grant County 
organization to function as a learning organization during this middle to high school transition initiative? Construct validity was measured by triangulating the quantitative and qualitative evidence to the four characteristics under investigation.

\section{External Validity}

External validity refers to the degree that results from this study can be generalized to other settings, people, and times (Shadish, Cook and Campbell, 2002). Three components are critical to measuring validity that includes reliability, accuracy and precision. In the process of coding the survey and interview comments of this study, reliability is important in order that others can replicate this process. Accuracy is critical to ensure the study is free from bias. A brief training on coding served to minimize bias. Precision allows for generalizability to other to other settings. In this study, potential threats to external validity included the following: the use of only two schools in one district in Kentucky, the schools' rural setting, and the lack of diversity in the study's sample. The results of this study may generalize to other schools that match the characteristics of these schools. A larger sample would have provided a stronger foundation for assessing the external validity of the study.

Validity was strengthened in this study through multiple sources used in to the triangulation of data and a second reviewer in the coding of comments to the research findings.

\section{Limitations}

All studies have limitations. Several limitations of the larger set of GCTI studies and of this dissertation are provided below. 
1. The sample size of the study was limited: data were gathered in two schools in one district.

2. The sample schools are located one rural, predominantly middle socio-economic status school district in Kentucky. The limited diversity and rural demographics constitute a limitation of this study.

3. The teacher/administrator sample is not demographically diverse. Teachers and administrators in Grant County were 100\% Caucasian.

4. Attrition of faculty from the original sample group and the addition of new enrollees during the study added a limitation to this study. Seven teachers new to Grant County middle and high school involved in only one year of GCTI may have responded differently on the surveys than teachers employed before the initiative.

5. At the start of the study, the high school had in place Freshman Academies and the middle school was already using teacher teaming. These structures fostered collaboration. The academy and teaming structure may have influenced teacher perceptions of articulation activities in the transition from grade eight to grade nine and limit generalizability to other contexts. Not all high schools have Freshman Academies and it is not known how schools without Freshman Academies would respond to this intervention.

6. Professional Learning Communities were in place in both schools prior to the inception of GCTI. Grant County's PLC's promoted use of data and collaboration.

7. The superintendent of schools served on the transition committee and was present during teacher interviews. His presence in the interviews may have influenced teacher responses. 


\section{Summary}

Chapter three has provided a description of the methods for data collection and the process for analysis used in this study. These methods were chosen to allow meaning to emerge that described the impact of GCTI and the thirteen articulation activities in determining if the Grant County system functioned as a learning organization during this transition initiative. Chapter four will report results related to the one research question of this study to the categories that align to the characteristics common to OL, HRO and ES that included systemic processes, collaboration, leadership/vision and the use of measures of quantitative and qualitative data. 


\section{CHAPTER FOUR}

\section{RESULTS}

The intent of this study was to investigate the impact of a research-based middleto-high-school transition program on a school district's ability to become a higherfunctioning learning organization. The organization at the center of this study was the Grant County School System. Results reflect the impact of two and a half years of development and implementation of articulation activities employed in an effort to improve a transition program between Grant County's middle school and high school.

The question guiding this dissertation has been as follows, "Has the creation and work of the Grant County Transition Initiative and the subsequent implementation of articulation activities enabled the middle-high school system to function as a productive learning organization?"

Quantitative results presented below include data analyses related to participation and value. Qualitative results are presented in the order of written open response question comments and analysis of results related to the four categories common to the conceptual framework of the study. These include systemic processes, leadership/vision, collaboration, and use of measures. 


\section{Teacher Participation and Valuing}

Using the teacher questionnaire discussed in Chapter 3, participation and valuing are reported by individual teacher, by school and in combined school results. Individual teacher participation results are provided in Figure 2. Teachers 1 through 12 were middle school teachers, 13 through 27 were high school teachers. The number of teacher "yes" responses to participation in the thirteen transition activities ranged from 1-12. Four teachers indicated they participated in twelve of thirteen activities; all four were middle school teachers. The lowest number of structured articulation activities in which an individual teacher reported having participated was one. Fourteen teachers participated in over half of the articulation activities that included nine middle school and five high school teachers. The average mean for middle school teacher participation was 8.75 with a standard deviation of 3.11. At the high school level the mean participation rate was 5.80 with a standard deviation of 3.03 . By design, seven articulation activities encouraged more middle school teacher involvement with job/title specific activities. These articulation activities included, A1 grade eight parent orientation, A2 grade eight parent meeting for scheduling, A5 HS special education teachers attending grade eight meetings, A7 counselor parent meetings, A8 HS counselor meeting with grade eight students, A11 team building sessions and A13 grade eight at-risk student meeting. 


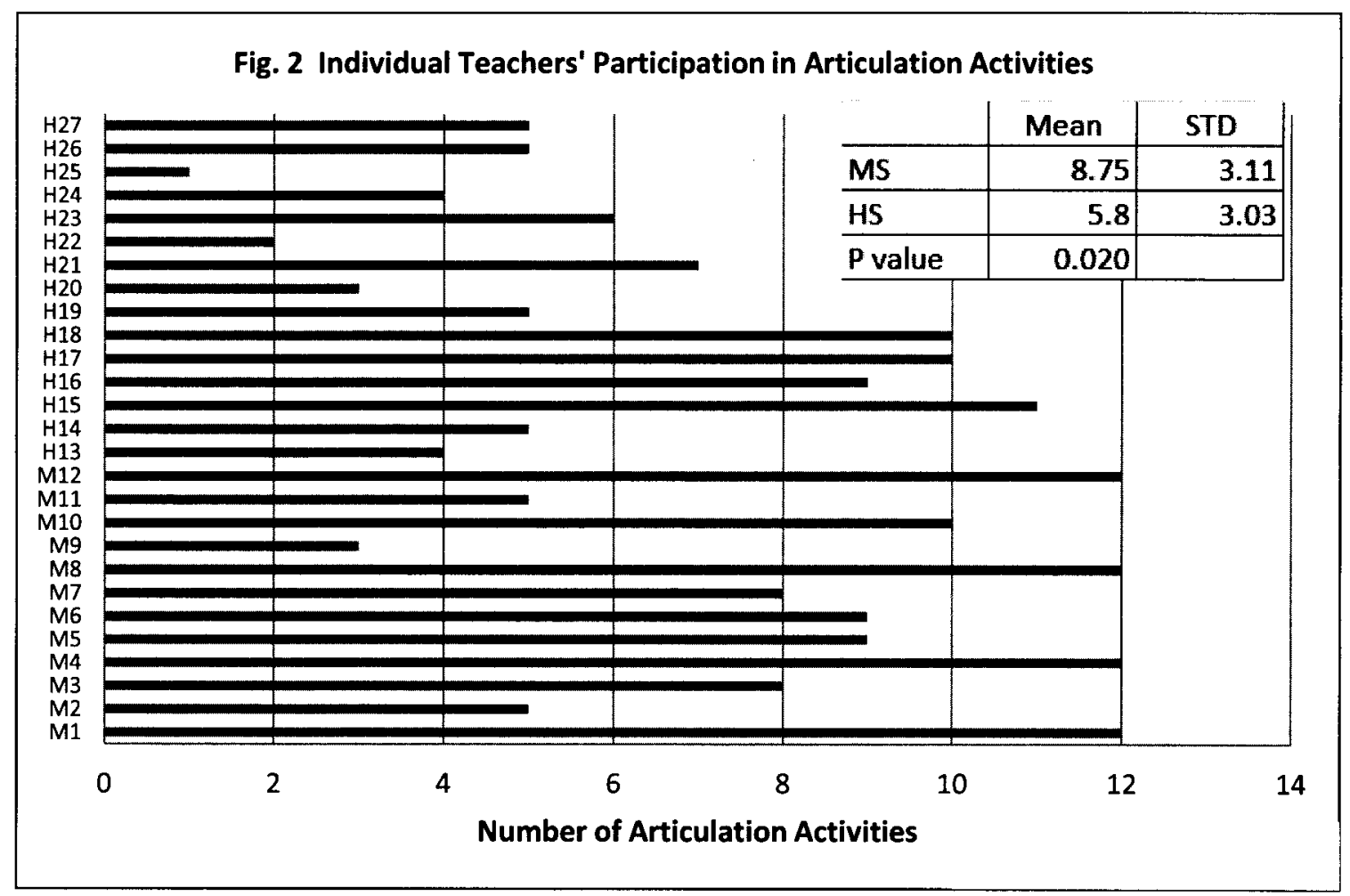

Note: The information in this table was compiled from the Freshman Transition Teacher Survey Part I participation.

M1-12= Middle School Teachers $\quad$ H13-H27= High School Teachers

Participation for school and combined school percent averages are provided in

Figure 3. A t-test $(\mathrm{P}=0.020)$ indicated a statistically significant difference at the 0.05

level in the middle and high school participation rates. The thirteen activities are

indicated in order on the survey (See Appendix B). Combined school data indicate eight

activities had over $50 \%$ teacher participation. These included $\mathrm{A} 1$ grade eight parent

orientation,A3 swap, A4 eighth and ninth grade progress meetings, A5 HS special

education teachers attending grade eight meetings, A6 tour, A9 middle school and high

school vertical alignment meetings, A10 high school teachers attending middle school

events and A11 team building sessions. All of these activities involved collaboration

among parents and teachers within and between schools. The two articulation activities

that had the highest percent participation rates $(81 \%)$ were the $\mathrm{A} 3$ teacher swap and $\mathrm{A} 10$ 
HS teachers attending middle school events. These two activities required collaborative exchange between schools. Activity A12, the Summer Transition Program had the lowest percent of teacher participation (19\%).

Activity A2 grade eight parent orientation for scheduling, and A8 HS counselor meeting with grade eight students, showed the greatest differences in participation between middle school and high school. These activities were specifically designed for middle school students, parents and teachers therefore would not have elicited high school teacher participation.

Two activities, A3 the swap, and A11 the team building session, produced the highest levels of school similarities in participation rates. Activity three had over $80 \%$ participation in each school and activity eleven had over $75 \%$ participation in each school.

Eleven activities showed similar movement in participation between the schools. When participation in activities one, three, six, nine, ten, eleven and twelve went up at the middle school, they went up at the high school as well. When activities went down in four activities the parent orientation meeting, progress meetings, counselor parent meeting, and grade eight at-risk student meetings they went down in both schools. The middle school had twelve out of thirteen activities with over 50\% participation and the high school had six of thirteen activities with over $50 \%$ participation.

Activities with the lowest percent participation at the high school included A2 parent orientation, A8 HS counselor meeting with students and A12 Summer Transition Program with under $20 \%$ participation. These activities were, by design, more middleschool role/job specific, and that accounted for greater middle school participation. 


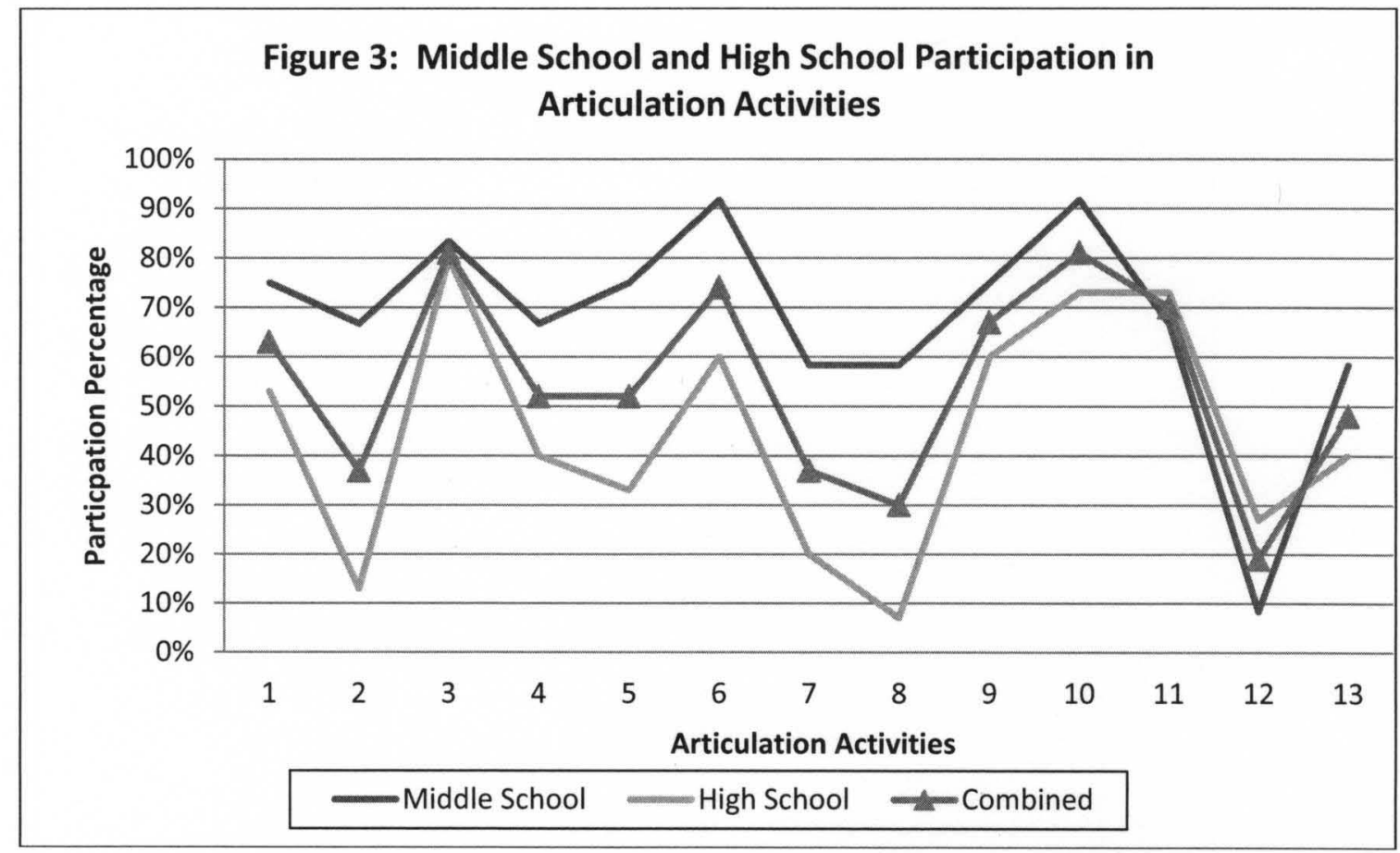

Part III of the Freshman Transition Teacher Survey provided data regarding the extent to which teachers found various transition activities valuable. The value section of the survey was designed to provide information on the value teachers assigned each of the thirteen articulation activities. To determine value on each activity, teachers responded with a $1-4$ rating $(1=$ no value, $2=$ minor value, $3=$ much value and $4=$ very much value).

Figure 4 presents each teacher's average value rating for all thirteen articulation activities overall. Teacher average value ratings on the thirteen articulation activities ranged from 1.5 to 4.0 . Fourteen of twenty seven teachers reported over-all valuing in the range of 3.0 or higher, indicating that they perceived the activities, in total, to have much value. Two teachers' average value rating produced a 4 rating of very much value. One teacher rated the activities overall with a 1.5 (indicating a perception of very little value). 


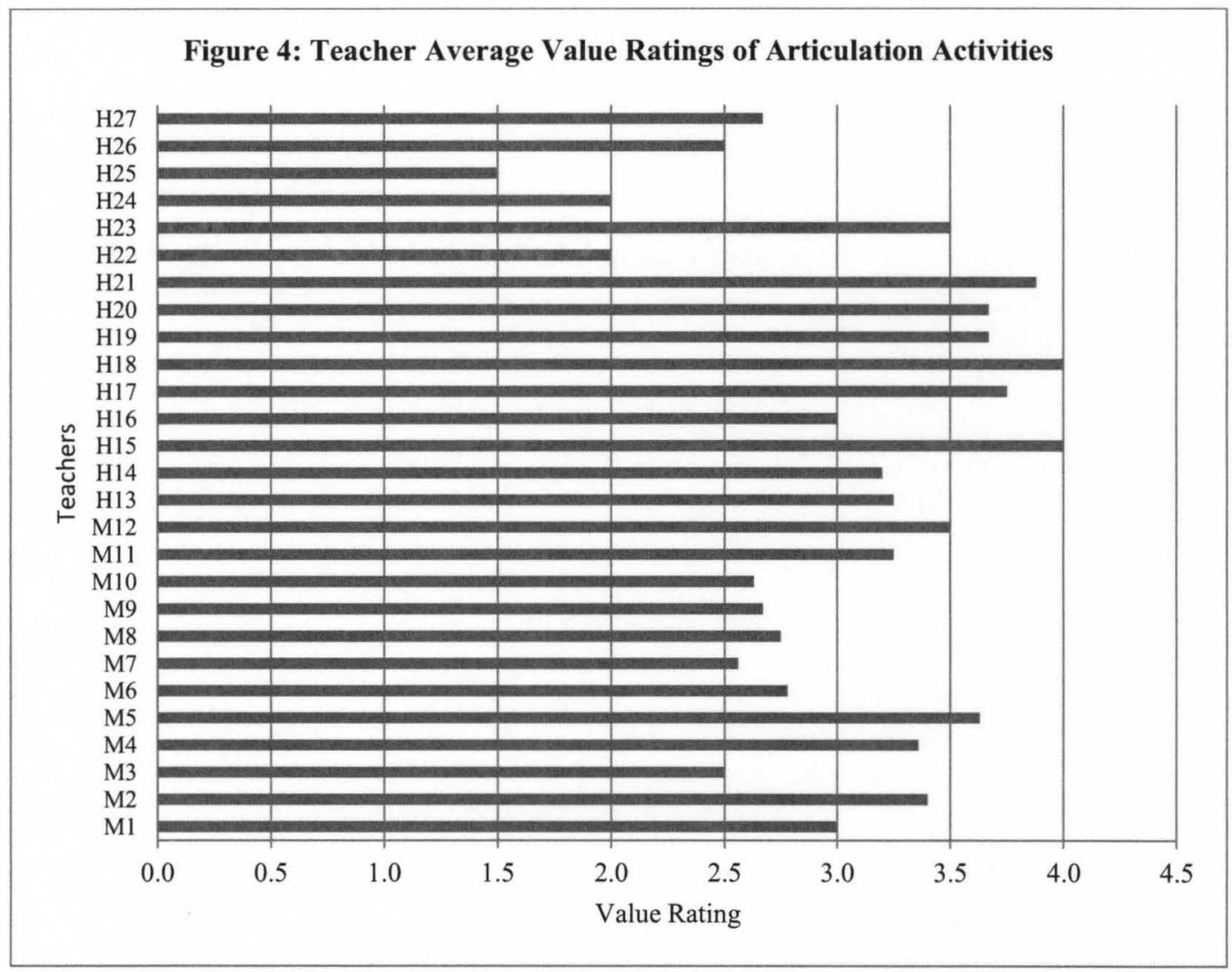

Note: The information in this table was compiled from the Freshman Transition Teacher Survey Part III value. $\mathrm{x}=(1-4)$ value rating M1-12= Middle School Teachers $\mathrm{y}=(1-27)$ Teachers; H13-H27= High School Teachers

School and combined school average value ratings for each of the thirteen articulation activities are presented in Figure 5. In analyzing school average value ratings, A2 parent orientation, A6 tour and A8 HS counselor meeting with grade eight students showed a spike in high school value ratings. The middle schools produced a spike in A2 parent orientation and A11 team building sessions. Activity three results show a dip in value ratings at the high school with a dip at the middle school in A3 swap, A9 middle school high school vertical alignment meetings and A12 the summer transition program. 
The activity with the highest combined average value rating was activity six, the tour of the high school, with a 3.5 rating. The activity with the lowest combined average value rating (2.6) was the teachers' middle-high school swap. Twelve of thirteen activities combine values received ratings of much value (3) to very much value (4).

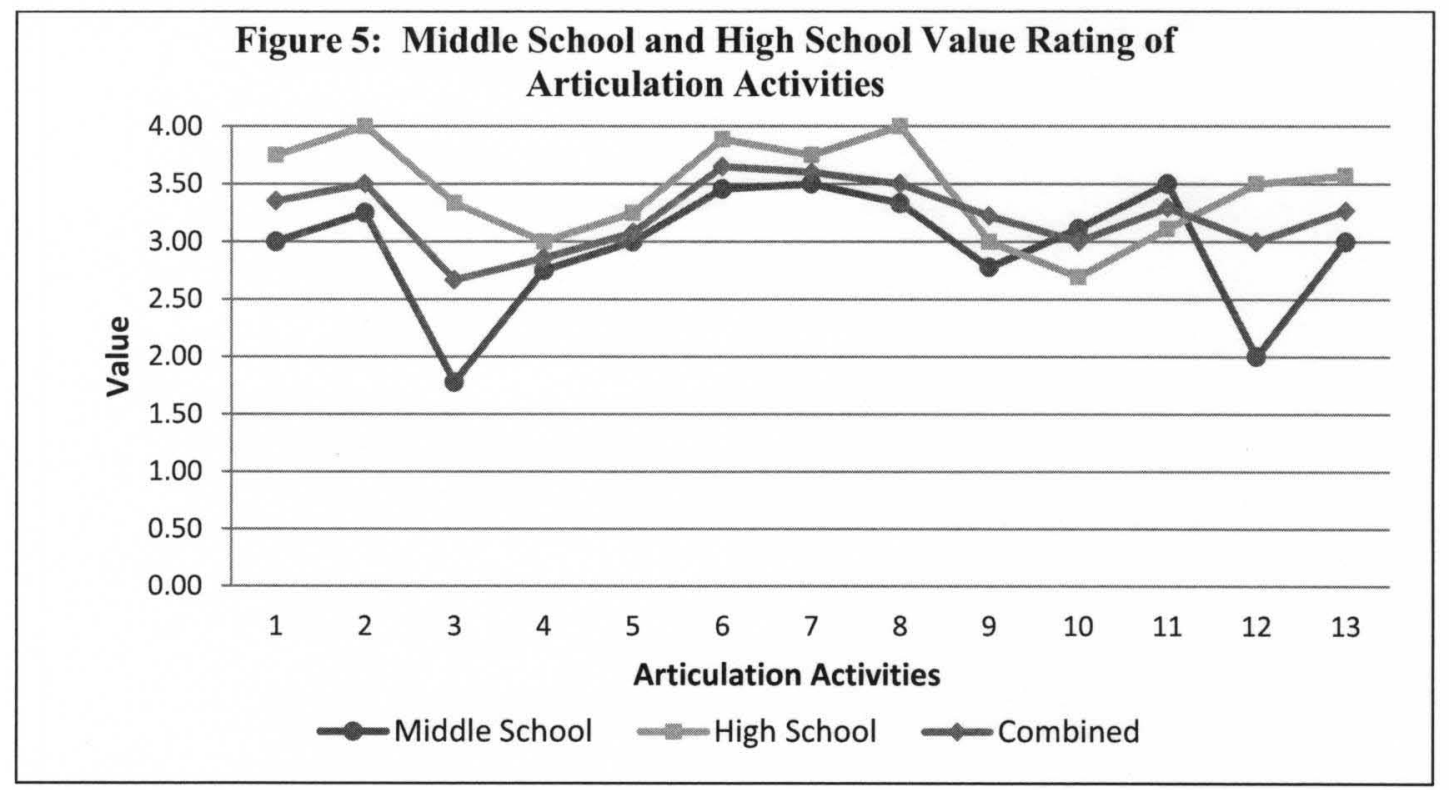

Note: The information in figure 5 was compiled from the Freshman Transition Teacher Survey Part III.

$\mathrm{x}=\mathrm{A} 1-\mathrm{A} 13$ Articulation Activities

$y=$ value rating $(1=$ no value, $2=$ minor value, $3=$ much value, $4=$ very much value $)$

Combined school average value ratings and combined participation ratings are

presented in Figure 6. A Pearson correlation provided results indicate relationships between value and participation. A coefficient correlation of 0.41 indicates that a positive relationship exists between an increase in participation and an increase in value. 


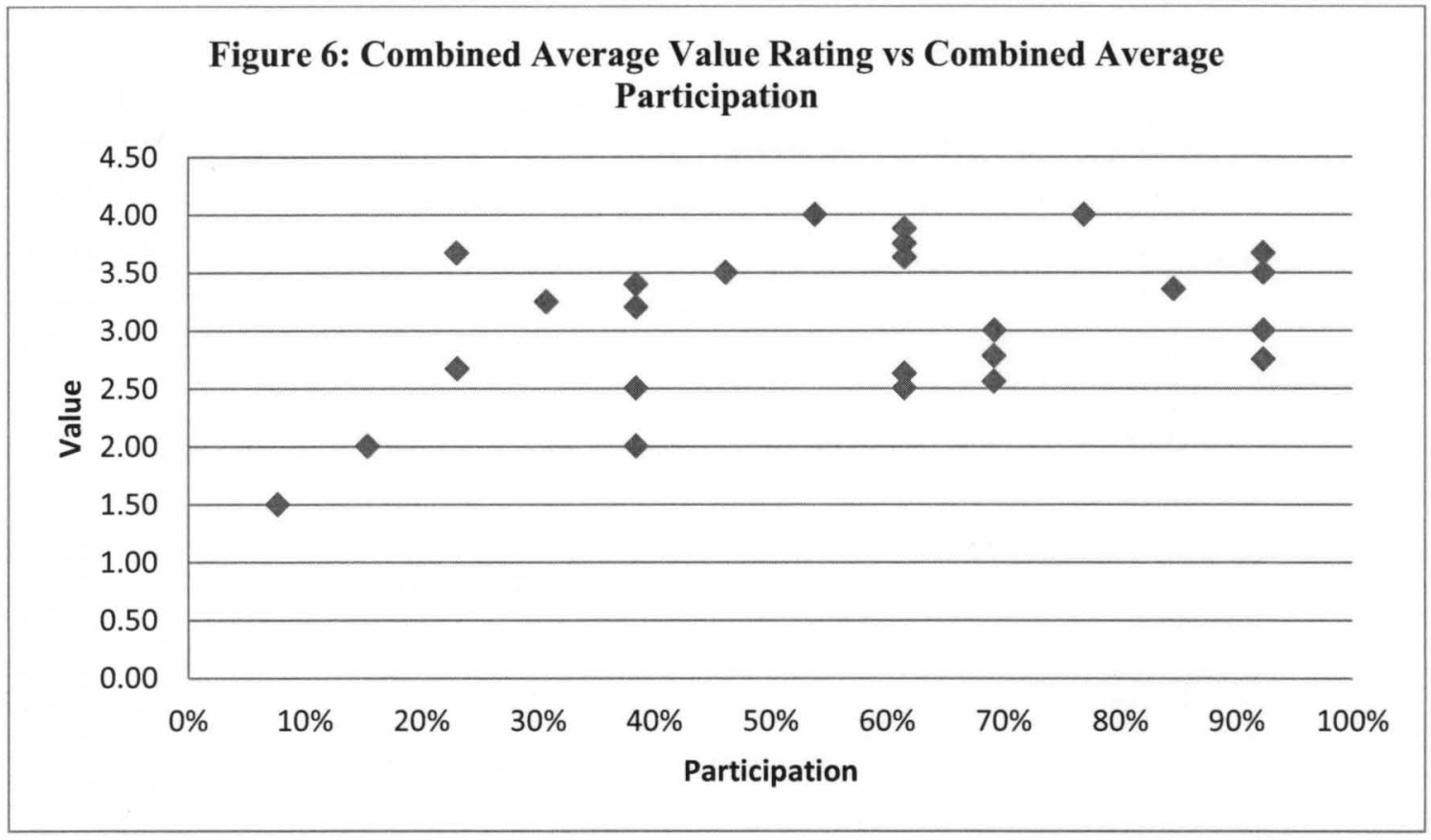

Table 5 provides school value data conducting multiple t-tests. Five activities were determined to show a significant difference the between middle school and high school value ratings with higher value ratings at the high school at the $\mathrm{p}<.05$ level. The five activities that include A1 parent orientation/introduction, A2 grade eight parent orientation/scheduling, A3 swap, A6 tour and A8 HS counselor meeting with grade eight students. Eleven of thirteen activity average value ratings are higher at the high than the average middle school. The three activities that resulted in the highest average value ratings at the middle school included A2 parent orientation/scheduling 3.25, A6 tour 3.45 and A11 3.50 team building session. Results indicated that the three highest school value scores at the high school were recorded for A1 parent orientation introduction $3.75, \mathrm{~A} 2$ parent orientation/scheduling 4.00 and A8 HS counselor meeting with grade eight students. Nine of twelve middle school activities were valued at a (3-4) or much value to very much value rating. Eleven of twelve activities at the high school were valued at a 
(3-4) indicating as a school, high school teachers valued the activities at a higher level over middle school teachers. Similarly, both schools demonstrated a high level of value for the articulation activities with only one activity, A3 below a two value as rated by the middle school.

Table 5

Teacher Value Data Providing Mean and Standard Deviation

\begin{tabular}{|c|c|c|c|c|c|}
\hline & \multicolumn{2}{|c|}{$\begin{array}{l}\text { Middle School } \\
\text { Responses }\end{array}$} & \multicolumn{2}{|c|}{$\begin{array}{c}\text { High School } \\
\text { Responses }\end{array}$} & \multirow[t]{2}{*}{$\mathbf{P}$} \\
\hline & MS-AVG & S.D. & HS-AVG & S.D. & \\
\hline A1 & 3.000 & 0.667 & $3.750 *$ & 0.433 & 0.020 \\
\hline A2 & 3.250 & 0.661 & $4.000 *$ & 0.000 & 0.020 \\
\hline A3 & 1.778 & 0.786 & $3.333^{*}$ & 0.745 & 0.000 \\
\hline A4 & 2.750 & 0.968 & 3.000 & 0.816 & 0.637 \\
\hline A5 & 3.000 & 1.155 & 3.250 & 0.829 & 0.703 \\
\hline A6 & 3.455 & 0.498 & $3.889 *$ & 0.314 & 0.038 \\
\hline A7 & 3.500 & 0.764 & 3.750 & 0.433 & 0.571 \\
\hline A8 & 3.333 & 0.471 & $4.000 *$ & 0.000 & 0.025 \\
\hline A9 & 2.778 & 1.133 & 3.000 & 1.651 & 0.109 \\
\hline A10 & 3.111 & 0.737 & 2.917 & 0.862 & 0.603 \\
\hline A11 & 3.500 & 0.500 & 3.111 & 0.737 & 0.247 \\
\hline A 12 & 2.000 & 0.000 & 3.500 & 0.500 & N.A.* \\
\hline A 13 & 3.000 & 0.707 & 3.571 & 0.495 & 0.112 \\
\hline
\end{tabular}

Note: Information in this table was measured on a 4 point scale. The level of significance is measured at $(\mathrm{p}<05)$. *The $\mathrm{n}$ was too few to compute a $\mathrm{P}$ value.

\section{Analysis of Written Open Response Comments}

A description of the open-response questions from the Freshman Transition

Teacher Survey, the articulation activity in which the question is connected and the organizing categories of this study is presented in Appendix I. Data from the Freshman Transition Survey and interview questions, along with thirteen articulation activities, 
allowed the researcher to further analyze the data according to the categories that aligned to the robust structure of this study.

Data collected from the fourteen open response questions provided information in more than one categorical area. Ten questions provided information on systemic processes, ten provided data on collaboration, four questions provided information on leadership/vision, and five questions provided data on the use of measures on student and organizational outcomes.

An analysis of open response data indicated that numerous systemic processes were in place as the GCTI team implemented the articulation activities. Teachers were aware of the many activities, when the activities took place, and who was involved.

Collaboration findings from open-response comments indicated middle school and high school teachers collaborated in various meetings to analyze student outcome and behavioral data. Data show teachers met on a regular basis within and between schools. Teachers discussed transition issues with various stakeholders that included teachers, parents, students, administrators and students.

Data gathered from the open-response items indicated principals and central office administrators created the vision and need for GCTI in the development of systemic processes and strong communication with all stakeholders on the vision and goals of the initiative. Teachers reported on surveys their participation and perceptions of the benefits of the various activities. Although teachers may not have liked some of the activities, they understood the benefit of the activities to students and elected to continue with the activities.

\section{Analysis of Results in the Four Categories}


The following section describes the results that support the four categories common to the conceptual framework. Results were collected from the open-response portion of the Freshman Transition Survey, the transition committee interview, teacher interview and archival documents.

Multiple sources of evidence were used to triangulate information to the four categories determined from the previous research that supported the conceptual framework of this study that included the following: 1) systemic process, 2)

collaboration, 3) leadership/vision and 4) the use of measures or data on student academic performance, student behavior and organizational outcomes.

\section{Category 1: Systemic Processes}

The initial analysis was intended to identify whether or not a structure existed in which the middle school faculty and high school faculty worked together to support a systemic process in the implementation of a set of structured articulation activities. Data were gathered from open-response comments from the Freshman Transition Survey, teacher and transition committee interviews, and archived document minutes. Data providing evidence of systemic processes will be presented in the following order; archival documents, transition committee interview data, teacher interview data and open response data. Survey and interview questions are not in numerical order but numbered according to the order of the question aligned to the survey or protocol.

\section{Archival document analysis providing evidence of systemic processes.}

Documents gathered in hard copy or electronically from school administrators at the middle school and high school included department/PLC meetings, progress meetings, vertical alignment meetings, tour organizational processes, teacher swap lesson plans, 
weekly Freshman Academy meetings, and weekly grade eight team meetings. These sets of documents provided evidence of a systemic process for organizing and conducting meetings and implementing the structured articulation activities during the implementation of GCTI.

One document, the district Status of School Report provided from district leadership contained the transition committee's list of selected structured articulation activities with timelines. The Status of School Report provided evidence that a consistent procedure or process for reporting information on attendance, grades and discipline was developed. Status of School Report documents were produced quarterly. Documents secured from both the middle and the high school included agendas and minutes from the following: department /PLC meetings, lesson plan template used in teacher swap, vertical alignment meeting agendas, progress meeting agendas and freshman academy and middle school team meeting documents. Meeting agendas revealed the topic of transition and the task of analyzing student transition data were regularly scheduled topics of discussion during the implementation of GCTI.

The Freshman Transition Student Form developed by the high school counselor created a systemic process for collecting information on extra-curricular participation documentation for freshman. Documents as noted in meeting agendas and minutes indicated both schools were provided student data on grades, behavior and attendance on a regular basis by school administrators and counselors. Some data were provided by the principal on articulation activities, middle school event participation, lesson plans for teacher swap, station rotation duties and schedules for the middle school tour of the high school, as noted in meeting minutes. 
An analysis of archival documents was conducted on meeting agendas and minutes prior to and during the implementation GCTI. Prior GCTI documents of agendas and minutes indicated meetings were less structured and more focused on topics that included trip planning, scheduling issues and teacher material needs. Department and team meetings indicated little focus on student academic performance and behavior with regard to transition data. No transition committee was in place. No systemic process of implementing articulation activities was in place. According to agenda documents, no middle school to high school transition data had been shared in these meetings nor was it a regular agenda topic of discussion. Prior to GCTI, none of the following meetings or activities were documented or in place; middle school and high school vertical alignment meetings, teacher swap, parent orientation meetings, progress meetings, Status of School Report, Summer Transition Program, high school teachers attending middle school events and transition committee meetings.

\section{Transition committee interview results regarding systemic processes.}

Transition committee interview results provided further evidence of committee members' knowledge of systemic processes used in the development of GCTI. Transition committee members' comments provided information on how GCTI came to fruition, how the committee was formed, how often the committee met, how the thirteen structured articulation activities were selected, who was involved in the selection of the structured articulation activities, how activities were monitored and if a systemic process was in place to disseminate information to other stakeholders on GCTI.

Question 1. Describe how this committee was formed?

This question provided information on the vision of GCTI and who was involved. 
$\mathrm{TCHA}^{2}$ : The high school administration first recognized the problem in our freshman failure rates and drop-out data. Our high school was viewed as a dropout factory. We discussed the issue with central office leadership and they developed the transition committee to address it that included middle and high school members and the district superintendent.

TCHC: The initiative came to being as a result of the collaborative efforts of the high school and central office administrators recognizing the fact that something had to be done to address the low high school freshman grades, attendance and drop-out data.

TCMA: I was invited to participate in the development of this initiative by the superintendent. We were made of aware our high student data and together we realized we had to do something to improve the data.

TCMC: I was invited also to participate in this initiative. We met in the central office with the other committee members in the summer of 2008 to begin discussing strategies to counter the data on failures, attendance and behavior with ninth graders.

TCMC: I am not sure if I was appointed to serve on this committee or by whom, but I certainly saw the need and was glad to be a part of this committee. We agreed upon the vision and what the literature told us and the committee began its work in developing this initiative.

${ }^{2} \mathrm{TCHA}=$ transition committee high school administrator, $\mathrm{TCHC}=$ transition committee high school counselor, TCMA = transition committee middle school administrator and TCMC $=$ transition committee middle school counselor. 
Superintendent: We needed to find an answer to the problem on freshman failure rates, high absenteeism and increased behavior incidences in grade nine. After a review of literature, we formed a committee from the central office involving MS and HS members and called it the transition committee.

Follow-up question: How often do you meet, were agendas kept and did you have a subcommittee structure in place?

This question provided information on a systemic process for regularly scheduling meetings, monitoring the structured articulation activities and data available in meetings and activities.

TCHA: We met following monthly principal meetings. No agendas were kept to my knowledge but the focus was on discussing the articulation activities we have in place and their progress and improved student data in the form of grades and failures.

TCHC: We met after the principal meetings. No agendas were shared.

TCMA: We met after principal meetings. I did not receive an agenda but we had a routine process of addressing the articulation activities by the timeline we had developed. Student data provided at these meetings included grades, failures, behavior and attendance data.

TCMC: We met after monthly principal meetings. That first year we had maybe two larger meetings during the year after school that included the teachers on that committee. Those teachers are no longer in the district this year. We did not have agendas but we regularly discussed the articulation activities and student academic performance data. 
Superintendent: It was difficult to get teachers on the committee out of buildings during the school day. We did have several big group meetings. Principals relayed what was shared in the principal meetings back to committee members who were not able to attend during the day. Meetings followed a general format of discussing the activities and student results on a regular basis.

Question 3. How did you determine the activities to be used in the initiative?

TCHA: The transition committee was provided some research on articulation activities and transitions from the superintendent. Collectively we discussed what the literature and came to a consensus on the ones selected.

TCHC: In determining what activities we wanted to do, we looked at all of the possibilities with regard to activities recognized in the research. We looked at the research on what others had done and came to an agreement on the thirteen that we decided to put in place.

TCMA: We made an attempt to choose activities that were in the five areas of research that was shared with us. Articles were available for us to read that someone had already done the work on. I assume central office provided these materials.

TCMC: We had lots of research to look at and discuss. I did not feel like it was pre-determined what activities we were going to implement. This decision was ours as a group to decide as a group, and I for one appreciated that.

TCMA: We were provided some literature on the topic of middle school to high school transitions. We added some and picked what we thought would work for us that was evident in the research. 
TCMC: We just sort of came to a consensus as to the activities we liked that we felt would benefit our students that seemed like a good fit and that were readily doable that were grounded in the research we were looking at.

Superintendent: I wanted it to be a committee decision and not a central office decision on what activities would be used. I felt I created the vision in sharing the research on articulation activities.

Follow-up question: Who was involved in activity selection and how did you arrive at the number and types of activities?

TCHA: There were originally nine on the committee, all of us and two teachers from each school. Central office did not replace these vacancies. We looked at the research and just sort of narrowed the focus to activities we wanted to do based on the research and what we liked.

TCHC: We were all involved in choosing the activities. We wanted more than five and at least one to two in each of the five areas.

TCMA: We as a committee made the decision. It did not go out to other people until we had decided what we were going to go with and we decided on these thirteen. We ended with several activities in each area of the research. Superintendent: I tried to engage the committee in full discussion, research and selection of the activities.

Question 4. Describe any process used to monitor the process and activities.

This question provided data on teacher understanding of a systemic process for monitoring the set of structured articulation activities. 
TCHA: We monitored progress in various school meetings, PLC's, vertical alignment meetings, team meetings and academy meetings. Each of us took several activities to be in charge of implementing by the pre-determined timelines. That person made the arrangements for organizing people and activities and sharing information with others.

TCMA: Data was collected and shared in most of the activities on student academic performance, behavior and attendance. Principals were the ones responsible for providing the data for these meetings. Some department meetings, PLC's and vertical alignment meetings provided data in the form of agendas and minutes.

TCMC: My principal and I gathered the data for meetings. We made a strong effort to get hard data in front of teachers. The data helped us monitor progress. Superintendent: It was expected that data would be provided at meetings. Analyses of agendas indicated that people were monitoring student progress and that transition was the topic focus of discussion in the meetings.

Transition Committee interview data indicated that collectively, committee members understood the process used to develop GCTI. Members indicated they understood the need for the schools to address the freshman transition data. Comments indicated members knew when the committee regularly met and how often they met. These results indicate a systemic process was in place. Transition committee interviews revealed a shared understanding among members on how the thirteen structured articulation activities were selected from the research provided to them. Committee 
members demonstrated a systemic process for school leaders to provide data in many regularly scheduled activities.

Interviews revealed committee members met monthly to discuss activity progress and student outcome data after principal meetings. The transition committee created an expectation of systems thinking between the middle school and high school in the implementation, monitoring and follow through of the activities.

Teacher interview results regarding systemic processes. Information collected from the teacher interview provided evidence of a systemic process in the implementation of the structured articulation activities. The eight teachers interviewed included four middle school and four high school teachers. Six questions were administered to the teachers with various follow-up questions. One teacher question provided evidence of a systemic process.

Question 5. Are you aware of student participation in extra-curricular activities? This question asked whether teachers were aware if the school had a systemic process in place to track student involvement in extra-curricular activities.

TH13: Our counselor created a Freshman Transition Form where individual students fill out information on themselves. This form included EXPLORE information, grades, attendance, and extra activities the student is involved in. TM1: That is pretty much the same process at the middle school. Coaches and sponsors turn in that data but no one has compiled it to my knowledge.

${ }^{3} \mathrm{TH}=$ teacher at the high school followed by the identifying teacher number. $\mathrm{TM}=$ teacher at the middle school and the identifying teacher number. 
TM4: We have talked about the importance of students being involved in and connected to something at school but we have not acted upon that in a systematic way at the middle school.

Teacher comments indicated a systemic process was in place for collecting information on student involvement in extra-curricular activities, more intentionally at the high school than the middle school, but little had been done with that information. Data were collected on extra-curricular participation at both schools but had not been compiled.

Open response comments providing evidence of systemic processes. The following questions where categorized under systemic processes as providing data that indicated systemic processes were in place in the implementation of GCTI. Survey openresponse comment results provided information on whether the activity was planned, if teachers were intentionally assigned duties during articulation activities and if a regular schedule for meetings existed.

Question 5. Did grade eight students take a tour of the high school? If so, when did this happen and what was your role in this activity?

Question five results show a systemic process was in place for implementing the middle school student tour of the high school. All twenty-seven teachers responded yes, indicating they participated in the activity and they knew this activity was intentionally scheduled in May.

M1: The tour activity is scheduled in advance to occur in May. I was assigned to supervise a group of students during the tour to keep them in good behavior and rotating through the various rotations planned for this activity. 
MT9: May. As a part of the tour, students were assigned to a station rotation at the high school where high school students informed middle school students of various high school activities, support systems and expectations.

HT26: It happened during the last week in May. I was assigned to a tour group to supervise.

Collectively these data indicated that teachers understood their roles and responsibilities for the tour to occur and the systemic structures needed to organize and implement this activity involving students and teachers at both schools.

Question 6. Does your school conduct counselor/parent meetings to discuss student transition to high school? If your school conducts these meetings, does it occur during the school year or during the summer?

Twenty-one of twenty seven teachers indicated they knew the counselor conducts these meetings. Some variance existed as to when these meetings took place.

MT1: During the school year.

MT10: One in spring.

HT15: During the year and one in summer.

HT17: During the school year and at orientation.

A majority of the teachers indicated they were aware of the structure and organization of this scheduled activity.

Question 7. Does the counselor at your school meet with eighth graders during the year to discuss transition to high school? (Yes or No) If the answer is yes, when during the year does this occur and what is discussed. 
Nineteen teachers (eight middle school teachers and eleven high school teachers) responded yes indicating they knew the counselor meets with students to discuss transition issues. Responses to when these meeting occurred varied.

MT2: March and at scheduling.

MT7: January and May.

HT18: Transition-spring.

HT27: During the year.

Most teachers indicated they were aware of these intentionally scheduled student meetings with the counselor and teachers indicated they were cognizant that the topic of discussion was to prepare students for the transition to the high school.

Question 8. Do any of the high school freshman staff (administrators, counselors, teachers) attend middle school eighth grade activities (ex. dances, field trips, graduation etc.) (Yes or no). If your answer is yes, what specific activities did you participate in?

Twenty-six of twenty seven teachers (eleven middle school teachers and fifteen high school teachers) responded yes indicating they knew high-school staff and administrators attended middle school events.

MT1: Dances and graduation. Attendance was required at these two events.

MT2: Dances, graduation and field trips.

HT15: Dances, grade eight graduation, awards night and grade eight trip.

HT20: We saw the need for teachers, administrators and counselors to attend dances, field trips and graduation to show support of our incoming students and build relationships in advance of them entering the high school. 
Teachers indicated an expectation of participation at middle school events and that this was a shared vision between schools. High school freshman teachers indicated attendance was mandatory at two events, the middle school graduation and dance. Question 10. How often do you participate in vertical alignment meetings with middle school and high school teachers to discuss curriculum, behavior and philosophical aspects to preparing students for transition?

Twenty two teachers stated that they participated in these meetings. How often these meetings occurred varied from once time a year to once a month. Results indicated a systemic process existed within the various content departments as to when each department met.

MT4: In math, 4 times.

MT8: One in my subject area.

HT 13: One time a month in my subject.

HT14: Two-three times a year in my department.

A system was in place for meeting in content area departments but varied among the departments on how many times they met a year. Meeting were determined and scheduled by the separate departments and on file in the principal's office.

Question 12. Does your school provide "at-risk" students meetings with identified teachers to build rapport and relationships for students transitioning to high school?

Question twelve inquired as to teacher knowledge of the systemic process for providing meetings on at-risk students. A total of nineteen teachers (seven middle school teachers and twelve high school teachers) indicated they were aware of these regularly scheduled meetings. 
MT9: Our counselor has started these.

HT15: Yes, counselors and special educators attend.

Most teachers at both schools indicated they had knowledge this activity was organized by the school counselors.

Question 13. How many activities are you aware of that your school is involved in that relate to students transitioning from eighth to ninth grade?

Responses from teachers ranged from 1-25 in the number of GCTI transition activities in which they were involved. Nine high school teachers responded with five or more. Six middle school teachers responded with five or more. Over half of the twenty seven teachers involved in the initiative were aware the initiative implemented more than five structured articulation activities. This data indicated that a systemic process for implementing a number of structured articulation activities was in place.

MT1: 5-6

MT6: 10

HT13: 5-6

HT15: 25

Ten open response questions provided evidence that a systemic process was in was in place in the implementation of GCTI. Comments indicated teachers were aware of the structure for participation in numerous activities between the middle school and high school.

Ten open response questions, four transition committee questions, one teacher interview question and numerous documents provided evidence of a systemic process (See Appendices F, G and H). 


\section{Category 2: Leadership/Vision}

There was a structure in which district and school leadership worked to create the vision for GCTI that included the selection, implementation, monitoring and follow through of the thirteen articulation activities. School and district leadership served as the guiding coalition that created the vision of GCTI that addressed transition issues for improving student outcomes in the areas of academic performance and student behavior. Results from open-response comments, transition committee interviews, teacher interviews and documents provided data to determine if GCTI created a shared vision of GCTI among and between schools. Data gathered indicated the extent to which teachers understood the reasons for implementing GCTI, if they understood the vision of the initiative and if it impacted their beliefs and practices. Teachers commented they believe this initiative was one of the best things they have done in years and they have never worked so in unison as a school and between schools.

Teacher interview and transition committee data indicated that steps likely to result in long term sustainability were beginning to occur as a result of GCTI. Teachers and committee members from both schools shared that teachers have elected to continue with all thirteen of the articulation activities into year three with some modifications. Data collected from teachers and transition committee members indicated that leadership had created a unified vision of the benefit and need to continue with the GCTI initiative. Interviews revealed teacher opinions were valued and suggestions for improvement were gathered from teachers to expand and improve the vision for GCTI. Archival documents, transition committee member comments, teacher comments and open response comments provided data that indicated the vision for GCTI had been created and shared. 


\section{Archival document analysis providing evidence of leadership/vision.}

Numerous documents that included the list of the structured articulation activities and agendas and minutes from faculty meetings, department/PLC meetings, progress meetings, vertical alignment meetings, organizational process information from the tour and swap, weekly Freshman Academy and grade eight team meetings and Status of School Report data provided evidence of a unified vision on the implementation of GCTI. A content analysis of the meeting agendas demonstrated minutes were focused on transition issues addressed in this initiative at both the middle school and high school. Documents were found in both schools from faculty meetings, academy and team meetings and department meetings that had transition as a topic of discussion. The lesson plan template used for the swap activity was used in each school. Agendas were on file for the tour, vertical alignment meetings, building level progress meetings, and district Status of Schools Reports. Agendas and minutes indicated an intentional focus on transition and analyzing student outcome data in these meetings. High school academy and department meetings were more data driven than the middle school meetings. It was the expectation of district and school leadership that agendas include the intentional scheduling of transitions as a topic of discussion and that student measures on academic performance, attendance and behavior data be provided, discussed and analyzed in these meetings on a regular basis.

\section{Transition committee interview results providing evidence of leadership/}

vision. Two transition committee interview questions provided data to support the category of leadership/vision and on how the vision of GCTI was shared with others beyond the few that served that served on the guiding coalition. 
Question 2. How was this initiative shared with the middle school and high school? TCHA: The Freshman Academy principal and counselor who served on the transition committee shared the GCTI initiative information with the faculty during faculty meetings with follow-up discussion in various school meetings at the high school.

TCHC: We discussed the transition program in faculty meetings. We made GCTI a focal point of our discussion in all of our meetings. The academy principal informed us of the strategies and activities being implemented during meetings.

TCHA: I had the luxury of being able to meet with transition committee members who were teachers during their planning periods to update them on the transition initiative. Information with others was usually shared via faculty meetings. TCMA: We shared information on the middle school and high school initiative during faculty meetings.

TCMC: Mostly during faculty meetings is where the initiative was shared. Follow-up discussion took place in all other meetings similar to how the high school did it.

Question 6. If you could change anything about the activities and the process used in delivering the activities, what would you suggest?

This question provided information on adjustments teachers envisioned for future improvements and refinement of GCTI.

TCHA: I would have perhaps tried to get feedback from the faculty on the activities to be selected instead of telling them what we are going to do. 
TCHC: Build capacity within the schools in the follow-through and follow-up of the activities. Need to provide the committees with more success data to share with schools and celebrating on the improved data more intentionally.

TCMC: I would suggest we involve more stakeholders. Also, when committee members leave for whatever reason, they should be replaced. Not replacing them added to other committee members' already full plates.

Superintendent: I agree that district leadership needs to be more diligent in replacing transition committee members. We were remiss in not replacing these people.

Results indicate transition committee members provided the leadership and structure for teachers to work together as they worked collaboratively to create the vision for GCTI. Members who served as the guiding coalition worked in partnership to design the initiative and create the vision of GCTI in the selection, implementation and monitoring of the chosen structured articulation activities. Committee members created a similar process for both schools to follow in disseminating information from the committee to the teachers in faculty meetings that would inform all stakeholders of the initiative. Evidence indicated committee members look to the future in adding more activities, indicating leadership had created a vision for the need for this transition initiative to be continued and improved upon.

Teacher interview results providing evidence of leadership/vision. One teacher interview question aligned to the category of leadership/vision.

Question 7. If there was anything you could change to manage these student issues, what would you recommend? 
This question inquired as to the vision teachers had for GCTI.

TH1: I am glad we are continuing with all of these activities that we have implemented over the past two years. I have never felt more unified as a district as I do now. This has been the best couple of years I have experienced in all of my years in the district.

TM2: I would like to see us focus more of our activities on students who are performing well academically, that come to school, that behave. We can always improve there and many times we do not intentionally do anything to address their needs.

Data gathered from teacher interviews indicated teachers have an understanding of the vision for GCTI created by school leadership. Teacher interviews revealed teachers believed they are in a better place as an organization than they were prior to GCTI. This indicated a shift in attitudes and beliefs of teachers in support of the activities since administering of the Freshman Transition Teacher Survey. Data gathered from interviews provided evidence that teachers have a better vision for what the organization is and what the organization can do to continue to improve.

\section{Open response comments providing evidence of leadership/vision.}

Question 2. A follow-up question to question number two inquired if the swap activity was of value and should it be continued.

If teachers see the value in an activity, they share in the vision and need for an articulation activity to be continued. One middle school teacher and eleven high school teachers responded yes to continue the swap activity. 
Question 4. Question four inquired if teachers shared the vision and the importance of high school teachers attending middle school special education grade eight meetings.

Eleven middle school and thirteen high school teacher responded yes to the importance of these meetings.

Question 10. Question ten inquired about vertical alignment meetings, what was most useful and what could be done to improve them.

Ten middle school teachers and twelve high school teachers responded that they participated in these meetings.

MT1: These meetings get everyone on the same page to create a common goal.

HT19: We started doing these vertical alignment meetings this year. These were the most beneficial thing I have done since I have been teaching.

Question 14. This question inquired if teachers believed the school did an efficient job at transitioning students to the high school.

All twenty seven teachers responded that they believe their school does a good job transitioning students.

MT11: Much better than in the past.

HT25: I intend to use many of these ideas when I become a principal.

Teacher comments indicated leadership created a vision for GCTI. Teachers were aware of the numerous structured articulation activities being offered and both school faculties felt the school individually and collectively were doing a good job preparing students for the transition. Teachers leaders have chosen to continue with and add to the activities as both schools see the growth in student outcomes and organization improvements. Teachers stated the school now functions better as an organization that 
before the initiative. Four open response questions, two transition committee interview questions and two interview questions provided evidence of leadership/vision within the organization and transition program.

\section{Category 3: Collaboration}

Previous research indicated that change is more likely if there is a collaborative culture in which people from the middle school and high school work together. In this section I present triangulation of evidence established by comparing results from these three sources: documents, transition committee interviews, teacher interviews and open response comments that support the category of collaboration.

Results indicated that collaboration among teachers and committee members occurred regularly and often. Data gathered provided evidence of whether teachers and committee members worked together or in isolation to solve problems and whether they collaborated in the selection, implementation and monitoring of the structured articulation activities as supported by documents.

Archival document analysis providing evidence of collaboration. Numerous documents were available that provided information that collaboration occurred within and among teachers at Grant County High School and Grant County Middle. Documents that provided evidence of collaboration included agendas and minutes from faculty meetings, freshman academy and team meetings, PLC meetings, student progress meetings, vertical alignment meeting and Status of School Reports. Agendas indicated student academic progress, attendance and behavior were regularly discussed among teachers and between schools. Teachers and transition committee interviews revealed teachers came together on a systematic basis to analyze student data in regularly 
scheduled vertical alignment meetings, PLC meetings and academy and team meetings. Documents revealed meetings were not called on an as needed basis, but that they were intentionally and regularly planned scheduled meetings with focused agendas at both schools.

Information gathered at both the middle school and high school demonstrated that a collaborative culture exists in the Grant County learning organization. Results indicated middle school and high school teachers try to solve issues on their own first, but do turn to colleagues, parents, counselors and attendance clerks for support and ideas. Results indicated teachers now take more initiative to communicate and collaborate with others in addition to the regularly scheduled collaborative meetings.

Many articulation activities were purposely chosen to promote collaboration and teacher comments indicated these collaborative meetings have forged relationships within and between schools. Inclusion has become the norm for working together as meetings include parents, attendance clerks, teachers, administrators and students in the collaborative process.

Transition committee interview providing evidence of collaboration. Under the category of collaboration, one transition committee interview question provided evidence of collaboration. Evidence provided included how teachers worked together. Question 7. Does the counselor at your school meet with eighth graders during the school year to discuss transition to high school? (Yes or no)? If your answer is yes, when during the year does this occur and what is discussed?

TCHA: We developed a structure for meeting on a regularly basis by departments in after school vertical alignment meetings by content areas. Teacher 
attendance in these vertical alignment meetings was required for middle school and high school teachers.

TCHC: Some of the activities we selected were purposefully chosen to encourage and promote collaboration among both schools like attending middle school events, teachers collaborating with middle school teachers, counselor meeting with students, swap, vertical alignment meetings, the tour and rotation schedule for students during the tour.

TCMA: I heard many teachers comment that the vertical alignment meetings built relationships among teachers in both schools. Various other activities brought teachers together that would have never occurred without the implementation of these activities and did not occur prior to this initiative. TCMC: The fact that we had to work together to get these activities off the ground is a success story in and of itself. Most of the activities required some form of collaboration between both schools that has allowed us to engage in richer dialogue.

Superintendent: It was discussed in the development of GCTI that we wanted to intentionally select activities that would bridge the communication gap between the middle school and high school to improve student outcomes and curricular issues. We chose activities to encourage collaboration on a regular basis.

The transition committee purposefully and collaboratively selected structured articulation activities that would promote collaboration among and between schools. Results indicate the structured articulation activities brought various groups together including content teachers, parents and counselors, counselors and students and middle school and high 
school faculty, to work together to address student transition issues. The guiding coalition of transition committee members worked collaboratively to involve stakeholders from both schools. Teachers within the schools collaborated often through the various inter and intra school level building meetings.

Teacher interview providing evidence of collaboration. Under the category of collaboration, four of six interview questions provided evidence of collaboration.

Question 1. What does your school do to help students in the transition from grade eight to grade nine?

The swap activity included the collaborative efforts of faculty at the middle school and high school trading places for a day. Vertical alignment meetings brought teachers from both schools together to discuss student academic and behavioral progress as well as curriculum alignment and transition issues. High school teachers attending middle school events provided evidence of a middle school and high school collaborative partnership.

TH1: We do a one day swap activity with the middle school teachers. This gives students a reasonable view of what to expect from their classes when they arrive at the high school.

TH2: We have meetings with the middle school teachers in our content areas that produce insights to the needs of the students on a regular basis. These are enjoyable meetings. It is nice to hear other teachers and their struggles and successes.

TH3: The Freshman Academy works very hard at transitional activities. My experiences with these activities have been very rewarding for me. I have been 
involved in the teacher swap that I found to be beneficial. This helps me start evaluating students before they come to the high school and helps me with my planning.

TH4: One activity that I think helps kids in the transition is attending their events. I found it rewarding to attend the middle school events. You see the kids in a different perspective and they get to know you and know you care before they get to the high school.

TM1: At the middle school our department meetings are more focused on identifying students as they begin to have poor performance in the areas of identified by GCTI; grades, behavior and attendance. We really make an effort to connect the kids to interventions.

TM2: Many MS teachers voiced that they saw no benefit to them in the teacher swap activity. They felt like they were babysitting. But, when it came time to discuss if we needed to lop that activity off, they thought the activity should continue because it was of benefit to the students.

TM3: We have provided lots of activities for kids to become familiar with our high school before they arrive there. They have toured the building, met the counselor, sat in high school teacher's classrooms for a day. The station rotation activity allowed our eighth graders to interact with high school kids who led the sessions.

TM4: We have really made the effort to look at student data and kids headed in the wrong direction with poor grades. We have provided interventions working closely with the high school in our alignment meetings. 
Teacher interview comments provided evidence that teachers at both the middle school and high and collaborate regularly with teachers within their building as well as among the middle school and high school teacher as a result of the GCTI. Collaboration is more intentionally planned by the design of the articulation activities.

Follow-up question: With what schools (and individuals) have you collaborated with on this process:

TH1: We collaborate with MS/HS teachers in the vertical alignment meetings each month.

TH2: We collaborate with MS teachers in the alignment meetings and in our Freshman Academy meetings and PLC meetings.

TH3: We meet with MS content area people in the monthly vertical alignment meetings. I myself have made an effort to meet with individuals at the middle school concerning our math program. We are implementing an advanced math program at the high school and we really need to make sure the students coming from the MS are getting what they need in math.

TH4: We had to collaborate on lots of things as a result of the GCTI program. We have had to coordinate activities and work together on the implementation of the activities. I think these activities have opened up the lines of communication between our schools.

TM1: We work together in alignment meetings, PLC's, department meeting and team meetings.

TM2: We collaborate in vertical alignment meetings with HS faculty and in team meetings and various other meetings at the middle school. Our math department 
communicates a little more than others because of some advance classes they are offering at the high school.

TM3: There is far more collaboration going on with the middle school and the high school in the past two years than what was done prior.

TM4: All of our meetings seem to be focused on transitions. This unified topic of focus helps us in our collaborative vertical alignment meetings and other meetings because we are focused on the same goal.

Question 2. What do you do if you have a student in your class/school who is acting out? These data were gathered to determine the extent to which teachers work in isolation or collaboratively to solve problems.

TH4: I try to handle the problem on my own but I also try to find out if others are having the same problem before I go to the office with it.

TH1: At the high school we have a process teachers should follow; try to address the issue with various classroom management techniques, confer with other team members, involve the school counselor, contact the parent and then as a last resort, involve administration.

TM3: We have a plan we follow. Handle it, turn to my grade level team for assistance, involve the parents in a conference and if all else fails, pull administrators in.

TM4: I try to handle it on my own. I follow-up with parents, if no progress, I turn it over to the assistant principal. Our school counselor is extremely helpful when I have a student issue. 
Teachers at both schools collectively handle student academic, behavior and attendance issues within their classroom first and then turn to their colleagues and school leaders for solutions to their problems. Parents were considered partners in solving issues at both schools.

Question 3. What do you do when you have a student who is absent numerous times from you class/school?

Data gathered provided information in whether teachers handled student attendance issues on their own or with the help of others.

TH1: I spend a great deal of time communicating with students and parents on the phone or computer. After three days of absence, I am right on the phone or computer until the problem is solved.

TH3: I make calls home to the parents. I discuss the absence issue with our attendance clerk. She is very helpful here and stays on this issue until she gets to the bottom of the reason why the student is missing.

TH4: I check with the counselor or office to see if they know what the issue might be with this student. I make calls home. I check to see if they are absent or just skipping my class.

TM1: At the middle school, our administration makes home visits to get to the bottom of students missing lots of school.

TM2: We meet regularly as a team to discuss student absenteeism. Our attendance clerk at the MS is included in our meetings when asked to attend to address an attendance issue. 
TM3: We follow the same thing we do with behavior issues. We try to address the absences on our own, we see if other team members are having the same issues, we make calls home and then involve the principal.

TM4: We are unified on the way we handle our problems.

Question 4. What do you do when a student is failing in your class?

Information gathered provided information on how teachers address student failures and whether they handled them on their own or conferred with others to address the problem.

TH4: Our administrators started a program last year they call the Fifteen Day Plan. Every fifteen days teachers meet with PLC groups to discuss the names of students who are failing to connect them to interventions we have in place before, during or after school.

TM2: Again, we tend to address the problem as a team and make sure we understand what the student is not mastering and connect them to the available resources.

TM3: I like to look at cumulative folder information and prior test results. I try and see if it as a patterned problem for this student. Our counselor is good at letting us have access to that information.

Four teacher interview questions provided evidence that the district initiative created opportunities for collaboration to occur within and between schools and parents. All eight responding teachers indicated the middle school and high school followed similar processes in handling student attendance issues. Both schools made parent phone calls for follow-up. The high school teachers turned to academy colleagues and middle 
school teachers turn to their teams to collaborate and solve the problems. Both schools utilized the knowledge of their attendance clerks in meetings. Teacher interviews indicated teachers do not work in isolation but regularly collaborate to analyze student data and curricular information. Teacher interviews revealed parents and school administrators are considered a part of the team and academy and included in meetings. Faculty from both schools indicated there is deliberate effort to improve and encourage collaboration among teachers with and between schools.

\section{Open response comments from the freshman transition survey providing}

evidence of collaboration. Multiple open response questions provided data on how this transition initiative encouraged collaboration within the organization among teachers, administrators and parents at the middle school and high school. The question numbers are not in numerical order but aligned with the number of the question from the protocol that provide evidence of collaboration. Examples follow:

Question 1. If you participated in an orientation meeting with grade eight parents during the school year to discuss transition to high school, please share what particular components were most helpful (and why) and which components were not so helpful (and what could be done to change them).

Seven middle school teachers and five high school teachers responded to participating in this structured articulation activity. This activity promoted collaboration among parents.

MT2: This meeting was helpful in explaining the high school schedule and expectations to parents.

MT4: I liked these meetings because you meet parents in an unbiased meeting. 
Question 2. If you participated in a teacher-swap between eighth and ninth grade teachers, trading places for the day, what was your role? If you participated in the teacher-swap, was this activity valuable to you? Should it be continued? If you did not participate in the teacher swap, would you be willing to participate in this type of activity and what would you gain from it?

This activity required the coordinated efforts of middle school and high school teachers sharing lesson plans in order to trade places for a day. Eight middle school teachers responded to participating in this activity to twelve high school teachers. Middle school and high school teachers coordinated efforts in trading places for the day that included a tour and a station rotation.

MT1: I went to the HS. It was not beneficial to me but was good for students.

MT10: I taught science at the HS.

HT14: I swapped with a social studies teacher.

HT23: I switched with and eight grade teacher.

Question 3. If you participated in an eighth and ninth grade teacher meeting after each grading period to discuss student progress, share what particular components were most useful (and why) and which components were not so helpful (and what could be done to change them).

These meetings were intentionally scheduled following the end of each nine week grading period. Five high school teachers and no middle school teachers responded to participating in these meetings.

H15: Progress meetings helped improve collaboration among teachers identifying strengths and weaknesses of students. 
HT26: I met with my academy members to discuss grades end of grading period grades. It was very helpful and will be even more so with common planning. Question 4. Do you think it is beneficial for high school special education teachers to attend eighth grade transition meetings for students with special needs? (Yes or no and why?)

This activity included the collaboration of HS special education teachers and middle school grade eight teachers. Eleven middle school teachers and thirteen high school teachers responded positively to the benefit of this activity. These results indicate this activity promoted communication and collaboration among and between teachers.

MT1: This activity allows students and teachers to meet and prepare for future plans for kids with special needs.

HT13: These allow problems and solutions to be communicated without starting over in looking at the IEP together.

Question 6. Does your school conduct counselor/parent meetings to discuss student transition to high school? (Yes or no). If your school conducts these meetings, does it occur during the school year or during the summer?

This activity provided the opportunity for the counselor and parents to discuss the process of transition to high school. Eleven middle school teachers and nine high school teachers responded that these collaborative meetings that included the counselor and parents occurred.

MT1: Limited

MT8: Several times a year. Parents expressed they liked these meetings. 
The variance in teacher responses to this question is attributed to the fact that teachers were better informed on activities that involved them. Counselor/parent meetings by design limited teacher participation and knowledge of meeting time of the activity. Question 7. Does the counselor at your school meet with eighth graders during the school year to discuss transition to high school? (Yes or no). If your answer is yes, when during the year does this occur and what was discussed?

Eight middle school teachers and eleven high school teachers responded these collaborative meetings between the counselor and parent took place. Sample answers follow:

MT10: March

HT15: Once in spring

Question 8. Does any of the high school freshman staff (administrators, counselor, teachers) attend middle schools eighth grade activities (ex. Dances, field trips, graduation, etc.)? (Yes or no). If your answer is yes, what specific activities did you participate in?

This activity provided the opportunity for HS teachers to interact with grade eight students by attending MS events to build teacher/student relationships. Twenty six of twenty seven faculty who responded to the survey noted they participated in these activities.

MT6: Dances and graduation.

HT18: Attendance at grade eight dance and graduation is required. 
Question 9. To what degree do teachers communicate with teachers at the other school (middle or high school) pertaining to eighth grade students and their transition to high school?

Twelve middle school and twelve high school teachers responded these meetings take place.

MT4: I talk to team members mostly.

HT20: In vertical alignment meetings and at risk meetings.

Question 10. How often do you participate in vertical alignment meetings with middle and high school teachers to discuss curriculum, behavior and philosophical aspects to preparing students for transition? Share what particular outcomes of this activity were most useful (and why) and which outcomes were not so helpful (and what could be done to improve this process)? Eleven of twelve middle school teachers participated in this activity to eleven of fifteen high school teachers.

MT5: We meet monthly with the HS in alignment meetings.

HT21: These are one of the best things we have ever done. Keep these.

Question 12. Does your school provide at-risk students a meeting with identified teachers to build rapport and relationships with students for students transitioning to the high school?

Eight middle school teachers and nine high school teachers responded that these meeting took place to.

MT1: Our counselor organizes these.

H13: These meetings help us determine student strengths and weaknesses. 
Survey data indicated teachers worked collaboratively in various department, team/academy and combined school meetings. Data indicated meetings were focused on improving student outcomes. Parents were involved in the structured articulation activities. Collaboration included between schools, within schools, with parents, counselors and students. District school leaders collaborated with building level principals. The transition initiative, by design created intentional opportunities to increase collaboration. Teacher interviews revealed that because of the increased collaboration in activities that brought the middle school and high school together, more teachers were self-initiated to collaborate with teachers in the other schools in addition to the planned collaborative meetings. Eleven open response questions, one transition committee question, four teacher interview questions and nine documents noting collaboratively held meetings gathered data that provided evidence that GCTI helped provide opportunities for collaboration within and between schools.

\section{Category 4: Use of Measures}

There is a systemic structure in which the middle and high school demonstrated the use of measures in the form of student outcome and organizational data in various transition activities and transition meetings. Archival documents, transition committee member and teacher interview comments provided support to the use of measures.

\section{Archival document analysis providing evidence of use of measures.}

Documents were provided that revealed information on the use of measures in articulation activities and in meetings. Data were provided at meetings from school administrators and counselors that included student outcome data on academic performance, attendance, behavior, EXPLORE data, special education and at-risk data 
and student participation in extra-curricular activities. These documents included the transition committee's list of a set of structured articulation activities, department meeting agendas, Freshman Academy and middle school team meeting agendas, student progress meeting (PLC) agendas, vertical alignment meeting agendas and Status of School Reports. Faculty and department meetings at both schools demonstrated transition was an intentional focus of discussion. Vertical alignment meetings minutes demonstrated student and curricular data was analyzed. Progress meetings and Status of Schools Reports provided student improvement results on a regular basis. All meeting documents collected evidence that demonstrated the use of measures on academic performance student behaviors and organizational evidence on curriculum alignment data gathered.

Transition committee interview results providing evidence of use measures. Transition Committee interview results provided data that supported the use of measures. One question provided evidence of use of measures.

Question 4. Describe the processes used to monitor the process and activities. Follow-up questions asked committee members to describe any information collected on these activities.

TCHA: The person on the transition committee was in charge of disseminating, monitoring, planning and collecting information on a particular activity. That person organized the activity, the schedules and the people. As the freshman academy principal, I provided student data to the department chairs or committee chairs to be shared in the various meetings on performance, behavior and attendance. 
TCHC: I provided identified student data on kids falling through the cracks. I also provided student behavior information and strategies to help teachers help these students. I collected data on each student on a form I created called the Freshman Transition Form.

TCMA: Usually, as the principal, I provided student data at most meetings. The superintendent met every four and a half weeks with us to address mid-term student transition data to inquire what we were doing to address the data.

TCMC: At the middle school we let the data guide our decisions to help us connect kids to response to intervention plans we have in place. We have minutes and agendas on most meetings.

Superintendent: Principals knew that data was to be provided, analyzed and addressed in meetings with a focus on transition data. I developed mid-nine week grade period meeting with principals to have them share that data with me and their corrective strategies to address the data.

Results indicate the expectation that meetings were data driven and that school administrators in both the middle school and high school provide the needed data for meetings. Monitoring student failure, behavior and attendance data was a topic of focus during all meetings. School principals and the counselor provided teachers with data that included academic performance and behavior data. Measures were monitored at the school level in various departments, academy/team meetings, and vertical alignment meetings and district level principal and superintendent meetings.

Teacher interview results providing evidence of use of measures. Four teacher interview questions indicated use of measures. Teacher interview question numbers 2,3 , 
4 and 5 inquired about teacher use of data when looking for patterns of failing, behavior, attendance and involvement in extra-curricular activities. Questions are not in numerical order but aligned to the question number on the interview protocol.

Question 2. What do you do if you have a student in your class/school who is activing out?

TH3: I do not send a student to the office unless it is a level four offense (drugs, weapons etc.). I work on a progressive discipline data chart.

TH3: I discuss student absence data with our attendance clerk.

TH1: Our counselor created a Freshman Transition Form where individual students fill out information on themselves. The form includes student on EXPLORE information, grades, attendance and extra-curricular activity information student were involved in at the high school.

Teacher data indicated that meetings were data driven discussing student failures, attendance, behavior and participation in extra-curricular activities.

\section{Open response comments providing evidence of use of measures.}

Question 3. This activity inquired about progress meetings that were specifically designed to discuss student academic and behavior progress.

Three teachers provided comments to this question in support of use of measures. The question numbers are not in numerical order but aligned with the number of the question from the protocol that provide evidence of use of measures.

MT1: We share grade and behavior information on kids and problems.

HT21: We are constantly evaluating and analyzing information to improve student learning. 
HT26: I met with my team to discuss grades. It was very helpful and will be even more so with common planning.

Question 4. The activity associated with question four inquired about the importance of high school special education teachers attending grade eight meetings.

These meetings were designed to look at identified student data.

MT2: These meeting help us with goal setting for students.

HT13: These meetings allow us to analyze student grade and behavior information to look for solutions without starting over.

Question 10. The activity associated with this question was middle school and high school vertical alignment meetings.

These meetings were designed to discuss curricular issues and student outcome data.

MT4: These meetings helped us look at curricular gaps and overlaps and connecting students to response to intervention strategies. Very helpful.

MT7: Math alignment was geared toward algebra competency.

HT15: Vertical alignment meetings were conducted for math, science and English.

HT23: These meetings were one of the best things we have ever done. These meetings helped us focus on student failure data in a timelier manner.

Open response comments provided data that indicated data measures in the form on student grades and behavior data were analyzed regularly during articulation activities that included all students and identified populations. 
Question 12. This activity was associated with discussing at-risk students. Data were used to identify these at-risk students.

MT10: Our counselor started these this year and brought student information on these identified kids, strengths and weaknesses.

From the open response question comments, data indicated teachers were focused during meetings on analyzing student data that included failures, behavior and attendance. Meetings focused on discussion of student outcomes and connecting students to intervention strategies. Content area meetings were focused on content data with the goal of minimizing gaps and overlaps, especially in math. The expectation from school and district leadership was that meetings were to be data driven. Five open response questions, one transition committee interview question and four teacher interview questions and numerous documents provided information that indicated the use of measures in various meetings and articulation activities where transition information was discussed and shared.

\section{Summary}

A great deal of triangulating evidence was produced in surveys, interviews and documents. These data provided support for the four content categories of systemic process, leadership/vision, collaboration and use of measures that align with the characteristics common to OL, HRO and ES.

Surveys, interviews and document information demonstrated that a systemic process was in place for developing, implementing and monitoring the articulation activities during the GCTI. Structures were in place that included the types of activities and the timelines for implementation. A systemic process was used in the organization of 
activities and in disseminating activity information to teachers. Systemic processes were evident in the content analysis of documents indicating transition information was regularly analyzed and a focus of discussion in meetings at both schools.

Results from survey comments, interviews and documents revealed that district and school leaders created the vision for GCTI that involved a guiding coalition of leaders that developed the initiative and shared the vision with teachers.

Data revealed that an intentional effort was made to select activities that would improve collaboration among and between schools. Middle School and high school data revealed that both schools worked collaboratively to address student academic performance and behavior issues. Results indicated both schools collaborated to analyze student academic performance and behavioral data and school data such as curriculum data. Results indicated collaborative efforts included parents, counselors, students, administrators and district central office members during the transition initiative at both the middle school and high school.

Results from interviews and surveys indicated teachers used data regularly in meetings to guide discussions and decisions. Individual student and curricular data helped teachers connect students to response to intervention strategies and helped the organization in alignment of the curriculum. Meeting documents provided from both schools indicated student progress was monitored regularly at the building level, between buildings and with the district superintendent.

Information gathered from surveys, interviews and documents helped provide evidence as to the impact GCTI had on the two schools' ability to operate as a learning organization. Data analyses presented in Chapter Four indicated teachers participated- 
to varying degrees-in all of the articulation activities at both schools. Value results by school indicated some relationship exists between an increase in participation with an increase in value. Results revealed greater participation occurred at the middle school but high school value data and high school teacher interview comments revealed high school teachers valued the activities more than the middle school. High school results show eleven of thirteen articulation activities had higher school value means. Interviews and documents indicated the organization developed a shared vision and an intentional focus on addressing transition issues in their systemic processes, in their collaboration with each other and in the use of measures of student and organizational outcome data.

Some variance existed among teachers, within and between schools on participation and value. Since many activities were hosted at the middle school (parent orientation meetings, counselor meeting with grade eight students, counselor meeting with grade eight parents, team building session, grade eight progress meetings, special education teachers attending grade eight meetings and grade eight at-risk meetings), middle school teachers were more aware of and involved in these transition activities. Job specific activities such as the counselor meeting with grade eight parents and students and special education teacher involvement determined some of the variance in responses among high school teachers in participation and value.

The findings from this study will be further discussed in Chapter 5 . 


\section{CHAPTER FIVE}

\section{CONCLUSIONS, IMPLICATIONS AND RECOMMENDATIONS}

This dissertation has provided data on key aspects of a multi-year effort to improve students' transitions from middle school to high school. Prior research indicated that many students find the transition difficult, and that students who do not begin $9^{\text {th }}$ grade successfully are at risk of failing $9^{\text {th- }}$ grade and dropping out of school. Research revealed steps schools could take to facilitate successful student transitions (Hertzog \& Morgan 1999; Mizelle \& Irvin, 2000).

Research from the fields of Effective Schools (Teddlie \& Reynolds, 2000; Lezotte, 2007), High Reliability Organizations (Stringfield, Reynolds \& Schaffer, 2008), and Organizational Learning (Murphy, 1992) indicate there are strategies schools and school districts can take to make school reforms more likely to succeed. However, no prior studies grounding an intervention in the literature of ES, HRO, and OL with research on transitions had been conducted that that asked whether articulation activities used in a combination of interventions could positively impact key outcomes. In this study, I examined the desired outcome of increased organizational learning.

Beginning in 2008-2009, the Grant County Public schools undertook a middle-tohigh-school transition program with the goal of increasing students' $9^{\text {th }}$ grade success. The initiative was investigated by a three-person research team. Data on student achievement and student behavior effects were reported by Denise Allen (2011), and data on student attitude effects are being analyzed by Michael Hibbett (in process). This 
dissertation focused on the impact of the Grant County Transition Initiative (GCTI) that included articulation activities on Grant County Schools' ability to operate as a learning organization during a middle school to high school transition initiative.

Surveys, transition committee interview comments and teacher interview comments from twenty-seven participants, along with available archival documents provided data as to whether the Grant County Transition Initiative had a positive impact on the middle school and high school in the schools' ability to function as a learning organization.

\section{Findings and Conclusions}

\section{Research Question}

The research question guiding this study was: Has the creation and work of the Grant County Transition Initiative and subsequent implementation of articulation activities enabled the middle-high school system to function as a more productive learning organization?

Findings are summarized below under four headings: systemic processes; leadership/vision; collaboration; and the use of measures. These findings will be followed by a summary statement addressing the research question and implications for practice and for research.

\section{Learning Organization Category 1: Systemic Processes}

Multi-method and multi-source findings indicated that the articulation activities were systematically selected, developed and implemented by the guiding coalition of leaders that represented of both schools. School and district leadership created systemic processes for implementing articulation activities and meetings as revealed by interview 
comments and documents. Comments from transition committee members and teachers revealed that activities were organized, scheduled and implemented in a purposeful manner as documented through various school meetings that included timelines, agendas and minutes.

School leaders had a systemic process in place for disseminating data at various PLC/department, faculty, academy/team and combined school vertical alignment meetings. Teacher interview comments revealed that teachers worked collaboratively within these systemic processes during freshman academy and grade eight team meetings when analyzing student outcome data, connecting students to interventions and discussing student failures, behaviors and attendance. Findings from transition committee interview comments demonstrated systemic processes were developed for implementing and organizing the structured articulation activities, PLC meetings, vertical alignment meetings and department meetings. Teachers could name most of the activities, what time of the year they occurred and their role in these activities.

Interviews indicated meetings were scheduled on a regular basis with the expectation of addressing student transition data, transition activities data and organizational data. Teacher interviews revealed that as a result of GCTI, they better understand the systemic processes or protocols for working on the work. Meetings, as a result of GCTI were more intentionally developed and focused with a shared vision of improving transition data, student outcomes and the organization. Teachers interviews demonstrated that as a result of the systemic processes developed in the implementation of GCTI the middle school and high school have learned how to work more deliberately, collaboratively and effectively as an organization as they focused on transition issues 
together. Teacher interviews revealed that the district had never before been more unified nor had they worked together toward a common goal with the middle school.

Transition committee and teacher interview findings revealed that systemic growth occurred in the learning organization and that systemic processes are now in place as a result of GCTI, but were not as prevalent prior to the implementation of GCTI. These findings indicated changes occurred in the Grant County learning organization system-wide as a result of GCTI. Interviews indicated teachers at the middle school and high school collaborated more frequently and followed similar processes when addressing student grades, behavior, and attendance. Both schools shared a similar systemic process for collecting student information for identifying student involvement in extra-curricular activities. This further demonstrated the presence of systemic processes and the sharing of information. Documents indicated the existence of structures or systemic processes for organizing various school meetings that addressed transition information as evidenced in agenda and minute documentation are now in place. Many of these activities and meetings were not documented or developed prior to GCTI. Documents also demonstrated similar processes in both the middle school and high school prevailed.

Transition committee comments, teacher interview comments and documents from both schools indicated that both schools deliberately addressed transition issues and transition data as a topic agenda at regularly scheduled meetings as evident on agendas and minutes. Schedules of the various meetings and their dates, times and locations indicated an organizational system was in place for meetings and activities. Meeting agendas and minutes revealed transition information was often the priority topic of 
discussion with student data provided at meetings on a regular basis. Principals and counselors at both schools gathered student outcome data for department meeting/PLC meetings, academy/team meetings and vertical alignment meetings. These findings included data on student academic performance, behavior and curriculum that provided information in support of an intentional focus on transitions with corrective strategies for improving outcomes.

School documents indicated a systemic process was in place that involved district leadership in the monitoring of GCTI. District leadership used processes for meeting with both school administrators in four-and-a half week grading period progress meetings. These meeting provided opportunities for communication among school level principals and the superintendent to share student academic performance and behavior data as reported on the Status of School Report. These meetings allowed administrators to identify areas of student outcome growth and areas that needed intervention strategies, attention and support. These meetings revealed that little was being done to celebrate successes and that improved student outcome data was not always shared back to middle and high school faculty members.

The Grant County Transition Initiative was effective in impacting the ability of the middle school and high school to function as a learning organization in part because the initiative was clearly grounded in researched best practices. School leaders did not merely gather together and design and implement activities by random choice but rather based all decisions on a series data driven decisions supported by research. District leadership saw the vision and need to build a guiding coalition of leaders that would take the initiative plans forward to the building level for buy-in and support. Teachers were 
introduced to the activities in a methodical manner during faculty meetings. The initiative focus on middle school to high school transitions was embedded into agendas and an expected topic of discussion in all meetings. Activities were not developed from the top down but involved the collaborative efforts of the guiding coalition that included middle school, high school and central office members. The selection of the thirteen activities for the initiative was intentional, purposeful and aligned to proven research from prior studies. Processes included timelines for implementation of the activities, processes for providing data at meetings, processes for documenting agendas and minutes and monitoring the activities. Numerous stakeholders were involved that included district support, school level teachers and administrators and parents. People were empowered and involved in the systemic processes each step of the journey.

\section{Learning Organization Category 2: Leadership/Vision}

In the area of leadership/vision, school and district leadership created a unified vision for the initiative with a focus on middle school to high school transition activities. A shared vision that was developed and nurtured by district leadership and accepted and acted upon by school leaders and teaching staff. Findings from transition committee interviews indicated that a guiding coalition of teachers and leaders was assembled to identify the transition problem and develop strategies to address the high school freshman academic performance and behavior data. This committee included district level involvement in the initiative. Transition committee comments and teacher interview comments revealed that the vision for GCTI was successfully disseminated from committee members and building principals to the faculty at the middle school and high 
school. Teacher interviews revealed a shared vision to address student transition data became the foremost focus of most meetings as evidence in meeting documents.

Transition committee interview findings revealed that although more stakeholders could have been involved in the initial research and selection of the set of structured articulation activities than just the few transition committee members, teachers at both schools were actively involved in the implementation and follow-through. Teacher interviews revealed the high school created a vision of high expectations with mandatory participation in at least two middle school events; the grade eight dance and grade eight graduation.

Teacher interview comments on what they would change about GCTI indicated teachers would make minor adjustments in some activities but the vision would remain the same as teachers liked the activities that seemed to be working as teachers elected to keep all thirteen articulation activities. Electing to continue with all thirteen articulation activities in year three indicated the vision was understood, accepted, shared and that buy-in had occurred between both schools. Teachers at both schools indicated during interviews that they looked to the future of GCTI in making suggestions for improvement of GCTI. Teachers suggested that student data on improvement results be shared on a more frequent and intentional basis with activities built in for celebrating these improvements.

Teacher interview findings revealed growth had occurred the two years since the inception of GCTI. Teacher comments revealed school efforts have been the best they have ever been during the two years with GCTI and that the teachers have never felt more unified as a district. 
Transition committee interviews showed that committee members had integrated data from the literature review on articulation activities and transition research into this initiative. Teachers shared the common belief that, in order to impact student academic performance and behavior in the transition from middle school to high school, a series of issues must be addressed collaboratively at both the middle and high school levels. Collaboratively teachers embedded transition research into GCTI on what matters most to students moving from the middle school to high school, what activities can increase the chances of a successful transition and how to bring the organization together in this shared vision.

Transition committee interviews revealed the vision for improving student transition data must go beyond the high school to include middle school teachers, district leadership and parents in the systemic processes. Teacher interview findings showed the middle school and high school teachers were unified in the vision of this transition initiative and that district support was included in the development, implementation and monitoring.

Interview and document findings revealed change had occurred since the Freshman Transition Teacher Survey was administered. Freshman Transition Teacher Survey findings revealed that teachers at both schools participated in and valued the articulation activities with a much value to very much value rating. Seven months after the survey results were collected the transition committee and teacher interview, findings revealed teachers had grown in their understanding and vision of the initiative. As time went on, teachers experienced first-hand the positive results of this collaborative partnership. Teachers became more self-initiated to meet with others to address 
academic and behavior problems in addition to the regularly scheduled meetings. Multiple partners began to be included in the process that encompassed teachers, administrators, parents, counselors and attendance clerks. Middle school survey data from May 2010 indicated did not see the value in some activities like the teacher swap. Interview findings in December 2010 revealed teachers elected to keep the all of the activities because of their increased knowledge of the activity benefit to the students. The best interest of students became the reason for continuing with the articulation activities in GCTI.

The high school participation data revealed lower high school participation data but value scores revealed high school teachers valued the articulation activities with a 3-4 value rating that was higher than the middle school.

Transition committee interviews revealed that the vision of the initiative extended beyond the middle school and high school. The superintendent shared that elementary school leaders elected to emulate the GCTI structure for implementing articulation activities in the transition from grade five to grade six. This finding revealed an unexpected and unintended positive impact GCTI had on other school leaders in the district. Transition committee interview findings revealed that GCTI discussion and progress shared following monthly principal meetings impacted the leadership and vision of the elementary school principals. The elementary school principals in the district reviewed the research from this study on transitions and articulation activities and elected to collaboratively start a similar initiative in their schools.

Analyses of archival documents revealed a consistent and unified vision was evident on the scope and purpose of the GCTI initiative. Documents show school leaders 
and teachers understood the vision of GCTI through the systemic processes developed and implemented through GCTI. From the time of administering the Freshman Transition Teacher Survey in May 2010 to the time of the interviews in December 2010, findings indicated growth occurred in the vision of what the organization was and what it can be as a result of GCTI. Teachers believed that the district had never been more unified. Findings revealed the Grant County system operated more effectively as a learning organization as a result of GCTI. Participants reported that this progress came through the collaborative meetings that unified the district, helped teachers build relationships with each other in solving problems and focused leadership and teachers on systemic processes for improving student and school organizational outcomes.

\section{Learning Organization Category 3: Collaboration}

GCTI impacted the extent to which teachers collaborated during this middle to high school transition initiative. Survey participation and value findings revealed some relationship between greater participation in activities increases school value of the articulation activity. Survey findings revealed the more teaches worked collaboratively in the articulation activities, the greater the participation and value assigned.

Findings from transition committee interviews revealed the GCTI articulation activities purposely encouraged and promoted collaboration among and between the middle school and high school. Teacher interview findings indicated more collaboration occurred among teachers, between schools and with parents in both schools as a result of the collaborative articulation activities implemented through CGTI. Freshman Transition Survey findings collected in May 2010 indicated that teachers valued the collaborative activities at high levels. Seven months later, interview comments demonstrated teacher 
continued to value these articulation activities and perceived benefits to the students. Teacher interview comments revealed that teachers came to see the benefits of the transition activities as the student outcomes were positively impacted by GCTI. Teachers saw the benefit of the articulation activities to students the benefits of GCTI to the organization as teachers worked in more structured, intentional ways. Teacher collaboration in meetings among and within schools enable teachers to work collectively to solve problems and address student and curricular issues that might not otherwise be addressed in isolation. Teacher interview comments indicated that many activities such as grade eight parent orientation, teacher swap, eighth to nine grade progress meetings, HS teachers attending grade eight meetings, tour, counselor/parent meeting, counselor/student meeting, MS/HS vertical alignment meetings, HS teacher attending MS events, team building sessions and grade eight at-risk meetings helped improve teacher relationships and collaboration both vertically and horizontally.

Teacher interview comments revealed that teachers felt more comfortable in contacting and working with other teachers because they had worked together in the scheduled meetings and structured articulation activities. Transition committee and teacher interviews revealed school leadership intentionally scheduled the monthly collaborative vertical alignment meetings for the purpose of improving collaboration among and between people to improve student outcome data and organizational curriculum alignment information. Teacher interviews showed more individual teachers, as a result of GCTI take the initiative to communicate with other teachers at the other school to discuss curricular and transition issues because of the relationships forged from these collaborative meetings. Teacher interviews revealed that teachers came to work 
collaboratively rather than in isolation to solve problems with regard to failing students, students acting out in class and high absenteeism.

Teacher comments on the regularly scheduled vertical alignment meetings revealed the middle school and high school communicated monthly in discussing student transition data, articulation activities and curricular issues. Interview comments from teachers found that teachers work together in the academy structure at the high school and the team structure at the middle school to find solutions to their problems. Interviews revealed many of these meetings and activities were not in place before GCTI.

Teacher interview comments from both schools revealed these academy and team meetings included a diverse group of stakeholder to identify and solve problems that included the counselor, attendance clerk, parents and administration. Findings revealed school leaders and teachers made an intentional focus of involving parents in several structured articulation activities. Documents that included meeting agendas and minutes supported the finding that these collaborative vertical alignment meetings and academy and team meetings were systematically scheduled with an intentional focus on transition issues.

Regularly scheduled faculty meetings, monthly scheduled transition committee meetings, monthly scheduled MS/HS vertical alignment meetings, progress meetings, Status of School Report meetings and weekly academy and team meetings provided evidence of intentional collaboration. Teacher comments during interviews revealed the past two years have been some of the best they have seen and that they have never felt more unified as a school and as a district. As a result of the GCTI teachers reported working together and being more focused on improving student outcomes. These finding 
demonstrated the positive impact these systemic processes had on the middle school and high school learning organization as a result of GCTI.

Interviews revealed that as time passed, teachers increasingly recognized the benefit of GCTI's activities that promoted collaboration. Teachers were informed of improved student performance and behavior data and began to see their collaborative efforts paying off. A triangulation of findings on open response surveys, interviews and documents supported the finding that GCTI provided systemic processes or structures for teachers to work collaboratively within and between schools that positively impacted the schools' ability to operate as one learning organization.

\section{Learning Organization Category 4: Use of Measures}

The use of student data measures was supported throughout the analyses. District and school leadership were successful in creating the vision for and expectation of the use of measures in the GCTI initiative. Minutes and agendas from faculty meetings, PLC/department meetings, team/academy meetings, student progress meetings and vertical alignment meetings provided information that confirmed the use of measures with a focus on improving student transition data. Data from the district-wide student data reporting system provided school administrators with student data on academic performance and student behaviors. Grades, failure rates, attendance reports and student behavior incidence data were provided at the various meetings. Vertical alignment meetings included curriculum alignment information for improving the organization.

Documents and interviews revealed the collaborative involvement of the district in analyzing and monitoring transition data. The middle school and high school were fairly clear in the types of documents available on file that included student measures on 
grades, behavior and attendance. Data from agendas and minutes revealed that the high school was more intentional in providing student data at meetings than the middle school. Both schools had hard or electronic copies of meeting agendas and minutes for middle school and high school vertical alignment meetings, Freshman Academy meetings, grade eight team meetings, department/PLC meetings, swap lesson plan documents and the Status of School Report. Data were also provided on extra-curricular activity participation at the high school through the newly created Freshman Transition Student Data Form.

Teacher interviews revealed school administrators provided use of measure data for meetings with regard to student academic performance, behavior and attendance. Teacher interview findings revealed teachers regularly analyzed student data but they were not always as informed of improvement results. Teacher interview findings revealed that teachers were pleased to hear student results shared by the superintendent at the end of the teacher interviews. Data indicated that sharing and celebrating results was an area of needed growth. The use of measures and the expectation that student transition data guide the meetings and articulation activities was critical to the success of this initiative. It would benefit organizations wanting to replicate this study to provide data measures of improved student results of the initiative back to the faculty on a regular basis. Teachers began to see the benefits of middle and high school collaboration during GCTI activities in analyzing data to solve problems associated with academic performance, behavior and the organization like curricular issues. Teachers shared solutions and strategies to improve both teaching and learning with an intentional focus on math and reading strategies noted in vertical alignment meetings. The use of 
measures helped to focus the organization on data with the goal of improving middle school to high school transition data that served as the catalyst for the creation of GCTI.

\section{Findings Summary ,}

A wide range of triangulated data provided ample evidence that answered this study's research question. Clearly, the creation and work of the GCTI and subsequent implementation of articulation activities enabled the middle-high system to function as a more productive learning environment during this transition initiative. As a result of GCTI's middle to high school transition initiative, growth in the organization's ability to function as a learning organization occurred as both schools intentionally incorporated the characteristics common to Organizational Learning, High Reliability Organizations and Effective Schools that included systemic processes, leadership/vision, collaboration and the use of measures that guided the organization's growth as a learning organization.

The highlights of the impact of this Grant County Transition Initiative study are noted in Table 6.

Table 6

Summary of Evidence that the GCTI Enhanced Grant County Schools' Ability to Operate as a Learning Organization

\section{Systemic Processes:}

- Teachers at the middle school and high school changed practices as a result of the systemic processes of GCTI that included articulation activities. Data was shared more systemically with a clear focus on improving student outcomes.

- Meetings became more data driven, with a unified focus on specifically addressing transition data.

- Activities and timelines were intentionally planned to better prepare students for the transition from the middle school to high school.

- The district created the structure and the provided the time and support for teachers to meet and work together.

\section{Leadership/Vision:}

- Long-term sustainability of GCTI appears promising as middle school and high school teachers have elected to enter into year three continuing with all of the 
GCTI activities.

- Teachers were invited to share in the district vision for GCTI. Teachers were invited to provide strategies for improvement of the initiative.

- The vision leadership created in the middle school to high school transition initiative went beyond these two schools to subsequently include the five elementary schools in the district. The elementary schools learned from this middle to high school partnership and elected to incorporate the articulation activities and processes in the transition from elementary school to middle school and grade to grade.

- What started as a middle to high school initiative became a district-wide initiative.

Collaboration:

- Teachers reported that the two post-GCTI-initiation years have been some of the best teachers have seen. Teachers felt more unified as a school and as a district. Teachers became more comfortable in contacting other teachers to share information and provide support because of the relationships built during this collaborative/partnership initiative.

- More stakeholders were involved in helping improve the successful transition of students from middle to high school. Parents, teachers, central office members, attendance clerks and counselors have come together to find solutions to the transition problems.

- The high school appreciated the middle school support in recognizing that the high school should not solely own the problem and could not work in isolation in solving transition outcomes. Both schools realized the importance of a middle school and high school team working to improve these results. The elementary schools have seen the benefits of this collaborative partnership and have elected to join in this effort.

- As a result of GCTI, teachers were working together at the middle school and high school with a shared focus on improving student and organizational outcomes.

\section{Use of Measures:}

- District and school leadership through GCTI created an expectation of data driven decision making. Data were provided in meetings and articulation activities that focused the schools on analyzing middle to high school transition data and providing intervention strategies.

- Teachers reported more clearly seeing the benefits of middle and high school teachers collaborating in systemic ways to analyze data with the goal of improving student and organizational outcomes.

- Teachers were beginning to see positive results as they shared improved student outcome data and strategies for support.

By the fall of 2011, the chances of long term sustainability looked promising as teachers continued into year three with this initiative. Growth impacted the two schools involved in this study and as an outgrowth of the initiative impacted organizational 
learning among the other schools in the district. The elementary schools elected to incorporate the researched strategies and conceptual framework of GCTI by developing similar transition programs within their schools.

\section{Implications for Practice}

The following recommendations are intended to address Grant County and other schools and systems striving to function as true learning organizations during the implementation of middle-to-high-school transition programs.

1. Provide all stakeholders, not just the guiding coalition that served as the transition committee members, with a synthesis of the main points highlighted in current research on the topic of transitions, articulation activities, organizational learning, high reliability organizations and effective schools.

2. Develop a larger, more diverse guiding coalition of school leaders from each participating school to lead the initiative. Replace vacancies when members of this coalition leave the district or relinquish membership.

3. Involve all stakeholders in the processes. Build leadership capacity within the schools. Develop a sub-committee structure to provide feedback to and from the transition committee to better ensure decisions are not top-down driven.

4. Develop processes to create a collaborative culture within and among the middle school and high school to address problematic issues such as transition from grade eight to grade nine.

5. Set an expectation of data-driven decision making. Create a process for disseminating data at meetings. 
6. Create a process to ensure proper follow-up, monitoring and celebrating organizational and student success in both schools and throughout the district.

7. Collaboratively develop systematic processes for selecting, implementing and monitoring articulation activities. Involve more stakeholders in the selection of articulation activities beyond the small numbers that serve on the transition committee. .

\section{Implications for Future Research}

The following are suggestions for future research studies to expand the body of knowledge to help middle school to high school transition initiatives.

Examine the impact of the implementation of articulation activities on an entire $\mathrm{K}-12$ school district as a learning organization. How different or similar are the transition needs of students at various levels?

A study of regional and state-wide middle schools and high schools that are implementing articulation activities could be conducted, examining the impact of articulation activities on successful student transitions from grade eight to grade nine and the success of the organization.

1. A continued longitudinal study of GCTI would strengthen the results of this study and provide additional data on what articulation activities have a greater impact on student outcomes, what student populations benefit more from these types of activities and what common characteristic of the conceptual framework produce greater improvement results.

2. An analysis of pre-test and post-test information on teacher surveys of participation, value, interviews and documents would add depth to future studies 
and provide comparative data to further demonstrate the impact of articulation activities on a learning organization as a result of a transition initiative. What activities had more of an impact over others? What categories if any have a greater impact on the learning organization, systemic processes, leadership/vision, collaboration or use of measures?

3. An examination of the four separate characteristics common to OL, HRO and ES would provide data on what characteristics of a learning organization have a greater impact on improving the ability of the organization to function as a learning organization.

4. A further examination of articulation activities could provide data on which articulation activities have the greatest impact on improving student transition success and student outcome success.

5. A study of low socio-economic status, minority and male/female populations could provide valuable data on what works with specific sub-groups.

The implications of these studies can provide specific research on how schools design professional development programs and what works with the intent of improving middle school to high school transition data of academic performance and behavior.

\section{Summary}

This study yielded information on what impact articulation activities had on Grant County as a learning organization during a middle to high school transition initiative. This study found that growth occurred in the Grant County middle-high school partnership as a result of the GCTI and the implementation of articulation activities. The Grant County Schools came to the conclusion that in incorporating the characteristics 
common to Organizational Learning, High Reliability Organizations and Effective Schools the middle school and high school demonstrated growth in each characteristic as a result of GCTI. The presence of systematic processes for implementing the articulation activities, the use of measures of student and organizational outcomes, the collaboration among and between teachers in activity participation and the shared sense of urgency to create the vision and need for this transition initiative answered the overarching research question of this study in the affirmative.

The fact that the GCTI has continued into a third year with all thirteen activities in place indicates this study may have an ongoing impact on the Grant County Schools as they work to improve the district's ability to function and grow as a learning organization.

This study demonstrated that improvement need not be about investing in expensive programs, but rather investing in people by creating a shared vision, using systematic processes for implementation, improving collaboration and using measures of outcome data to monitor growth within the learning organization. As a result of this transition initiative, Grant County Public Schools were clearly more able to operate as an increasingly sophisticated learning organization. 


\section{REFERENCES}

Adler, P., \& Adler, P. A. (1987). Membership roles in field research. Thousand Oaks, CA: Sage.

Abell Foundation (2007). A "jump start" on college: how early college access programs can help high school students in Baltimore City. Baltimore, MD: Abell Foundation.

Akos, P., \& Galassi, J. (2004). Gender and race as variable in psychological adjustment to middle and high school. The Journal of Educational Research, 98(2), 102-108.

Allen, D., (2011). Lost in transition: A grade nine transition program using articulation activities (Unpublished doctoral dissertation). University of Louisville, Louisville, KY.

Allensworth, E. M., \& Easton, J. Q. (2005). The on-track indicator as a predictor of high school graduation. Chicago: Consortium on Chicago School Research, University of Chicago.

Alspaugh, J. W. (1998). Achievement loss associated with the transition to middle school and high school. The Journal of Educational Research, 92(1), 20-26.

Barone, C., Aquirre-Deandreis, A. I., \& Trickett, E. J. (1991). Means-ends problem solving skills, life stress and social support mediators of adjustment in the normative transition to high school. American Journal of Community Psychology, $19(2), 207-225$.

Black, S. (February). The pivotal year. American School Board, 191(2), 42-44. 
Blyth, D. A., Simmons, R. G. \& Bush, D. (1978). The transition into early adolescence: A longitudinal comparison of youth in two educational contexts. Sociology of Education, 51, 149-162.

Bragg, D. \& Rudd, C. (2007). Career pathways, academic performance, and transition to college and careers. The impact of two elect career and technical education (CTE) transition programs on student outcomes. Champagne, IL: Office of Community College Research and Leadership, University of Illinois at UrbanaChampaign.

Brookover, W. B., Beamer, L., Eftim, H., Hathaway, D., Lezotte, L., Miller, S., Passalacqua, J., \& Tornastshy, L. (1982). Creating effective schools. Holmes Beach, FL: Learning Publications, Inc.

Bryk, A. S., \& Driscoll, M. E. (1988). The school as community: Theoretical foundations, contextual influences, and consequences for students and teachers. Madison, WI: National Center on Effective Secondary Schools, University of WisconsinMadison.

Carroll, S. J., \& Scherer, E. (2008). The impact of educational quality on the community, a literature review. Santa Monica, CA: RAND Education.

Center for Equity and Excellence in Education (2009). Strengthening the transition from middle grades to high school in the Mid-Atlantic region: $D C, D E, M D, N J, P A$. Washington, DC: Author.

Chapman, M. V., \& Sawyer, J. S. (2001). Bridging the gap for students at risk of school failure: a social work-initiated middle school to high school transition program. Children \& Schools, 23(4), 235-240. 
Cognato, C. A. (1999). The effects of transition activities on adolescent self-perception and academic achievement during the progression from eighth to ninth grade. Paper presented at the National Annual Meeting of the National Middle School Association, Orlando.

Cook, T.D. \& Campbell, D.T. (1979). Quasi-experimentation: Design and analysis issues for field settings. Chicago: Rand McNally.

Cousins, B. (1998). Intellectual roots of organizational learning. In K. Leithwood \& K. S. Louis (Eds.), Organizational Learning in Schools, 219-235. Lissem NL: Swets 7 Zeitlinger.

Darling-Hammond, D. \& Friedlaender, D. (2008). Creating excellent and equitable schools. Educational Leadership, 65(8), 14-21.

Datnow, A., Hubbard, L. \&Mehan, H. (1998). Educational reform implementation: A coconstructed process. University of California, Santa Cruz: Center for Research on Education, Diversity, and Excellence.

Datnow, A., \& Stringfield, S. (2000). Working together for reliable school reform. Journal of Education for Students Placed at Risk, 5(1\&2), 183-204.

Deal, T.E., Intili, J., Roasler \& Stackhouse, A. (1977). The early childhood education program. An assessment of its impact and implementation. Sacramento, CA: California State Department of Education.

Denzin, N. K. \& Lincoln, Y.S. (Ed.). (2005). Handbook of qualitative research. Thousand Oaks, CA: Sage. 
DuFour, Richard., DuFour, Rebecca., Eaker, R., \& Karhanek, G. (2004). Whatever it takes: How professional learning communities respond when kids don't learn. Bloomington, IN: National Educational Service.

Eccles, J. S., Midgley, C. \& Adler T. F. (1984). Grade-related changes in the school environment: effects on achievement motivation. In J.G. Nicholls (Ed.) Advances in motivation and achievement, Vol. 3, pp. 228-331. Greenwich, CT: JAI Press.

Edmonds, R. R. (1980). Search for effective schools. Paper presented at the Strategies for Urban School Improvement Workshop Series, Washington, DC. (ERIC Document Reproduction Service No. ED212689)

Edmonds, R. R. (1982). Programs of school improvement: An overview. Educational Leadership, 40(3), 1-11.

Entin, D. (2009). On realizing it's worse than I thought. Journal of College Admission, (202), 14-17.

Epstein, J. L., (1995) School/family/community partnerships: Caring for the children we share. Phi Delta Kappan, 76(9), 701-712.

Fiol, C. M. \& Lyles, M.A. (1985). Organizational Learning. Academy of Management Review, 10(4), 803-813.

Fullan, M. (1993). Change forces: Probing the depths of educational reform. London: Falmer Press.

George, P., \& McEwin, C. (1999). High schools for a new century: Why is the high school changing? NASSP Bulletin, 83(606), 10-24.

Giles, C., \& Hargreaves, A. (2003). Daring to be different: The sustainability of schools as learning organizations and professional learning communities during 
standard-based reform. Paper presented at the annual meeting of the American Education Research Association, Chicago.

Greenwood, P.W., Mann, D., \& McLaughlin, M.W. (1975). Federal programs supporting education change, Vol. III: The process of change. U. S. Office of Education. Department of Health, Education and Welfare. Santa Monica, CA: Rand.

Gruhn, W. T., \& Douglas, H. R. (1947). The modern junior high school. New York: The Ronald Press Company.

Haney, W., Madaus, G., Abrams, L., Wheelock, A., Miao, J. \& Gruia, I. (2004). The education pipeline in the United States 1970 - 2000. Chestnut Hill, MA: Boston College, National Board on Education Testing and Public Policy.

Hertzog, C. J., Morgan, P. L., Diamond, P. A., \& Walker, M. J., (1996). Transition to high school: a look at student perceptions. Becoming, 7(2), 6-8.

Hertzog and Morgan (1998). Breaking the barriers between middle school and high school: Developing a transition team for student success. NASSP Bulletin. 82(597), 94-98.

Hertzog, C. J., \& Morgan, P.L. (1999). Making the transition from middle level to high school. High School Magazine, 6(4), 26-30.

Hibbett, M. (in process). Lost in transition: A grade nine transition program using articulation activities. Unpublished doctoral dissertation. University of Louisville. Innes, R. G. (2009). Examining Kentucky's 'No child left behind' Tier 5 schools. Bowling Green, KY: Bluegrass Institute for Public Policy Solutions. 
Isakson, K., \& Jarvis, P. (1999). The adjustments of adolescents during the transition into high school: a short-term longitudinal study. Journal of Youth and Adolescence, $28(1), 1-26$

Johnston, J. H. (1992). Climate and culture as mediators of school values and collaborative behavior. In L. Irvin, (ed.). Transforming middle level education: Perspectives and possibilities (pp.77-92). Needham Heights, MA: Allyn \& Bacon.

Kennelly, L. \& Monrad, M. (July, 2007). Easing the transition to high school: Research and best practices designed to support high school learning. National High School Center. Retrieved from: http://www.better high schools.com/docs/NHSC TransitionReport.pdf

Kinney, D.A. (1993). From nerds to normals: the recovery of identity adolescents from middle school to high school. Sociology of Education, 66(1), 21-40.

LaPorte, T., \& Consoline, P. (1991). Working in practice but not in theory: theoretical challenges of high reliability organizations. Journal of Public Administration Research and Theory, 1(1), 19-48.

Lee, V. E., Byrk, A. S., \& Smith, J. B. (1993). The organization of effective secondary schools. In L. Darling-Hammond (Ed.) Review of Research in Education (pp. 171-267). Washington, DC: American Educational Research Association.

Lee, V. E., \& Smith, J. B. (1995). Effects of high school restructuring and size on early gains in achievement and engagement. Sociology of Education, 68(4), 241-270.

Levitt, B. \& March, J. (1988). Organizational learning. Annual Review of Sociology, 14, $319-340$. 
Lezotte, L. W. (2007). Effective schools: past, present and future. Retrieved from http://www.effectiveschools.com/images/stories/brockpaper.pdf

Louis, K.S. (1994). Beyond managed change: Rethinking how schools improve. School Effectiveness and School Improvement, 5(1), 2-24.

Louis, K.S. (2006). Changing the culture of schools: Professional community, organizational learning, and trust. Journal of School Leadership, 16(5), 477-489.

MacIver, D. J., (1990). Meeting the needs of young adolescences: Advisory groups, interdisciplinary teaching teams, and school transition programs. Phi Delta Kappan, 71(6), 458-464.

Mac Iver, M., Kemper, E., \& Stringfield, S. (2003). The Baltimore Curriculum Project: Final Report of the Fourteen Year Evaluation Study. Center for Research on the Education of students Placed At Risk. Baltimore, MD.

Manning, M. L., \& Baruth, L. G. (1995). Students at Risk. Needham Heights: Allyn \& Bacon.

Marais, K., Dulac, N. \& Levison, N, (2004). Beyond normal accidents and high reliability organizations: The need for an alternative approach to safety in complex systems. Cambridge, MA: MIT.

Maute J. K. (1991). Transition concerns of eighth-grade students in six Illinois schools as they prepare for high school. Unpublished doctoral dissertation, National-Louis University, Evanston, IL.

McErwin, C. K. (1998). Concepts of continuing importance. In R. David (Ed.), Moving forward from the past: early writing and current reflections of middle school 
founders, pp. 35-30. Columbus: National Middle School Association. Pittsburg: Pennsylvania Middle School Association.

Miles, M. B. (1998). Finding the keys to school change: A 40-year odyssey. In A. Hargreaves, International Handbook of Educational Change (p. 37-69). London, GB: Kluwer.

Mizelle, N. B. (1995). Transition from middle school to high school. The student perspective. Paper presented at the annual meeting of the American Educational Research Association, San Francisco.

Mizelle, N., \& Irvin, J. (2000). Transition from middle school into high school. Middle School Journal, 31(5), 57-71.

Murphy, J., (1992). School effectiveness and school restructuring: Contributions to educational improvement. Paper presented at the Annual Meeting of the International Congress for School Effectiveness and Improvement.

National Association of School Boards of Education. (2008). Beginning in the middle: Critical steps in early secondary school reform. Arlington, VA: Author. National Middle School Association (2006). Transition from the middle to high school. (Research Summary). Westerville, OH: Author.

No Child Left Behind Act of 2001, Pub. L. No. 107-110, 115 Stat. 1425 (2002).

Oakes, A. (2009). Middle-to-high school transition practical strategies to consider. The Center for Comprehensive School Reform and Improvement Newsletter.

Oates, J., Flores, R., \& Weishew, N. (1998). Achieving student success in inner city schools is possible, provided...Research in Middle Level Education Quarterly, 21(3), 51-62. 
Patton, P. Q. (2002). Qualitative Research and Evaluation Methods (3 ${ }^{\text {rd }}$ ed.). Sage.

Phelan, P., Yu, H. C., \& Davidson, A. L. (1994). Navigating the psychosocial pressures of adolescence: the voices and experiences of high school youth. American Educational Research Journal, 31(2), 415-447.

Purkey, S.C., \& Smith, M. (1983). Effective schools: A review. Elementary School Journal, 83(4), 427-52.

Rumberger, R., \& Palardy, G. (2005). Test scores, dropout rates and transfer rates as alternative indicators of high school performance. American Educational Research Journal, 42(1), 3-42.

Schiller, K. S. (1999, October). Effects on feeder patterns on students' transition to high school. Sociology of Education, 72(4), 216-233.

Schlechty, P. (2001). Shaking up the school house: How to support and sustain educational innovation. San Francisco: Jossey-Bass.

Schumaker, D. (1998). The transition to middle school. ERIC Digest. Clearinghouse on Elementary and Early Childhood Education. Champagne, IL: University of Illinois.

Senge, P. (1990). The fifth discipline: The art and practice of the learning organization. New York: Doubleday.

Shadish, W.R., Cook, T.D. \& Campbell, D.T. (2002). Experimental and quasiexperimental designs for generalized causal inference. Boston, MA: Houghton Mifflin.

Silins, H.C., Mulford, W.R., \& Zarins, S. (2002). Organizational learning and school change. Educational Administration Quarterly, 38(5), 613-642. 
Silins, H.C., \& Mulford, W.R. (2002). Schools as learning organizations. Journal of Educational Administration, 40(5), 425-446.

Stringfield, S., Datnow, A., \& Ross, S. (1998). Scaling up school restructuring in multicultural, multilingual contexts: Early observations from Sunland County. (Technical Report No. 2). Santa Cruz, CA: University of California, Santa Cruz, Center for Research on Education, Diversity and Excellence.

Stringfield, S., Reynolds, D. and Schaeffer, E. C. (2008). Improving secondary school student's academic achievement through a focus on reform reliability: 4- and 9year findings from the High Reliability Schools project. School Effectiveness and School Improvement, 19(4), 409-428.

Stringfield, S. \&Teddlie, C. (1991). Observers as predicators of school's multi-year outlier status. Elementary School Journal, 91(4), 357-375.

Stringfield, S. \& Yonezawa, S. (2000). Special strategies for educating disadvantaged student's follow-up study: Examining the sustainability of research-based school reforms. Baltimore: John Hopkins University CRESPAR.

Teddlie C., \& Reynolds, D. (2000). The international handbook of school effectiveness research. New York: Falmer Press.

Vars, G. F. (1998). You've come a long way baby! In R. David (Ed.), Moving forward from the past: early writings and current reflections of middle school founders. Westerville, $\mathrm{OH}$ : National Middle School Association.

Waggoner, Jan. E. (1994). The relationship between instructional teaming and selfesteem of the sixth graders transitioning to a traditional junior high. Paper 
presented at a meeting of the Illinois Association of Teacher Educators Meeting, Lislle, Il. (ERIC Document Reproduction Service No ED379278).

Weber, B. J., \& Omotani, L. M. (1994). The power of believing. The Executive Educator, 16(9), 35-38.

Weick, K. E., Sutciffe, K. M., \& Obstfeld, D. (2000). Organizing for high reliability: processes of collective mindfulness. Research in Organizational Behavior, I(1), $81-123$.

Wells, M. C. (1996). Literacies lost: when students move from a progressive middle school to a traditional high school. New York: Teachers College Press.

Williamson, R., \& Johnston, J. H. (1999). Challenging orthodoxy: an emerging agenda for middle level reform. Middle School Journal, 30(4), 10-17.

Wise, B. (2008). High schools at the tipping point. Educational Leadership, 65(8), 8-13. 


\section{Appendix A}

Articulation Activities Timeline (2008-2010)

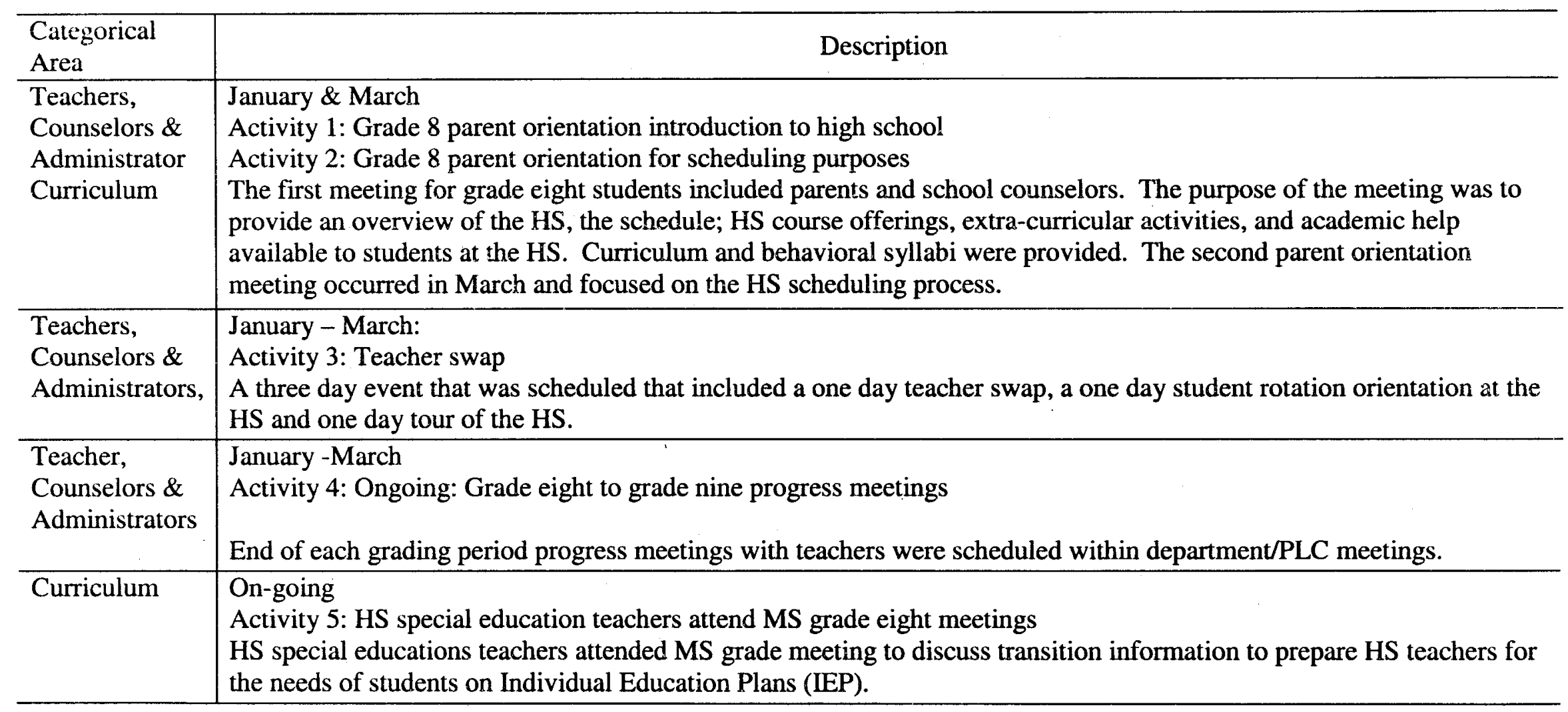




\begin{tabular}{|c|c|}
\hline $\begin{array}{l}\text { Categorical } \\
\text { Area }\end{array}$ & Description \\
\hline $\begin{array}{l}\text { General } \\
\text { Teachers, } \\
\text { Counselors \& } \\
\text { Administrators }\end{array}$ & $\begin{array}{l}\text { April } \\
\text { Activity 7: Counselor/Parent to discuss transition to HS } \\
\text { This meeting was designed to inform parents and students of freshman transition issues. Information was shared with } \\
\text { parents on how to help students develop good study habits and the need for strong parent/school communication. } \\
\text { Various social services available to students and parents such as Family Youth Resource Service information were also } \\
\text { shared. } \\
\text { Activity 3: Teacher Swap } \\
\text { This activity built student, teacher relationships }\end{array}$ \\
\hline $\begin{array}{l}\text { Curriculum \& } \\
\text { Safety }\end{array}$ & $\begin{array}{l}\text { April } \\
\text { Activity 8: HS Counselor meet with grade students } \\
\text { This meeting served as question and answer session for students with regard to HS student behavior code of conduct, } \\
\text { harassment and bullying. }\end{array}$ \\
\hline Curriculum & $\begin{array}{l}\text { On-going } \\
\text { Activity 9: MS/HS vertical alignment meetings } \\
\text { Grade eight and grade nine teachers met monthly in collaborative like-content area meetings to focus on academic, } \\
\text { behavior, transition and curricular issues. }\end{array}$ \\
\hline $\begin{array}{l}\text { Teachers, } \\
\text { Counselors \& } \\
\text { Administrators }\end{array}$ & $\begin{array}{l}\text { On-going } \\
\text { Activity 10: December: HS teachers attend grade eight events } \\
\text { Grade nine teachers were encouraged to participate in grade eight activities, such as dances, picnics, sporting events, } \\
\text { awards night, graduation and other extra-curricular activities. The expected result of this activity was to develop } \\
\text { teacher/student relationships that would carry forward into grade nine. Teacher participation was mandatory at the } \\
\text { eighth grade dance and grade eight graduation. } \\
\text { On-going }\end{array}$ \\
\hline
\end{tabular}




\begin{tabular}{l|l}
\hline $\begin{array}{l}\text { Categorical } \\
\text { Area }\end{array}$ & \multicolumn{1}{c}{ Description } \\
\hline $\begin{array}{l}\text { Teachers, } \\
\text { Administrators \& } \\
\text { Curriculum }\end{array}$ & $\begin{array}{l}\text { On-going } \\
\text { Activity 10: December: HS teachers attend grade eight events } \\
\text { Grade nine teachers were encouraged to participate in grade eight activities, such as dances, picnics, sporting events, } \\
\text { awards night, graduation and other extra-curricular activities. The expected result of this activity was to develop } \\
\text { teacher/student relationships that would carry forward into grade nine. Teacher participation was mandatory at the } \\
\text { eighth grade dance and grade eight graduation. } \\
\text { On-going }\end{array}$ \\
\hline Curriculum & $\begin{array}{l}\text { On-going } \\
\text { Activity 11: Team building sessions } \\
\text { Bi-weekly grade eight team meetings and Freshman Academy meetings were scheduled. These meetings were }\end{array}$ \\
\hline $\begin{array}{l}\text { General } \\
\text { scheduled to discuss grade eight EXPLORE information and grade nine PLAN data to improve college readiness } \\
\text { scores. } \\
\text { On-going }\end{array}$ & $\begin{array}{l}\text { July } \\
\text { Activity 12: Summer Transition Program }\end{array}$ \\
$\begin{array}{l}\text { During the summer between grade eight and grade nine, in-coming freshman were invited to participate in a two-day } \\
\text { summer session that took place two weeks prior to the start of the freshman year. The purpose of this session was to } \\
\text { provide students with organizational, team-building, and leadership skills. All activities were led by high school upper } \\
\text { class members and student Reserve Officer Training Candidates (ROTC). } \\
\text { On-going }\end{array}$ \\
$\begin{array}{l}\text { August } \\
\text { Activity 13: At-risk student meetings }\end{array}$ \\
$\begin{array}{l}\text { Two weeks prior to the start of the freshman year, parents of students who had been identified as at-risk students were } \\
\text { invited to attend a private session with school counselors and the academic principal to develop a student data form to } \\
\text { help monitor attendance, behavior, and grades. At-risk students were identified as students missing at least 20 or more } \\
\text { school days and/or failing one or more courses in grade eight. }\end{array}$ \\
\hline Curriculum
\end{tabular}




\section{APPENDIX B:}

\section{FRESHMAN TRANSITION TEACHER SURVEY}

Please answer each question as to the best of your knowledge

The questions in the table relate to various articulations your school may have implemented.

Your role in the school: Your school:

Primary Grade Level:

Years of Teaching Experience:

Primary Content Area: Years in Present School:

Value rating: $1=$ no value, $2=$ minor value, $3=$ much value, $4=$ very much value, $N A=$ do not $k$ now

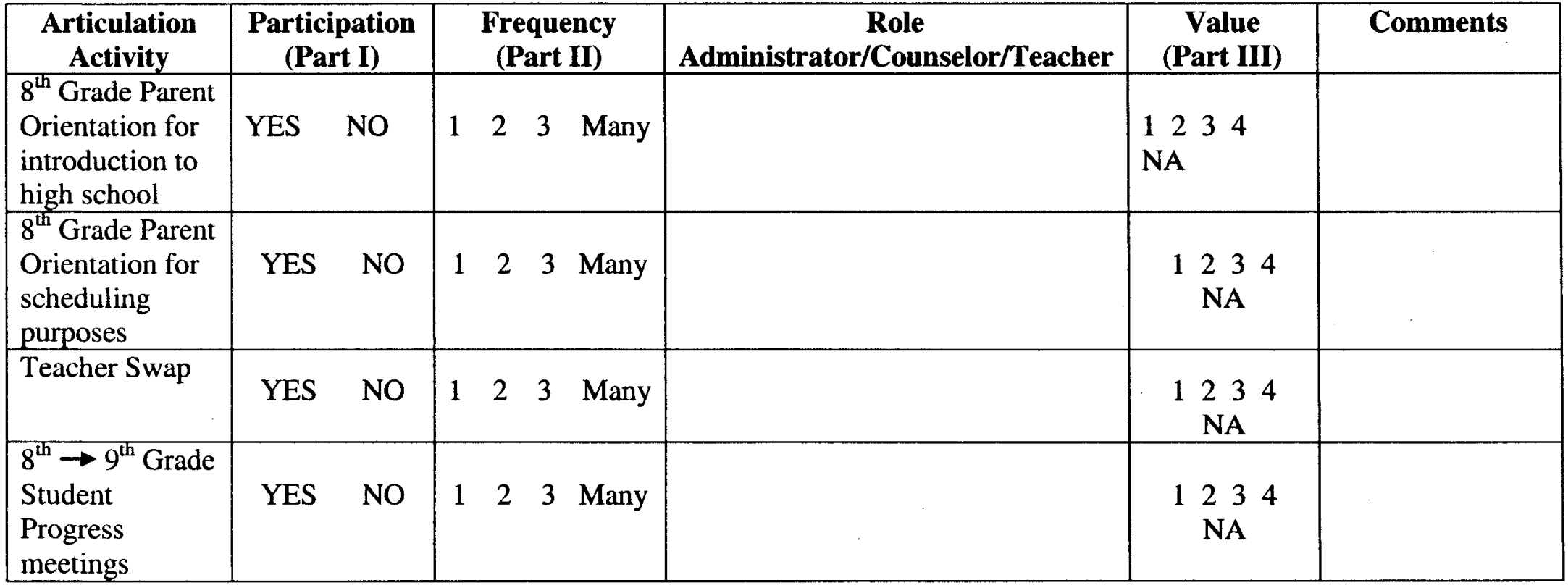




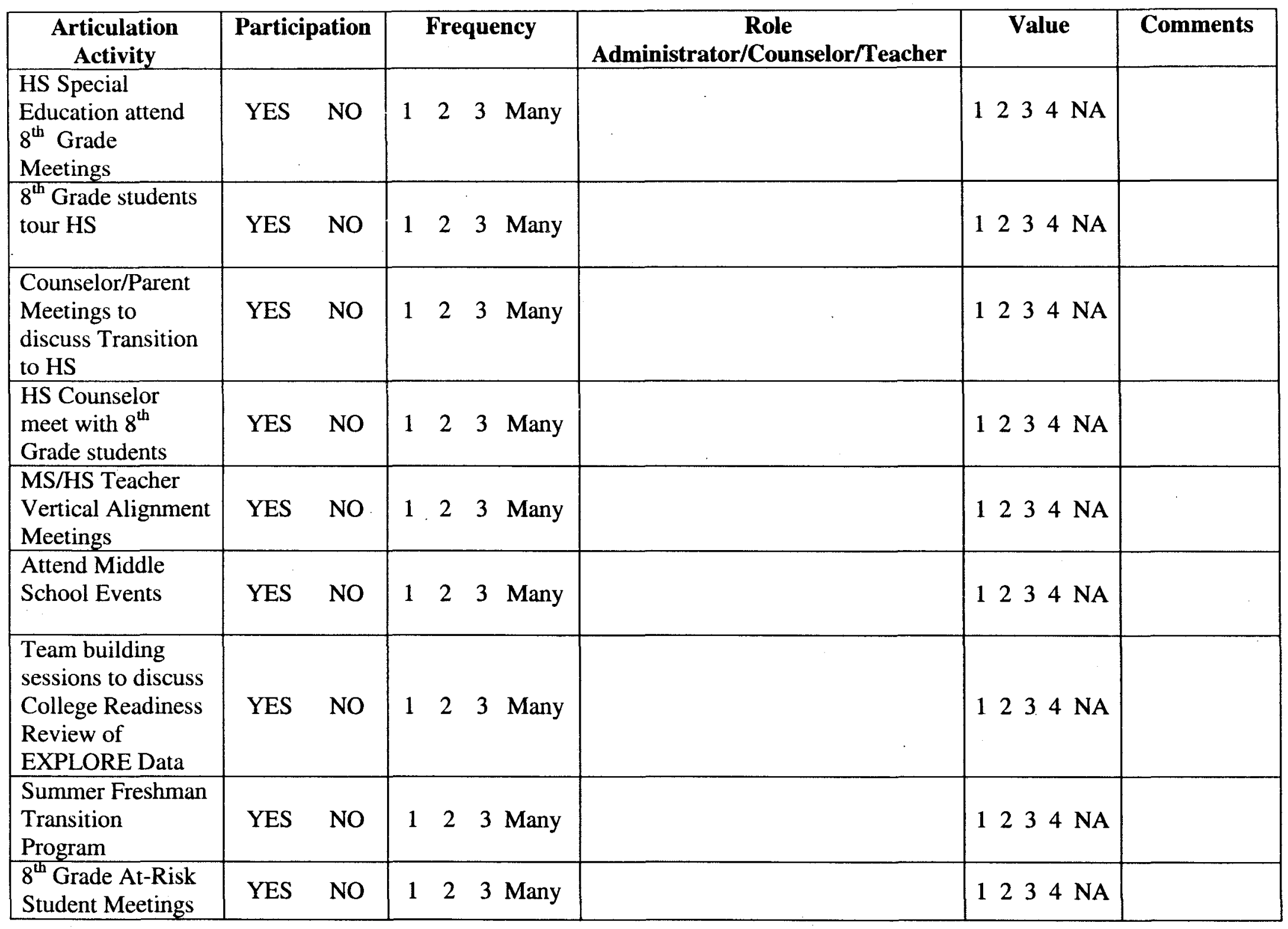




\section{(Part IV)}

1. If you participated in an orientation meeting with eighth grade parents during the school year to discuss transition to high school please share what particular components were most useful (and why) and which components were not so helpful (and what could be done to change them). If not, circle no participation.

2. If you participated in a teacher-swap between eighth and ninth grade teachers, trading places for the day, what was your role? If not, circle no participation.

a. If you participated in the teacher-swap, was this activity valuable to you? Should this activity be continued?

b. If you did not participate in the teacher-swap, would you be willing to participate in this type of articulation activity and what would you gain from it?

3. If you participated in an eighth and ninth grade teacher meeting after each grading period to discuss students' progress, share what particular components were most useful (and why) and which components were not so helpful (and what could be done to change them). If not, circle no participation. 
4. Do you think it is beneficial for high school special education teachers to attend eighth grade transition meetings for students with special needs? (Yes or no and why?). If you have participated in such activities explain where and when.

5. Did eighth grade students take a tour of the high school? If so, when did this happen and what was your role in this activity?

6. Does your school conduct counselor/parent meetings to discuss student transition to high school? (Yes or no) If your school conducts these meetings, does it occur during the school year or during the summer?

7. Does the counselor at your school meet with eighth graders during the school year to discuss transition to high school? (Yes or no) If your answer is yes, when during the year does this occur and what is discussed?

8. Does any of the high school freshman staff (administrators, counselors, teachers) attend middle school eighth grade activities (ex. Dances, field trips, graduation, etc.)? (Yes or no) If your answer is yes, what specific activities did you participate in? (This doesn't include participation as a parent). 
9. To what degree do you communicate with the teachers at the other school (middle or high school) pertaining to eighth grade students and their transition to high school?

10. How often do you participate in vertical alignment meetings with middle and high school teachers to discuss curriculum, behavior and philosophical aspects to preparing students for transition? Share what particular outcomes of this activity were most useful (and why) and which outcomes were not so helpful (and what could be done to improve this process)?

11. Does your school have a summer freshman transition program and if so, what the specifics of the program?

12. Does your school provide for "at-risk" students a meeting with identified teachers to build rapport and relationships for students transitioning to high school?

13. How many activities are you aware of that your school is involved in that relate to students transitioning from eighth to ninth grade? 
14. Do you believe your school does an efficient job at transitioning students to ninth grade? (Yes or no). If you answered yes, why? 


\section{Appendix C: Transition Committee Interview}

Thank you for allowing me this opportunity to ask you some questions that will provide support to a dissertation study. This interview should last approximately 20 minutes. These questions are school specific and not questions personal to you. The questions will focus on your school and student transition from grade eight to grade nine.

This interview is a follow-up interview to the "Freshman Transition Teacher Survey" that you previously filled out in late May, 2010.

1. Describe how this committee was formed.

Possible follow-up questions:

Who initiated it?

How often do you meet?

Do you have agendas/minutes?

Were there any sub-committees formed in addition to the transition committee? If so, who leads these?

2. How was this initiative shared with the middle school and high school?

Possible follow-up questions:

When was the initiative shared?

Who participated?

3. How did you determine the activities to be used in this initiative?

Possible follow-up questions:

Who was involved the activity selection?

How was the responsibility for each determined?

Describe how you arrived at the number and types of activities used. 
4. Describe any processes used to monitor the process and activities?

Possible follow-up:

Do you have data?

Describe any information collected on these activities?

What will you use to determine if this initiative has been of benefit?

5. Describe the activities in place for the 2010-2011 school year.

Possible follow-up questions:

Were any activities deleted? Enhanced? Added?

6. If you could change anything about the activities or the process used in delivering the activities, what would you suggest?

7. How do the MS and HS work collaboratively to address transition? 


\section{Appendix D:}

\section{Teacher Interview}

Thank you for allowing me this opportunity to ask you some questions that will provide support to a dissertation study. This interview should last approximately 20 minutes. These questions are school specific and not questions personal to you. The questions will focus on your school and student transition from grade eight to grade nine.

This interview is a follow-up to the "Freshman Transition Teacher Survey" that you previously filled out in late May, 2010.

1. What does your school do to help students in the transition from grade 8 to grade 9 ?

Possible follow-up questions:

What role have you played in that process?

With what schools (and individuals) have your school collaborated on this process?

What do you do with your students to address the transition from grade 8 to grade 9 ?

2. What do you do if you have a student in your class/school who is acting out?

Possible follow-up questions:

Do you try to solve the problem on your own?

Do you confer with other teachers (on your team or department) to help you solve the problem?

Do you check with other teachers who have this student in their classes?

Do you call or meet with the parent or guardian?

Do you involve the counselor and or the principal in solving behavior issues?

Do you look for patterns of behavior of this student from previous years?

How do you know if this is an isolated incident or a pattern of behavior?

Is there a (school or team) process you are to following when handling behavior issues? 
3. What do you do when a student is absent numerous times from your class/school?

Possible Follow-up questions:

Do you try and solve the problem on your own?

Do you confer with other teachers to help you solve the problem?

Do you call or meet with the parent or guardian?

Do you involve the counselor and or the principal in solving attendance issues?

Do you look for patterns of absences of this student from previous years?

How do you know if the student is missing other classes or if it is just your class?

Is there a process you are to following when handling student absence issues?

4. What do you do when a student is failing your class/school?

Possible follow-up questions:

Do you try and solve the issue on your own?

Do you confer with other teachers to help you solve the problem?

Do you call or meet with the parent or guardian?

Do you involve the counselor and or the principal in solving academic performance issues?

Do you look for patterns of poor academic performance of this student from previous years?

5. Are you aware of student participation in extra-curricular activities?

Possible follow-up questions:

Is there a process in place for collecting that information?

Are teachers informed of that information?

Is there a process in place to connect as many students possible to some activity?

6. If there was anything you could change to manage these student issues, what would you recommend? What suggestions would you make to help students more?

What changes if any do you see in your school organization as a result of the articulations?

Has growth occurred in student achievement in the past (2) years? 


\section{Appendix E}

Archival Documents Analyzed

Activity and Meeting
Transition Committee Meetings
MS Faculty Meeting
HS Faculty Meeting
HS Department Meetings
MS Department/PLC Meetings

Freshman Academy Meetings

Grade 8 Team Meetings

Grade 8 parent orientation meeting

Grade 8 parent meeting on scheduling

Teacher swap

Student Progress meetings

Documents

Provided

Agendas, minutes

Not available

Agenda, minutes

Agendas, minutes

Available

Available

Agendas, Minutes

Available

Agendas, Minutes

Available

Agendas, Minutes

Available

Agendas, Minutes

Available

Agendas, minutes, sign-in logs

Not available

Agendas, minutes, sign-in logs

Not available

Agendas participation logs, expectations for the swap,

Documented lesson plans

Agendas, minutes

Available

Status of School Reports with the superintendent 
HS Special Educators attend grade 8

meeting

Grade Tour of the HS

Counselor/parent meetings

MS/HS Vertical alignment meetings

HS attend MS events

Team Building Sessions

$\ddot{\alpha}$
Agendas

Agendas, minutes, sign-in logs

Agenda, minutes,

Log of participation

Agendas, minutes

Agenda, minutes, sign-in logs

Agendas, minutes
Not available

Available

Not available

Available

No logs of participation. High school faculty attendance at the Grade 8 dance and Grade 8 graduation is mandatory.

Not available

Not available

Not available

Note. The information provided in this table was compiled from information and documents collection through the end of December, 2010. 


\section{Appendix F}

\section{Categorical Coding of Open Response Questions, Articulation Activities}

\begin{tabular}{|c|c|c|}
\hline Question on Teacher Questionnaire & Articulation Activity & Framework Category \\
\hline $\begin{array}{l}\text { Question } 1 \\
\text { If you participated in an orientation meeting with grade eight } \\
\text { parents during the school year to discuss transition to high } \\
\text { school, please share what particular components were most } \\
\text { useful (and why) and which components were not so helpful (and } \\
\text { what could be done to change them). If not circle no } \\
\text { participation. }\end{array}$ & $\begin{array}{l}\text { Activity \# } 1 \\
\text { Grade eight parent orientation for } \\
\text { introduction to the high school }\end{array}$ & Collaboration \\
\hline $\begin{array}{l}\text { Question } 2 \\
\text { If you participated in a teacher-swap between grade eight and } \\
\text { grade nine teachers, trading places for the day, what was your } \\
\text { role? If not, circle, no participation. }\end{array}$ & $\begin{array}{l}\text { Activity \# } 3 \\
\text { Teacher swap }\end{array}$ & $\begin{array}{l}\text { Systemic process } \\
\text { Collaboration } \\
\text { Leadership/vision }\end{array}$ \\
\hline $\begin{array}{l}\text { Sub question (a) } \\
\text { If you participated in the teacher-swap, was the activity valuable } \\
\text { to you? Should this activity be continued? }\end{array}$ & & \\
\hline $\begin{array}{l}\text { Sub question (b) } \\
\text { If you participated in the teacher swap, would you be willing to } \\
\text { participate in this type of activity and what would you gain from } \\
\text { it? }\end{array}$ & & \\
\hline
\end{tabular}


Question 3

If you participated in the ninth grade teacher meeting after each grading period to discuss students' progress, share what particular components were most useful (and why) and which components were not so helpful (and what could be done to change them). If not, circle no participation.

\section{Question 4}

Do you think it is beneficial for high school special education teachers to attend eighth grade transition meetings for students with special needs? (Yes or no and why?). If you have participated in such activities explain where and when.

\section{Question 5}

Did grade eight students take a tour of the high school? If so, when did this happen and what was your role in this activity?

\section{Question 6}

Does your school conduct counselor/parent meetings to discuss student transition to high school? (Yes or no) If your school conducts these meetings, does it occur during the school year or during the summer?

\section{Question 7}

Does the counselor at you school meet with eighth graders during the year to discuss transition to high school? (Yes or No). If the answer is yes, when during the year does this occur and what is discussed.

\section{Question 8}

Does any of the high school freshman staff (administrators, counselors, teachers) attend middle school eighth grade activities (ex. Dances, field trips, graduation etc.) (Yes or no) If you answer is yes, what specific activities did you participate in? (This does not include participation as a parent)

\section{Activity \# 4}

Grade eight to grade nine student

progress meetings

Systemic process

Collaboration

Use of measures

\section{Activity \# 5}

HS special education teachers attend grade eight meetings

\section{Activity \# 6}

Grade eight student tour of the HS

\section{Activity \# 7}

Counselor/parent meetings to

discuss transition to HS

\section{Activity \# 8}

HS counselor meet with grade eight students

\section{Activity \# 10}

HS teacher attendance at MS events
Collaboration Leadership/vision Use of measures

Systemic process Collaboration

Systemic process Collaboration

Systemic Process Collaboration

Systemic process Collaboration 


\section{Question 9}

Collaboration

To what degree do you communicate with teachers at the other school (middle or high school) pertaining to eighth grade students and their transition to high school?

Question 10

How often do you participate in vertical alignment meetings with middle school and high school teachers to discuss curriculum, behavior and philosophical aspects to preparing students for transition? Share what particular outcomes of this activity were most useful (and why) and which outcomes were not so helpful (and what could be done to improve this process)?

Question 11

Does your school have a summer freshman transition program and if so, what the specifics of the program?

Question 12

Does your school provide "at-risk" students a meeting with identified teachers to build rapport and relationships for students transitioning to high school?

Question 13

How many activities are you aware of that your school is involved in that relate to students transitioning from eighth to ninth grade?

Question 14

Do you believe your school does any efficient job at transitioning students to ninth grade? (Yes or no) If you answered yes, why?

\section{Activity \# 9}

MS/HS Teacher vertical

alignment meetings

\section{Activity \# 12}

Summer Transition Program

\section{Activity \# 13}

Grade eight at-risk student

meetings
Systemic process

Collaboration

Leadership/vision

Use of measures

Systemic process

Systemic process

Use of measures

Collaboration

Systemic process

Use of measures

Note: Information provided in this table was compiled from the Freshman Transition Teacher Survey and second reviewer coding information. 


\section{Appendix G}

Categorical Coding of Transition Committee Interview Questions

Interview Question and Possible Follow-up Questions

characteristic

1. Describe how this committee was

formed.

(Systemic Process)

2. How was this initiative shared with the middle school and high school? (Leadership and Vision)

3. How did you determine the activities to be used in this initiative?

(Systemic Process)

4. Describe any processes used to monitor the process and activities?

(Systemic Process and Use of Measures)

5. Describe the activities in place for the 2010-2011 school year. (Systemic Process)

\section{Who initiated it?}

How often do you meet?

Do you have agendas/minutes?

Were there any sub-committees formed in addition to the transition committee? If so, who leads these?

When was the initiative shared?

Who participated?

Who was involved the activity selection?

How was the responsibility for each determined?

Describe how you arrived at the number and types of activities used.

Do you have data?

Describe any information collected on these activities?

What will you use to determine if this initiative

has been of benefit?

Were any activities deleted? Enhanced? Added? 
6. If you could change anything about the activities or the process used in delivering the activities, what would you suggest?

(Leadership and Vision)

7. How do the MS and HS work collaboratively to address transition? (Collaboration)

Table 6 Transition Committee Interview Questions. Note. The information provided in this table was compiled from the Transition Committee interview questions administered on December 15, 2010. 


\section{Appendix $\mathbf{H}$}

Categorical Coding of Teacher Interview Questions

Interview Questions and Characteristic

Possible Follow-up Questions

1. What does your school do to help students from the transition from grade 8 to grade 9 ? (Collaboration)

2. What do you do if you have a student in your class/school who is acting out?
3. What do you do when a student is absent numerous times from your class/school? (Collaboration, Use of Measures and Systemic Processes)
What role have you played in that process?

With what schools (and individuals) have your school collaborated on this process? What do you do with your students to address the transition from grade 8 to grade 9 ?

Do you try to solve the problem on your own?

Do you confer with other teachers (on your team or department) to help you solve the problem?

Do you check with other teachers who have this student in their classes?

Do you call or meet with the parent or guardian?

Do you involve the counselor and or the principal in solving behavior issues?

Do you look for patterns of behavior of this student from previous years? How do you know if this is an isolated incident or a pattern of behavior? Is there a (school or team) process you are to following when handling behavior issues?

Do you try and solve the problem on your own?

Do you confer with other teachers to help you solve the problem?

Do you call or meet with the parent or guardian?

Do you involve the counselor and or the principal in solving attendance issues?

Do you look for patterns of absences of this student from previous years?

How do you know if the student is missing other classes or if it is just your class?

Is there a process you are to follow when handling student absence issues? 
4. What do you do when a student is failing your class/school? (Collaboration and Use of Measures)

5. Are you aware of student participation in extra-curricular activities? (Systemic Processes and Use of Measure)

6. If there was anything you could change to manage these student issues, what would you recommend? (Leadership/Vision)
Do you try and solve the issue on your own?

Do you confer with other teachers to help you solve the problem?

Do you call or meet with the parent or guardian?

Do you involve the counselor and or the principal in solving academic performance issues?

Do you look for patterns of poor academic performance of this student from previous years?

Is there a process in place for collecting that information?

Are teachers informed of that information?

Is there a process in place to connect as many students possible to some activity?

What suggestions would you make to help students more?

What changes if any do you see in your school organization as a result of the set of structured articulation activities?

Has growth occurred in student achievement in the past (2) years? 


\section{Appendix I}

Categorical Coding of Comments

\begin{tabular}{|l|l|l|l|}
\hline Systemic Processes & \multicolumn{1}{|c|}{ Leadership/Vision } & \multicolumn{1}{c|}{ Collaboration } & \multicolumn{1}{c|}{ Use of Measures } \\
\hline Community & Vision & Stakeholders & Data \\
\hline Expectations & District-wide & Together & Results \\
\hline Timelines & Expectations & Collaborative & Outcomes \\
\hline Agendas & Belief & Shared & Grades \\
\hline Minutes & Unified & Group & Reports \\
\hline Procedures & Stakeholders & Committees & Behavior \\
\hline Lists & Alignment & Consensus & Maps \\
\hline Plans & & Collective & Forms \\
\hline Schedules & & Engage & Lists \\
\hline Routines & & & Monitor \\
\hline Structure & & & \\
\hline Forms & & & \\
\hline Monitor & & & \\
\hline
\end{tabular}




\section{CURRICULUM VITAE}

\section{Carol Jean Christian}

3332 Cheltenham Circle, Lexington, Kentucky 40509

Home (859) 263-4205

Cell (859) 321-0743

\section{E-Mail carol.christian@insightbb.com}

\section{Education}

Present Ed.D. Candidate (Educational Leadership)

University of Louisville

Educational Leadership and Administration

1979 M.A., Education

Eastern Kentucky University

1976 B.S., Physical Education

Eastern Kentucky University

\section{Employment}

2011-Present Morehead State University-Morehead, Kentucky

Title: Assistant Professor, Director P-16

2005-2010 Kentucky Department of Education- Frankfort, Kentucky

Title: District Achievement Gap Coordinator,

Office of Leadership and School Improvement

Regional Area: Central and Southeast/South Central Ky.

2004-2010 Eastern Kentucky University- Richmond, Kentucky

Title: Adjunct Professor

Graduate level courses in Administration and Leadership

2005-2010 Morehead State University- Morehead, Kentucky

Title: Adjunct Professor (Web classes)

Graduate level- EDIL 601 Intro. to School Leadership 
2006-2010 Northern Kentucky University- Highland Heights, Kentucky

Title: Adjunct Professor

Graduate level courses-Advanced Curriculum 618-619

2004-2005 Kentucky Department of Education-Frankfort, Kentucky

Title: District Support Facilitator

2001-2004 Kentucky Department of Education- Frankfort, Kentucky

Title: Highly Skilled Educator

1991-2001 Bourbon County Schools- Paris, Kentucky

Title: Middle School Principal

1988-1991 Bourbon County Schools- Paris, Kentucky

Title: Assistant Middle School Principal

1982-1988 Eastern Kentucky University (Model Laboratory School)

Title: K-12 Physical Education Teacher/Coach

(Also, taught graduate level and undergraduate level classes in the

College of Education)

1976-1982 University Heights Academy- Hopkinsville, Kentucky

Title: Athletic Director, K-12 Physical Education/Coach

Professional Memberships

- Selected to serve on the Central Kentucky P-16 Council (2007)

- Member of CERA (Center for Educational Research in Appalachia)

- Kentucky Leadership Academy (KLA Trainer)

- Kentucky Principal's Network Coach (KPN)

- Phi Delta Kappa Member

- Kentucky Association of School Administrators

- Kentucky Middle School Association (KASA)

- Kentucky Association of School Councils

- Kentucky Institute For Women In School Administration

- KASA Planning Committee

- KAHPERD (Kentucky Association of Health, Physical Education, Recreation and Dance)

Awards and Honors

- 2007 Selected to serve on CERA (Center for Educational Research in Appalachia)

- 2001 Selected into the Highly Skilled Educator program

- 1998 Selected "EKU Outstanding Alumni of the Year" recipient 
- 1997 Charter Member of the Kentucky Leadership Academy

- 1996 Voted "Central Kentucky Middle School Administrator of the Year" by the Central Kentucky Counselor's Association

- 1987 Voted state-wide "Kentucky Physical Education Teacher of the Year"

- 1990 "Give More of Yourself Award" recipient in Bourbon County for implementing a middle school parental involvement program called "PATS" (Parents and Teachers Sharing)

- "First Out of 13 Southern States." Produced an educational video to promote health and physical education used by the Kentucky Department of Education

- 1990-91 KERA, Charter, Task Force Member

- 1978 First Female Athletic Director In Kentucky

- KAHPERD Merit Award Recipient

- EKU Commencement Speaker for December graduation, P.E./Health

\section{Published}

Barnett, D., Christian, C., Hughes, R., \& Wallace, R. (2010). Privileged Thinking in Today's Schools: The Implications for Social Justice. Rowman \& Littlefield.

Christian, C., \& Wallace, R., (2009). Heart to Heart. Warner Printing Company. (This book is tied to the ISLLC standards for school administrators.) 